\title{
Parodontale und orale mikrobielle Parameter bei Patienten mit verschiedenen koronaren Herzerkrankungen
}

\author{
INAUGURAL-DISSERTATION \\ zur Erlangung des Doktorgrades \\ für Zahnheilkunde \\ der Medizinischen Fakultät der \\ Georg-August-Universität Göttingen
}

\author{
vorgelegt von \\ Stefan Krebs \\ aus Quedlinburg
}


Die Dissertation entstand in der Poliklinik für Präventive Zahnmedizin, Parodontologie und Kariologie der Universitätsmedizin Göttingen im Zeitraum 2009-2010.

Dekan:

1. Berichterstatter:

2. Berichterstatter/in:

3. Berichterstatter/in:

Tag der mündlichen Prüfung:
Prof. Dr. rer. nat. H. K. Kroemer

Prof. Dr. med. dent. Rainer Mausberg

Prof. Dr. Dipl.-Phys. Friedrich Schöndube

Prof. Dr. med. Martin Oppermann

22.11.2016 


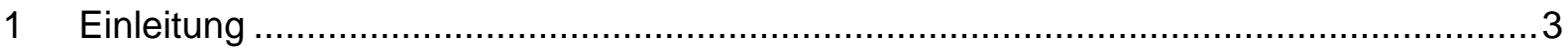

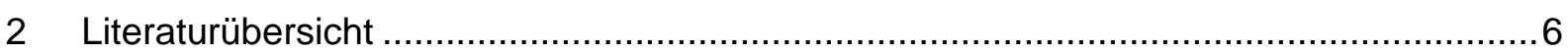

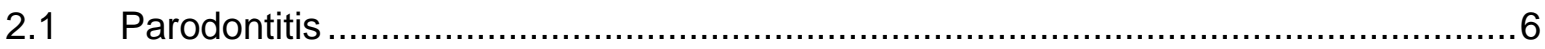

2.1.1 Definition und Klassifikation .......................................................................

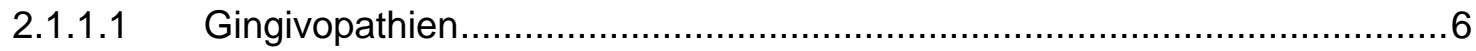

2.1.1.2 Chronische Parodontitis ......................................................................

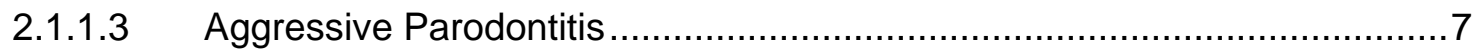

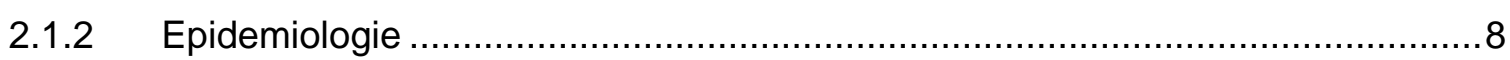

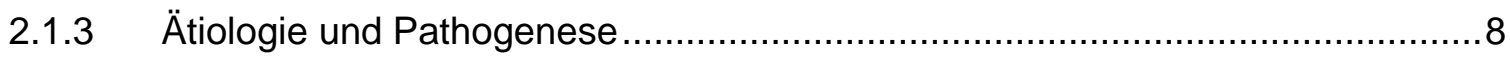

2.1.3.1 Parodontitis als multifaktorielles Geschehen .............................................

2.1.3.2 Der orale Biofilm ......................................................................... 10

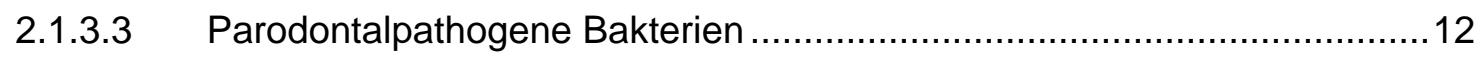

2.1.4 Immunologische Wirt-Bakterieninteraktion ................................................ 12

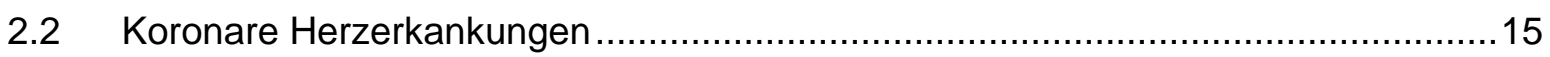

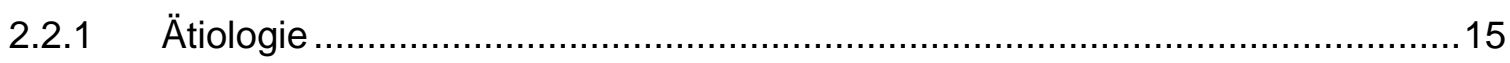

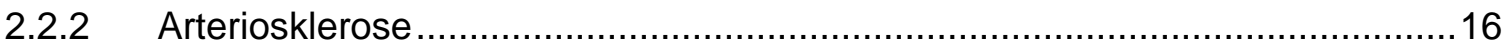

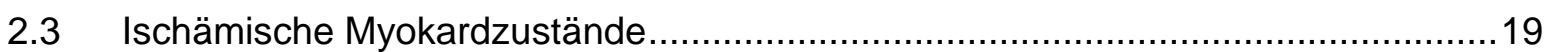

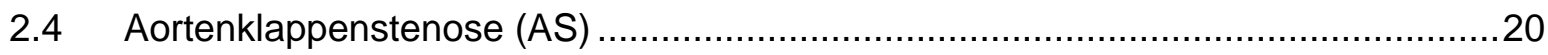

2.5 Kausalzusammenhänge zwischen Parodontitis und Herzerkrankungen ................21

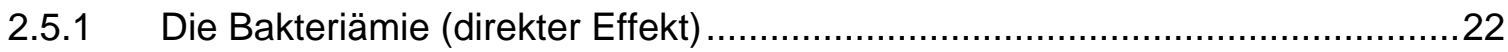

2.5.2 Zusammenhänge zwischen Parodontitis und Herzerkrankungen .....................22

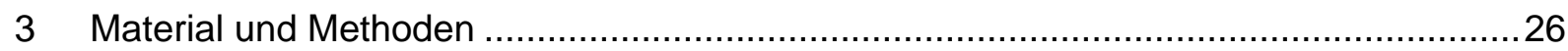

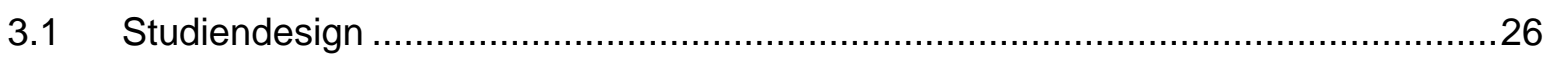

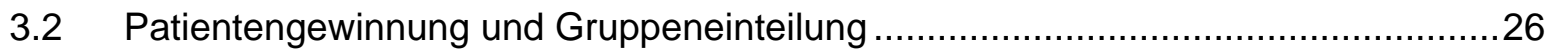

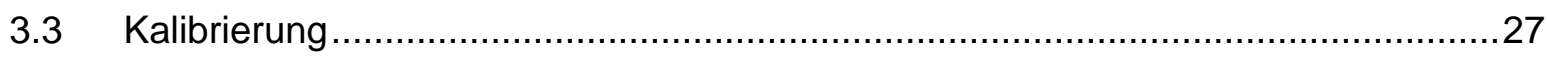

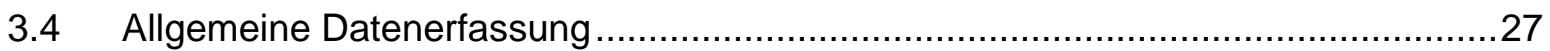

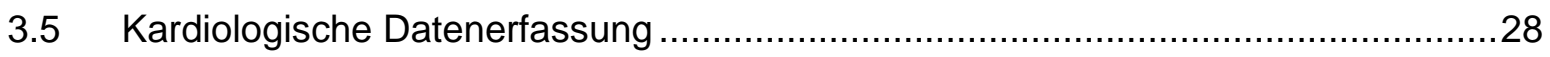

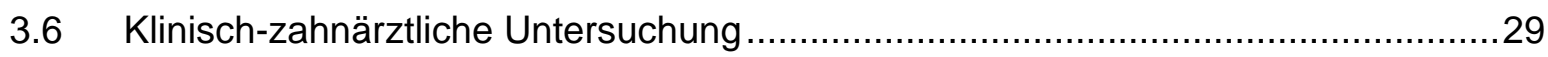

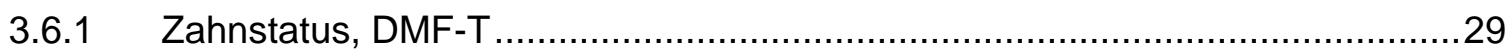

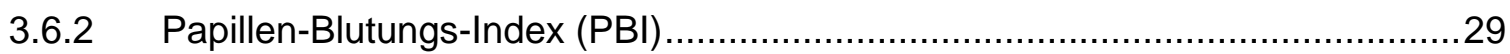

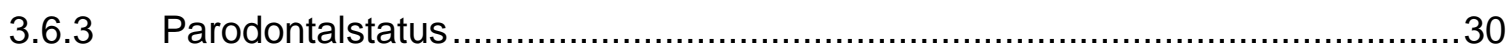

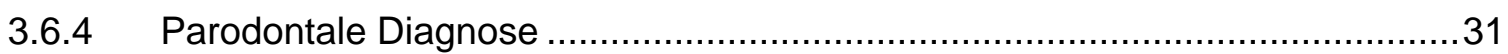

3.6.5 Mikrobiologische Analyse ........................................................................

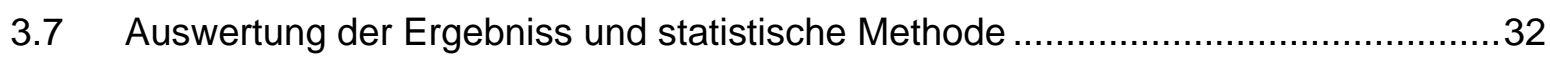

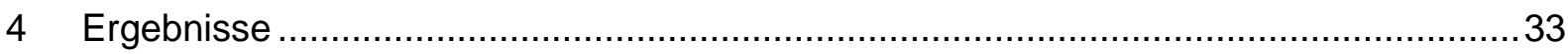

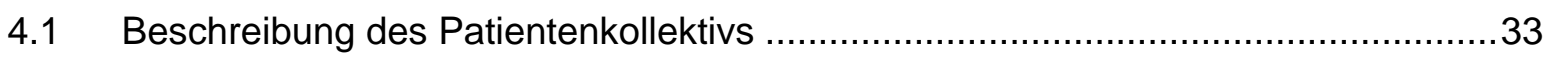

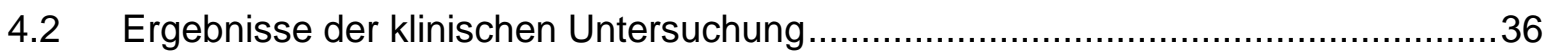

4.2.1 Zahnstatus, DMF-T und Papillen-Blutungs-Index (PBI) .................................36

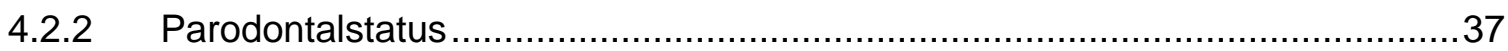

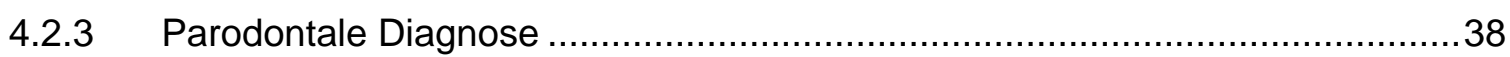

4.2.4 Statistik der parodontalen Parameter .............................................................

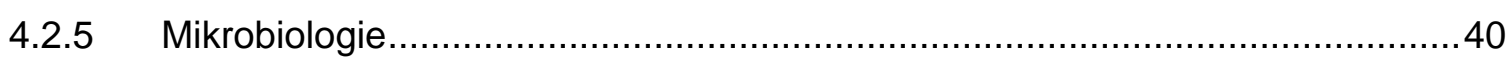

4.2.6 Statistische Auswertung der Mikrobiologie ....................................................42 
4.2.7 Parodontale Parameter unter der Anwesenheit von $\mathrm{Pg}$ und $\mathrm{Aac}$.....................43

4.3 Zusammenfassung der Ergebnisse .............................................................. 47

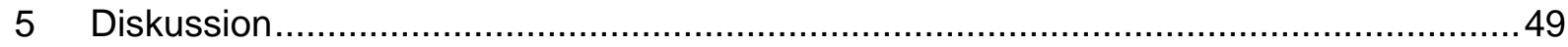

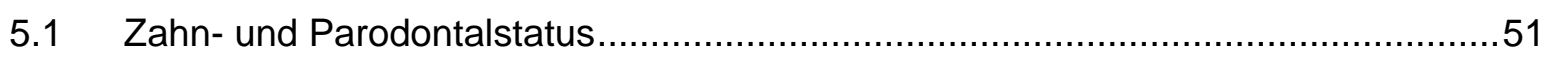

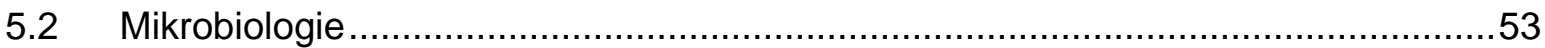

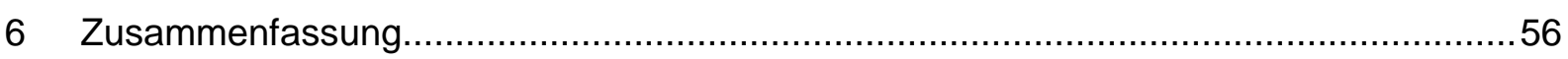

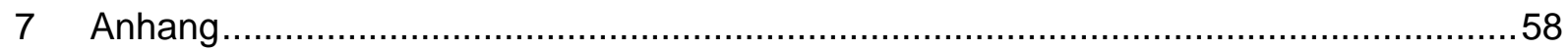

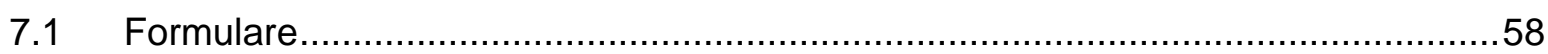

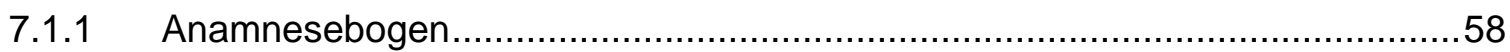

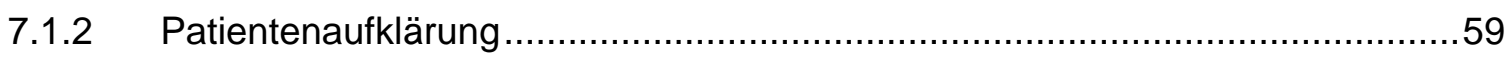

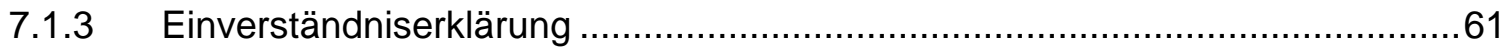

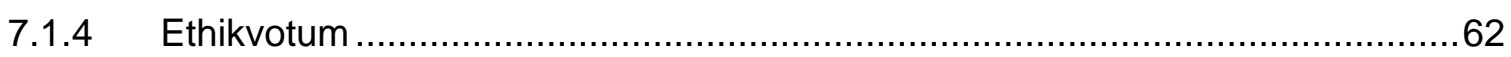

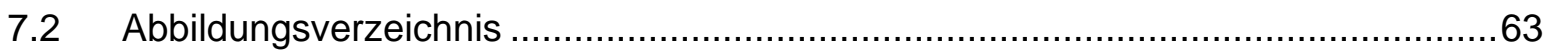

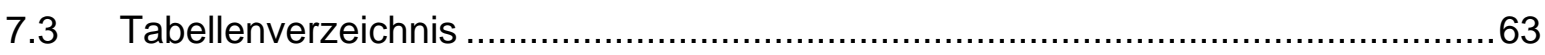

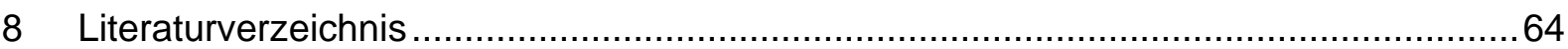


Die chronische ischämische Herzkrankheit, der akute Myokardinfarkt und die Herzinsuffzienz zählen weltweit zu den häufigsten Todesursachen (WHO 2011). Jeder vierte Verstorbene erlag in Deutschland im Jahr 2010 einer Erkrankung des Herz-Kreislaufsystems (Statistisches Bundesamt 2011).

1989 wurden erste Hinweise auf einen Zusammenhang zwischen oralen Infektionen und Schlaganfall, sowie Herzinfarkt beschrieben (Matilla et al. 1989, Syrjanen et al. 1989). Die häufigsten Parodontalerkrankungen sind die plaqueinduzierte Gingivitis und die chronische Parodontitis. Bleiben solche Erkrankungen unerkannt, kommt es zum irreversiblen Verlust des Zahnhalteapparates bis hin zum Zahnverlust. Als Ursache für den progressiven Verlust von Stützgewebe wird heute ein polymikrobieller Biofilm angesehen (Kebschull et al. 2010). Die Ätiologie und Pathogenese parodontaler Erkrankungen sind multifaktoriell und werden durch ein komplexes Zusammenspiel angeborener, erworbener und verhaltensbedingter Risikofaktoren bestimmt (Dalla et al. 2005, Genco et al. 1999, Page und Kornman 1997). Die genetische Prädisposition (Interleukin-1-Polymorphismen), habituelle Faktoren wie Rauchen und systemische Stoffwechselerkrankungen (z.B. Diabetes mellitus) treten dabei in den Vordergrund (Page und Kornman 1997, Sartori und Silvestri 2002). Für die mikrobielle Besiedelung der Mundhöhle stellen der Biofilm (Plaque/Zahnbeläge) und die darin vorhandenen parodontalpathogenen Bakterien eine grundlegende Bedingung dar. Die Qualität des Biofilms verändert sich mit steigender Sondierungstiefe und zunehmender Etablierung eines konnektiven Netzwerkes. Im Bereich des subgingivalen bakteriellen Biofilms spielen vorwiegend gramnegative Bakterienspezies eine entscheidende Rolle. Entsprechend ihrer Pathogenität werden diese Bakterien verschiedenen Komplexen zugeordnet (Socransky et al. 1998). Besondere Bedeutung kommt bei aktiven Läsionen vor allem dem roten Komplex zu, bestehend aus Porphyromonas gingivalis (Pg), Taneralla forsythia (Tf) und Treponema denticola $(T d)$. Variationen der Pathogenität eines Biofilms werden durch die Art und Menge der vorhandenen Bakterien bestimmt, wobei im Sinne einer opportunistischen Infektion nicht jeder Biofilm pathogen ist. Den Bakterien des roten Komplexes werden diverse negative Eigenschaften zugeschrieben. Die Wirkungen können lokal im Parodont, durch gewebeabbauende Kollagenase, Hyaluronidasen und Stoffwechselendprodukte wie Ammoniak, Endotoxine wie Lipopolysaccharide und Exotoxine wie Leukotoxin nachgewiesen werden (Dahlén et al. 1992, Hellström et al. 1996, Smulow et al. 1983, Tabia et al. 1981, Ximénez-Fyvie et al. 2000). Beim Übergang einer etablierten Gingivitis ohne bindegewebigen Attachmentverlust zu einer Parodontitis steht vor allem der progressive Attachmentverlust und Knochenabbau, sowie die Tiefenproliferation und teilweise Ulzeration des Saumepithels im Vordergrund. In akuten Phasen kommt es zur bakteriellen Invasion des Gewebes (Rateitschak et al. 1989). 
Parodontalpathogene Mikroorganismen, ihre Bestandteile und Stoffwechselendprodukte können über das ulzerierte Taschenepithel in die systemische Zirkulation gelangen und dort die Synthese von Entzündungsmolekülen induzieren. Dabei ist die Bakteriämie umso stärker, je schwerer die Parodontitis ausgeprägt ist (Jepsen et al. 2011, Silver et al. 1977). Einige parodontalpathogene Bakterien wie Actinobacillus actinomycetemcomitans (Aac) besitzen die Fähigkeit, direkt das parodontale Gewebe zu infiltrieren und sich direkt Zugang zum Gefäßsystem zu verschaffen (Allenspach-Petrzilka und Guggenheim 1983, Christersson et al. 1987, Meyer et al. 1991, Riviere et al. 1991).

Die Ergebnisse mehrerer Studien können als Indizien für einen moderaten Zusammenhang zwischen mariginalen Parodontitiden und systemischen Erkrankungen wie Diabetes mellitus (Aldridge et al. 1995, Deschner et al. 2011, Grossi et al. 1997), Herz-Kreislauf-Erkrankungen (DeStefano et al 1993, Beck et al. 1996), Schlaganfall, Schwangerschaftskomplikationen (Wimmer und Pihlstrom 2008, Offenbacher et al. 1998, Jeffcoat et al. 2001) angesehen werden. Es ist nicht geklärt, ob die Assoziation oraler und allgemeiner Erkrankungen bidirektional oder kausal verläuft. Es verstärkt sich die Annahme, dass Parodontitis als verursachender beziehungsweise modulierender Faktor für verschiedene systemische Erkrankungen fungiert (Slavkin und Baum 2000). In neueren Studien, die auf Daten der Normative Aging Study (NAS) beruhen, wurde vor allem für jüngere Patienten (21-59 Jahre) eine stärkere Assoziation zwischen parodontalen Infektionen und zerebro- beziehungsweise kardiovaskulären Ereignissen als bei älteren Patienten beschrieben (Dietrich et al. 2008, Jimenez et al. 2009). In anderen Untersuchungen wurden quantitative Zusammenhänge zwischen der Anzahl subgingival pardontalpathogener Bakterien und kardiovaskulären Ereignissen festgestellt (Nonnenmacher et al. 2007, Renvert et al. 2004, Spahr et al. 2006). In einigen Interventionsstudien, die die Auswirkungen einer Parodontitistherapie untersuchten, konnten klare Assoziationen zwischen parodontalen Erkrankungen und Arterioklerose nachgewiesen werden (Loos 2005, Seinost et al . 2005, Elter et al. 2006, Mercanoglu et al. 2004, Tonetti 2009). Bei der Untersuchung der Auswirkung einer Parodontitistherapie auf Arteriosklerosemarker spielen vor allem die Senkung der Parameter der systemischen Entzündungsantwort wie CRP, proinflammatorische Zytokine wie Interleukin-6, Interleukin-1 und Koagulationsfaktoren wie Fibrinogen, eine entscheidende Rolle (Loos 2005). Nach erfolgreicher Parodontaltherapie konnte eine Senkung der Entzündungsmarker gezeigt werden (Paraskevas et al. 2008). Ein weiterer entscheidender Punkt bei der Entstehung einer Arteriosklerose ist die Endothelfunktion (Seinost et al. 2005, Tonetti et al. 2007). Diese ist für die vaso-dilatatorische Kompetenz peripherer Gefäße, die primäre Stufe der Entwicklung einer Arteriosklerose, verantwortlich. Sowohl mit adjuvanter Antibiose (Seinost et al. 2005) als auch durch eine alleinige Parodontaltherapie konnte die Endothelfunktion deutlich verbessert werden (Elter et al. 2006, Mercanoglu et al. 2004, Tonetti 2009). 
Auf Grundlage dieser epidemiologischen und experimentellen Daten wird deutlich, dass es keinen empirischen, aber stets konstant moderaten Zusammenhang zwischen der parodontalen Infektion und verschiedenen kardiovaskulären Herzerkrankungen gibt.

Der Hintergrund dieser Arbeit ist die Betrachtung verschiedener kardiovaskulärer Erkrankungen im Hinblick auf die klinische parodontale Situation unter Berücksichtigung spezifischer parodontalpathogener Mikroogranismen. In einer 2007 veröffentlichen Metaanalyse konnte ein enger Zusammenhang zwischen der parodontalen Baktierenlast und kardiovaskulären Ereignissen gefunden werden (Mustapha et al. 2007). In einer Stellungnahme von 2012 wurde gezeigt, dass die Datenlage zur mikriobiologischen Beurteilung von parodontalen Erkrankungen und kardiovaskulären Ereignissen eher gering ist (Lockhart et al. 2012). Die Zusammenhänge von ausgewählten Keimen in Bezug auf dem akuten Myokardinfarkt sind bisher in wenigen Studien untersucht (Dogan et al. 2005, Stein et al. 2009). In anderen Arbeiten wurden ausgewählte Serum Antikörper gegen Pgund Aac in Zusammenahng mit akutem Mykoardinfarkt (Pussinen et al. 2003, Pussinen et al. 2004, Lund et al. 2008) und der koronaren Herzkrankheit (Spahr et al. 2006) gebracht.

Auf Grundlage dieser Daten sollten in dieser Arbeit verschiedene koronare Herzerkrankungen unter der Berücksichtigung von 11 definierten parodontalpathogenen Keimen und der klinischen parodontalen Situation hin untersucht werden. Folgende Hypothesen wurden formuliert:

- Es gibt einen direkten Zusammenhang verschiedener koronarer Herzerkrankungen mit parodontaler Gesundheit (gesund, Gingivitis, Parodontitis)

- Herzkranke Patienten weisen eine erhöhte parodontale Bakterienlast als herzgesunde Patienten auf

- Herzkranke Patienten weisen eine erhöhte Prävalenz stark parodontalpathogener Bakterien (Aggregatibacter actinomycetemcomitans (Aac), Porphyromonas gingivalis $(P g)$, Treponema denticola (Td), Tannerella forsythia (Tf)) auf 


\section{Literaturübersicht}

\subsection{Parodontitis}

\subsubsection{Definition und Klassifikation}

Als Parodontitis wird eine entzündliche, multifaktoriell bedingte Infektionskrankheit des Zahnhalteapparates bezeichnet. Die wesentlichen Komponenten einer Parodontitis sind Knochenabbau, Tiefenproliferation und Ulzeration des Saumepithels sowie der progressive Attachmentverlust (Schroeder 1997). Die klinischen Symptome sind Blutungen und gelegentlicher Pusaustritt bei Sondierung der Zahnfleischtaschen. Sie kann in allen Altersklassen und in verschiedenen Formen auftreten. Durch die irreversible Schädigung des Zahnhalteapparates kommt es langfristig zur Lockerung und ggf. zu Zahnstellungsänderung der betroffenen Zähne. Bei Ausbleiben therapeutischer Maßnahmen droht langfristig der Zahnverlust (Plagmann 1998).

1999 wurde die Klassifizierung von Parodontalerkrankungen von der American Academy of Periodontology (AAP) neu formuliert. Die verschiedenen Parodontopathien werden demnach in acht Erkrankungskategorien unterschieden (Armitage 1999).

\section{Gingivopathien}

2. Chronische Parodontitis

3. Aggressive Parodontitis

4. Parodontitis als Manifestation einer Systemerkrankung

5. Nekrotisierende Parodontalerkrankung

6. Parodontalabszesse

7. Parodontitis im Zusammenhang mit endodontalen Läsionen

8. Entwicklungsbedingte oder erworbene Deformationen und Zustände

Diese Hauptgruppen werden in verschiedene Untergruppen eingeteilt. Aus Gründen der Übersichtlichkeit und Thematik der Arbeit werden hier nur die gingivalen Erkrankungen, die chronische und aggressive Parodontitis erläutert.

\subsubsection{Gingivopathien}

Als Gingivitis bezeichnet man eine Zahnfleischentzündung ohne Attachmentverlust (Rateischak et al.1989). Die typisch klinischen Symptome einer Gingivitis sind Rötung, Schwellung des Zahnfleisches, eine erhöhte Sulkusflüssigkeitsfließrate (SFFR) und Blutung auf Sondieren. Die typische Stippelung der gesunden Gingiva durch senkrecht zur Oberfläche inserierende Kollagenfasern ist verschwunden. Bei den Gingivitiden unterscheidet man die plaqueinduzierten und die nicht durch dentale Plaque induzierten Gingivopathien. Die plaquebedingte Gingivitis ist die am häufigsten vorkommende gingivale Erkrankung (Micheelis und Reich 1999). Die Zähne 
sind massiv mit mikrobieller Plaque bedeckt. Bei den nicht plaqueinduzierten Gingivitiden bilden vor allem systemische Faktoren wie hormonelle Umstellungen, die während der Pubertät, des Menstruationszyklus oder der Schwangerschaft auftreten, die Schwerpunkte. Die Einnahme von Medikamenten wie Antikonvulsiva (z.B. Phenytoin), Immunsuppressiva (z.B. Cyclosporine) und Kalziumantagonisten (z.B.Nefidepin) können zu Gingivahyperplasien und somit zur Pseudotaschenbildung führen. Systemische Erkrankungen, allergische Reaktionen oder traumatische Läsionen können ebenfalls Auslöser für eine Gingivitis sein (Plagmann 1998).

\subsubsection{Chronische Parodontitis}

Die chronische Parodontitis ist die häufigste Form aller entzündlichen parodontologischen Erkrankungen (Page und Schroeder 1976). Hauptsymptom dieser Erkrankung ist der langsame, überwiegend horizontal stattfindende Knochenabbau. Klinisch manifestiert sich der Attachmentverlust durch freiliegende Zahnhälse, sondierbare Bi- und Trifurkationen und später durch erhöhte Lockerungsgrade. In Folge des Verlustes parodontalen Stützgewebes kommt es zur Ausbildung von parodontalen Taschen. Am häufigsten wird dieses Krankheitsbild bei Patienten der 4. Lebensdekade beobachtet, kann aber auch bei Kindern und Jugendlichen in Erscheinung treten. Prävalenz und Schwere nehmen mit dem Alter zu (Deutsche Gesellschaft für Parodontologie 2002). Je nach Ausmaß und Schweregrad kann eine Unterteilung in eine „lokalisierte Form“, wenn weniger als $30 \%$ der Zahnflächen betroffen sind und eine „generalisierte Form“ bei einem Befall von mehr als 30\% der Zahnflächen erfolgen. Der Schweregrad der Erkrankung, gemessen am Ausmaß des Attachmentverlustes, gestattet die Einteilung in eine leichte (1-2 mm), moderate (3-4 mm) und schwere Form ( $\geq 5 \mathrm{~mm}$ ) (Müller 2001). Eine andere Form der Graduierung nach Page und Eke wird in dieser Arbeit verwendet (Page und Eke 2007). Hier wird der Schweregrad der Erkrankung ebenfalls am klinischen Attachmentlevel (AL) und der Sondierungstiefe (ST) bestimmt. Wobei die Unterteilung nach schwerer Parodontitis ( $\geq 2$ approximale Messpunkte mit $\geq 6 \mathrm{~mm}$ und $\geq 1$ approximaler Messpunkt mit einer ST $\geq 5 \mathrm{~mm}$, nicht am selben Zahn), milder Parodontitis ( $\geq 2$ approximale Messpunkte mit $A L \geq 4 \mathrm{~mm}$ oder $\geq 2$ approximale Messpunkte mit einer ST $\geq 5 \mathrm{~mm}$, nicht am selben Zahn) und keiner Parodontitis (weder mild noch schwer) erfolgt (Page und Eke 2007).

\subsubsection{Aggressive Parodontitis}

Bei der aggressiven Parodontitis handelt es sich um eine spezifische, infektiöse und entzündliche Krankheitsform der Parodontitis. In der Regel ist der betroffene Patient klinisch völlig gesund. Der Beginn der Erkrankung liegt häufig zwischen der Pubertät und dem 30. Lebensjahr. Die Menge an Zahnbelag und iatrogenen Reizfaktoren korreliert nicht mit dem Ausmaß und der schnell fortschreitenden Gewebedestruktion. Eine genetische Prädisposition und schubhafte Verläufe sind charakteristisch (Schroeder 1997, Deutsche Gesellschaft für 
Parodontologie 2002). Es kann ebenfalls nach Ausmaß und Schwere der Erkrankung eine lokalisierte von einer generalisierten Form abgegrenzt werden. Die lokalisierte Form hat eine höhere Prävalenz während der Pubertät. Betroffen sind meistens die ersten Molaren und die Inzisivi der bleibenden Zähne. Bei der generalisierten Form liegt der Altersschwerpunkt vor dem 30. Lebensjahr, wobei auch spätere Entwicklungen möglich sind. Die betroffenen Zähne sind meistens 3 Zähne, die nicht die 1. Molaren/Inzisivi sind (Brunner et al. 2002). Das Auftreten spezifischer Keime wie Aggregatibacter actinomycetemcomitans und Porphyromonas gingivalis werden vermehrt beobachtet. Eine abnormale Phagozytenfunktion und ein hyperresponsiver Makrophagen-Phänotyp mit erhöhter Produktion von Prostaglandin-E2 (PGE2) und Interleukin$1 ß$ (IL-1ß) sowie eine selbstlimitierende Gewebedestruktion (Deutsche Gesellschaft für Parodontologie 2002) sind typisch.

\subsubsection{Epidemiologie}

Parodontale Erkrankungen sind die in den industrialisierten Ländern der Welt mit $95 \%$ am häufigsten vorkommenden Krankheitsbilder (Schroeder 2000). Sowohl die Dritte Deutsche Mundgesundheitsstudie/DMS III (Micheelis und Reich 1999) als auch die Vierte Deutsche Mundgesundheitsstudie/DMS IV (Micheelis und Schiffner 2006) geben eine Verbreitung von Parodontopathien mit annähernd $100 \%$ an. Schwere Formen dieser Erkrankung sind selten, während leichte bis morderate Verläufe häufiger bei Erwachsenen diagnostiziert werden (Sheiham 1991). Auswertungen der DMS IV zeigen eine hohe Prävalenz pardondontaler Erkrankungen im Erwachsenenalter. So leiden etwa 37 Millionen Erwachsene an einer moderaten (Altersgruppe: 35-74 Jahre, 24 Millionen) bis schweren Parodontitis (Altergruppe: 3574 Jahre, 13 Millionen) (Micheelis und Schiffner 2006). Bei etwa 82\% der erwachsenen USAmerikaner wurde eine Gingivitis mit Zahnfleischbluten festgestellt (Albandar und Rams 2002).

Die Auswertungen spanischer Studien zeigen keine Zeichen einer Parodontitis bei 19\% der Erwachsenen und 8,7\% der älteren Leute. Nach diversen epidemiologischen Erhebungen sind die meisten Erwachsenen in unterschiedlichem Ausmaß von gingivalen Erkrankungen oder chronischen Parodontitiden betroffen (Kleber 2000).

\subsection{3 Ätiologie und Pathogenese}

Die häufigsten Erkrankungen an Parodont und Gingiva sind biofilminduzierte entzündliche Veränderungen (Rateischak et al. 1989). Experimentelle Gingivitisstudien zeigen, dass die Ursache für die Gingivitis (Löe et al. 1965) und gewissermaßen auch für die Parodontitis (Löe et al. 1986) der mikrobielle Biofilm ist. Ein komplexes Zusammenspiel aus verschiedenen endogenen Faktoren (genetisch) und exogenen Faktoren (Umwelteinflüsse und erworben) beeinflusst die Ätiologie und Pathogenese der Parodontitis (Page und Kornmann 1997). 


\subsubsection{Parodontitis als multifaktorielles Geschehen}

Die primäre Ursache für entzündliche parodontale Erkrankungen stellt der polymikrobielle Biofilm dar (Kebschull et al. 2010). Die Organisation dieser Keime innerhalb des Biofilms und die Interaktion mit den Wirtsfaktoren sind entscheidend, ob die Bakterien eliminiert werden, auf nicht aggressiver Ebene im Gleichgewicht sind oder proliferieren und eine marginale Parodontitis auslösen (Sanderink 2004).

Der klinische Verlauf einer Parodontitis ist zyklisch progredient. Man unterscheidet kurze aktive Phasen (burst) und längere nicht aktive Phasen (dormant stage) (Kleber 1998). Die aktive Phase ist durch einen akuten Entzündungszustand mit ulzeriertem Saumepithel und einer erhöhten Anzahl von neutrophilen Granulozyten gekennzeichnet. Auslösender Faktor ist die Bakterienquantität, die eine kritische Schwelle in Richtung parodontalpathogener Erreger überschreitet. In den längeren Phasen der Stagnation findet man nichtulzeriertes Saumepithel, begleitet von einem subakuten Entzündungsverlauf (Sagalie et al. 1988).

Die Ätiologie und Pathogenese sind multifaktoriell und werden durch ein komplexes Zusammenspiel angeborener (genetischer), erworbener und verhaltensbedingter Faktoren, sogenannter Risikofaktoren, determiniert (Rateitschak et al. 1989, Schroeder 1997). Marginale Parodontopathien sind opportunistische Infektionen, welche mit subgingivalen Biofilmen und einer inkompetenten Immunabwehr gegen diverse Biofilmantigene assoziiert sind. Zu den exogenen, veränderbaren Risikofaktoren zählen das Rauchen (Albandar et al. 2000), Stress (Pistorius et al. 2002), der Ernährungszustand (Pischon et al. 2007), der Alkoholkonsum und der sozioökonomische Status (van Dyke und Sheilesh 2005). Systemische Erkrankungen wie Diabetes mellitus (Page und Kornmann 1997, Sartori und Silvestri 2002), rheumatoide Arthritis (Mercado et al. 2003) sowie HIV-Infektionen (Murray et al. 1989, Yeung 2000) treten als exogene, beeinflussbare Risikofaktoren in den Vordergrund.

Die genetische Prädisposition zählt zu den endogenen Faktoren. Bei der Untersuchung verschiedenster Gene, die eine Rolle bei der Entwicklung einer Parodontitis haben, treten vor allem Genvariationen in den Vordergrund, die die proinflammatorische Wirkung der Zytokine verstärken und die Infektabwehr beeinflussen (z.B. Interleukin-1 und Tumornekrosefaktor (TNFa)- Polymorphismen). In mehreren Familen- und Zwillingsstudien konnte unabhängig von Umweltfaktoren und bakteriellem Einfluss die genetisch bedingte Häufung parodontaler Erkrankungen nachgewiesen werden (van der Velden et al. 1993, Michalowicz 1994, Michalowicz et al. 2000).

Andere hereditäre Einflüsse wie Funktionsstörungen neutrophiler Granulozyten oder Mutationen in den Genloci für IgG2 steigern die Anfälligkeit des Organismus für den Verlauf parodontaler Erkrankungen und sind entscheidend für die eigentliche parodontale Destruktion (Kohal und Dennison 2000). 
Die parodontale Zerstörung ergibt sich als Zusammenspiel einer komplexen WirtBakterieninteraktion, deren Progredienz davon abhängt in welchem Zustand sich das Gleichgewicht aus allen beteiligten Faktoren (balanciert oder nicht balanciert) befindet.

\subsubsection{Der orale Biofilm}

Die Feinstruktur der Plaque wird als Biofilm bezeichnet. Dabei handelt es sich um die Fähigkeit, eine strukturierte Gemeinschaft zu bilden, die Bakterienpopulation räumlich dreidimensional zu organisieren und eingebettet in einer extrazellulären Matrix eine Art Schutzstruktur des Biofilms zu erreichen. Hauptbestandteil der Matrix sind von den Bakterien gebildete extrazelluläre Polysaccharide, die als Nahrungsspeicher dienen. Die vielen adhärenten Bakterien gehen miteinander Stoffwechselkooperationen ein, kommunizieren untereinander, bilden und entwickeln Mikrokreisläufe sowie mikroökologische Nischen (Flemming und Wingender 2001, Sanderink 2005). Die extrazellulären Polysaccharide bilden eine hoch hydratisierte heterogene Matrix, die die Mikroorganismen in ihrer drei-dimensionalen Anordnung stabilisiert. Polysaccharidhaltige Strukturen wie Kapseln werden auch „Glykokalix“ genannt (Costerton et al. 1987). Innerhalb dieser Glykokalix kommt es im Rahmen der Zellteilung zur Bildung von Mikrokolonien. Durch Zunahme von Größe und Anzahl der anhaftenden Mikrokolonien bilden sich etablierte Biofilme aus (Caldwell und Lawrence 1986). Diese werden als eine geschützte Form des mikrobiellen Wachstums angesehen, welche die Überlebensfähigkeit von Mikroorganismen erhöht (Sanderink et al. 2004). Extrazelluäre polymere Substanzen erlauben eine Art Abschirmung der Zellen innerhalb des Biofilms und ermöglichen damit erfolgreich, sich der Wirtsabwehr und antimikrobiellen sowie lokalen und systemischen antibiotischen Substanzen zu widersetzen (Khoury et al. 1992).

Die Entwicklung eines pathogenen Biofilms läuft in mehreren Phasen ab. Auf der gereinigten Zahnoberfläche bildet sich innerhalb von Minuten ein Schmelzoberhäutchen (Pellicle). Dieses besteht aus adsorbierten Glykoproteinen des Speichels, sauren Proteinen, Zellresten und einzelnen eingelagerten abgestorbenen Mikroorganismen. Das Pellicle bildet die initiale Grundlage für das Biofilmwachstum. Hier etablieren sich grampositive aerobe Pionierkeime. Durch Wachstum und Vermehrung binden sich sogenannte Nachfolgerkeime (gramnegative Kokken, grampositive und gramnegative Stäbchen, sowie Filamente). Auf der supragingivalen Zahnoberfläche entsteht so ein strukturierter Zahnbelag, auch Plaque genannt (Nyad und Fejerskov 1987).

Die Pathogenität der Plaque bzw. des Biofilms variiert mit der Art und der Häufigkeit der vorhandenen Bakterienspezies, dabei ist nicht jeder Biofilm pathogen (Schroeder 1997). Zwischen der Residentflora des gesunden Sulkus auf der einen und der individuellen Immunantwort und Mundhygiene des Wirts auf der anderen Seite, hat sich beim gesunden Erwachsenen ein dynamisches Gleichgewicht eingestellt (Listgarten 1994, Theilade 1990). 
Kommt es im Rahmen der Biofilmentwicklung zu einer übermäßigen Akkumulation von fakultativ anaeroben Bakterien, führt dies zum Absinken des Redoxpotentials von +70 auf $-50 \mathrm{mV}$. Das Wachstum von obligat anaeroben Keimen wird dadurch weiter begünstigt, so dass sich die Zusammensetzung der mikrobiellen Gemeinschaft langsam verschiebt. In anoxischen Lebensbedingungen werden für die Oxidation der anaeroben Atmung anstelle von Sauerstoff alternative Elektronenakzeptoren verwendet. Der Stoffwechsel dieser Keime ist an ein niedriges Redoxpotential angepasst und lebenswichtige Enzyme werden durch Sauerstoff gehemmt. Das Bakterienmilieu wird nun zunehmend von capnophilen, mikroaerophilen und obligat anaeroben Spezies (z.B. Porphyromonas gingivalis und Actinobacillus actinomycetemcomitans) dominiert (Ximenez-Fyvie et al 2000, Tanner et al. 1998). Das Saumepithel lockert sich durch vermehrte Exsudation und Migration von Leukozyten auf und die Mikroorganismen können in das subgingivale Bindegewebe gelangen (Rateitschak et al. 1989). Beim Übergang einer Gingivitis zu einer Parodontitis verändert sich die mikrobielle Gemeinschaft (Lindhe 1983). Die zahnadhärente, sich nach apikal ausbreitende Plaque besteht noch weitgehend aus grampositiven aeroben nicht-motilen Kokken und Stäbchen (Schroeder 1997). Die nun mehrere Millimeter tiefe Zahnfleischtasche bietet anaerobe Wachstumsbedingungen. Häufige Blutungen und eine erhöhte Sulkusflüssigkeitsfließrate (SFFR) bringen wichtige endogene Nährstoffe (z.B. Hämin) und fördern das Wachstum von anspruchsvollen, obligat anaeroben Arten wie Porphyromonas- und Treponema-Spezies. Auf dem Sulkus- bzw. Taschenepithel etabliert sich nun die nichtadhärente Plaque. Der überwiegende Teil dieser gramnegativen Spezies gewinnen inre Energie nicht durch die Spaltung von Zuckern wie Streptokokken oder Actinomyceten sondern durch Proteolyse. Sie selbst produzieren eine Reihe von Exotoxinen, die eine direkte Schädigung des Gewebes hervorrufen (Travis et al. 1995, Haffajee et al. 1994, Folt und Bramanti 1991). Einige dieser obligaten Anaerobier sind zudem in der Lage, in die Interzellularräume des parodontalen Gewebes einzudringen und es zu schädigen (Lux et al. 2001, Sagalie et al. 1982). Als Reaktion auf die Freisetzung von Exotoxinen (z.B. Lipopolysaccharide), sezernieren die Zellen des Saumepithels pro-inflammatorische Mediatoren (Interleukine, Tumor-Nekrose-Faktor a, Prostaglanine-E2, Matrix-Metallo-Proteinasen (MMP), etc.). Diese diffundieren zusammen mit bakteriellen Toxinen in das parodontale Bindegewebe und verstärken dort die Entzündungs-reaktion. Begleiterscheinungen sind die Degeneration der extrazellulären Matrix des Bindegewebes durch MMPs und der direkte Knochenabbau durch die Aktivierung der Osteoklasten (Taubmann et al. 2001). Auch generell gesunde Patienten mit einer guten zellulären und humoralen Immunantwort können Biofilminfektionen nicht durch ihre körpereigene Abwehr verhindern. Die Proliferation parodontalpathogener Bakterien in einem Biofilm initiiert und unterhält die entzündliche Immunantwort, die mit als Ursache der Zerstörung des Bindegewebes, des parodontalen Ligaments und des alveolären Knochens angesehen wird (Schroeder 1997, Sanderink et al. 2004). 


\subsubsection{Parodontalpathogene Bakterien}

Nicht die Quantität des Biofilms, vielmehr die Qualität, bestimmt durch eine Gruppe ganz bestimmter Bakterienarten, ist von besonderer Bedeutung für die Entwicklung einer parodontalen Entzündung. Die höchste Prävalenz bei akuten Parodontitiden konnte für Porphyromonas gingivalis (Pg), Prevotella intermedia (Pi), Fusobacterium nucleatum (Fn), Campylobacter rectus $(\mathrm{Cr})$ und Treponema denticola $(\mathrm{Td})$ gefunden werden, eine geringere hingegen für Actincobacillus actinomycetemcomitans (Aac) (Albandar et al. 1997). Erhöhte Serumspiegel von IgG- und IgA-Antikörpern gegen $P g$ und $A a c$ sowie $\lg A$ gegen $P i$ bei Patienten mit einer aggressiven Parodontitis geben Anlass für die Vermutung, dass $P g$, Aac und Pieine entscheidende Rolle in der Pathogenese der Parodontitis spielen (Albandar et al. 2001). Entsprechend den Ausführungen von Socransky et al. (1998) werden einige dieser Keime in Komplexen zusammengefasst.

Nach morphologischen, physiologischen, biochemischen, antigenetischen und genetischen Merkmalen können Bakterien in einem hierarchischen System nach verwandtschaftlichen Beziehungen geordnet werden. Bestimmte orale Mikroorganismen kommen dabei häufig gemeinsam vor und so in Clustern (Komplexen) zusammengefasst werden. Man unterscheidet zwischen einem roten, orangenen, gelben und grünen Komplex.

Bei dem orangenen Komplex handelt es sich um Spezies, die als Brückenkeime fungieren und erst später zahlenmäßig dominant werden. Diese überbrücken die Frühkolonisierer mit den Spezies des roten Komplexes (nach Socransky und Haffaje 2002). Die herausragende Rolle nimmt dabei $F n$ ein. Fn verfügt über Andockstellen für Spätkolonisierer des roten Komplexes und liefert mit seinen Stoffwechselendprodukten wichtige Nahrungsquellen (Quirynen et al. 2001). Den Auswertungen von Socransky et al. (1998) zu Folge sind vor allem Bakterien des roten Komplexes häufig mit parodontalen Erkrankungen vergesellschaftet, die anderen Keime hingegen vorwiegend mit parodontal gesunden Verhältnissen (Socransky et al. 1998). Die Anwesenheit von Mitgliedern des roten Komplexes, Porphyromonas gingivalis ( $\mathrm{Pg})$, Tannerella forsythia (Tf) und Treponema denticola (Td), erhöht die Signifikanz für Blutung auf Sondieren und erhöhte Sondierungstiefen.

\subsubsection{Immunologische Wirt-Bakterieninteraktion}

Der Schweregrad der Ausprägung und des Verlaufs einer parodontalen Erkrankung ist abhängig vom Gleichgewicht zwischen der Zahl pathogener Bakterien und der Immunabwehr des Wirts (Lindhe 1986). Den Schwerpunkt bilden die anaeroben Keime, die mit Hilfe von Stoffwechselendprodukten das Gewebe schädigen oder direkt in dieses einwandern (van Palenstein Helderman 1981). Bei der Beschreibung pathologischer Prozesse wird hier das Modell des critical pathway benutzt. Das Modell nimmt Abstand vom Prinzip Ursache und Wirkung. Vernachlässigte Mundhygiene und daraus resultierende Ablagerungen von 
parodontalpathogener Plaque stellen auch nach diesem Modell eine primär krankheitsinduzierende Ursache der marginalen Parodontitis dar. Die Etablierung eines pathogenen Biofilms setzt im subgingivalen Bereich des Zahnhalteapparates eine Immunreaktion in Gang, die zum Fortschreiten der Erkrankung führt (Offenbacher 1996, Salvi et al. 1997). In diesem Modell werden zwei Phasen der Immunantwort unterschieden, die initiale Phase (Etablierung einer Gingivitis) und die zweite Phase (Etablierung der Parodontitis). Die initiale Phase ist durch eine vollständige Trennung der Zellen des Immunsystems und der parodontopathogenen Keime durch das Saumepithel gekennzeichnet (Müller 2001). Der Alveolarknochen, der Wurzelzement und das Desmodont werden als intakte funktionelle Einheit betrachtet. Die Aktivierung erfolgt primär durch Stoffwechselprodukte, Enzyme und Toxine der Bakterien. Bei den Enzymen handelt es sich um Proteasen, Kollagenasen und Hyaluronidasen (Slots 1979). Lipopolysaccharid (LPS) stellt dabei den potentesten Aktivator des immunologischen Entzündungsprozesses dar (Loppnow et al. 1989, Kornmann et al. 1997). Durch den Kontakt von LPS, bakteriellen Enzymen und Endotoxinen mit den Zellen des Saumepithels kommt es zu einer direkten Schädigung der Wirtszellen des Parodontiums (Slots 1979). Aus dem in unmittelbarer Nachbarschaft zum Saumepithel liegenden Blutgefäß-Plexus verlassen Leukozyten die postkapillären Venolen. Die Zahl der neutrophilen Granulozyten und die Sulkusfküssigkeitsfließrate (SFFR) steigen stark an. Neben Elektrolyten, Immunglobulinen und Komplementfaktoren enthält die Sulkusflüssigkeit Wachstumfaktoren für $P g, F n$ und $T d$ (van Palenstein Heldermann 1981) Migration durch das Saumepithel in den Sulkus bzw. Tasche sind typisch (Schiött und Löe 1970; Dennison et al. 1997). Das balancierte Gleichgewicht beginnt sich zu verschieben. Mit zunehmender Ausbreitung des Biofilms nach apikal, in den gingivalen Sulkus hinein, wird die Proliferation des Saumepithels angeregt. Dieses dehnt sich entlang der Wurzeloberfläche aus und wandelt sich schließlich in ulzerierendes Taschenepithel um (Kornman et al. 1997). Die frühen Stadien sind von der Anwesenheit von Lymphozyten, einschließlich B- und T-Lymphozyten mit charakteristischen Th1- und Th2-Zellen, gekennzeichnet (Dennison und Van Dyke 1997, Ischikawa et al. 1997). Etablierte parodontale Läsionen zeigen die Dominanz von spezifischen B-Zellen. B- und T-Zellen werden durch spezifische bakterielle Antigene und Mitogene zur klonalen Replikation angeregt. B-Zellen wandeln sich zu hoch spezifischen, antikörperproduzierenden Plasmazellen um. Die Epithelzellen selbst sezernieren verstärkt Interleukine wie Interleukin-1 $\beta$ (IL-1 $\beta$ ) oder Interleukin6 zur Signalisierung der Infektion an Leukozyten (Eckmann et al. 1995, Tonetti et al. 1993, Abbas et al. 1996). Die Einwanderung von Leukozyten in das entzündete Gewebe erfolgt unspezifisch. Durch proinflammatorische Zytokine und Adhäsionsmoleküle auf dem Endothel, wie ELAM-1 (endothelial leucocyteadhesion molecule-1) und ICAM-1 (intercellular attachment molecule-1), wird die Diapedese möglich. Der Weg durch Endothelzellkontakte (parazellulär) scheint der Hauptweg bei der Auswanderung von Leukozyten aus den Blutgefäßen und der 
Einwanderung in entzündete Gewebe zu sein (Schulte et al. 2011). Im Gewebe wandern die Leukozyten entlang eines intraepithelialen Konzentrationsgradienten der beteiligten Chemokine zum Ort der Entzündung. Es entsteht ein Leukozytenwall zwischen Plaque und Saumepithel, der im Medium des Sulkusfluid die Plaque vom Verbindungsepithel und Sulkusepithel abgrenzt (Zambon et al. 1996). Die Aufrechterhaltung von spezifischen Immunzellen am Entzündungsort wird zum Beispiel durch endotheliale und leukozytäre Adhäsionsmoleküle auf der Oberfläche von neutrophilen Granulozyten (Genco 1992), Interleukin-8 oder ICAM gewährleistet (Tonetti et al. 1994). Ortsständige Fibroblasten werden durch Entzündungsmediatoren zur verstärkten Chemokinproduktion angeregt. Dadurch steigert sich die vasale Permeabilität für Blutbestandteile (Kinane et al. 1991). Unterstützt wird die gezielte Leukodiapedese auch von den chemotaktisch wirkenden Komplementfaktoren (C3a und C5a). Nach der Einwanderung der neutrophilen Granulozyten in das Zentrum der Infektion werden die opsonierten pathogenen Keime phagozytiert und durch verschiedene oxidierende und nicht oxidierende Enzymsysteme abgebaut (Dennison et al. 1997). Kann diese erste Phase des mikrobiellen Angriffs eingedämmt werden und eine Bakterieninvasion in das Gewebe verhindert werden, bleibt die Entzündung auf die marginale Gingiva beschränkt. Der Zahnhalteapparat bleibt unverletzt (Kornman et al. 1997, Salvi et al. 1997). Gelingt die Abwehr nicht, treten nachfolgende Immunabwehrmechanismen in Kraft. Monozyten werden vermehrt aus dem peripheren Blutzyklus rekrutiert und durchsetzen das parodontale Gewebe (Salvi et al. 1997). Der subgingivale Biofilm etabliert sich. Die Streptokokkenzahl nimmt ab, anaerobe Aktinomyzeten und gramnegative Kokken dominieren die Plaque. Das Saumepithel proliferiert durch verstärkte basale Proliferation und erhöhte vasale Permeabilität (Müller 2001). Bakterien durchsetzen jetzt verstärkt das Endothel. Die Konzentration von Lipopolysacchariden (LPS) steigt. LPS führt am Endothel subepithelialer Blutgefäße zur Steigerung der Bildung zusätzlicher Integrine, wie zum Beispiel „Endothelial Cell Adhesion Molecule 1" (ECAM1). ECAM ist ein Vertreter des retikuloendothelialen Systems (RES) und steigert die Diapedese von Monozyten (Kornmann et al. 1997). Die eingewanderten Monozyten differenzieren zu Makrophagen. Es werden ihnen zwei Hauptfunktionen zugeschrieben. Zum einen phagozytieren sie eingedrungene Bakterien und zum anderen präsentieren CD4-Helferzellen bakterielle Antigene über MHC-II- Komplexe. Als CD4Helferzellen werden unter anderen Th1- und Th2-Zellen bezeichnet. Diese regulieren die zellvermittelte und humorale Immunantwort über Zytokine. Hier bilden Interleukin-2, Interferon- $ү$, makrophagenhemmendes Interleukin-10, Interleukin-4 und proinflammatorische Zytokone (IL-1 $\beta$, TNF- $\alpha$ ) die Schwerpunkte (Gemmell et al. 1997). INF- $\gamma$ gilt als der stärkste makrophagenaktivierende Faktor (Abbas et al. 1996). Zur Bereitstellung hochspezifischer Antikörper werden Plasmazellen rekrutiert, die unter dem Einfluss von Th2-zellspezifischen Interleukinen zur Klonbildung angeregt werden (Müller 2001, S.37). B-Zellen produzieren pround antiinflammatorische Zytokine, wie z.B. IL-1 $\beta$, Interleukin-6 und Interleukin-8, aber auch 
TNF- $\alpha$. Monozyten und Makrophagen produzieren gewebeschädigende Enzyme der MatrixMetallo-Proteinasen (MMP), z.B. Kollagenase und Mediatoren (z.B. Prostaglandin-E2). Die Kollagenase hat einen direkten Einfluss auf die Gewebeschädigung, Prostaglandin-E2 steigert die Gefäßpermeabilität und damit die Freisetzung von Zytokinen und MMPs (Sanderink et al. 2004). Dadurch wird eine entzündliche Parodontolyse herbeigeführt, sowie die Immunabwehr umgangen. Die Aktivierung von Osteoklasten erfolgt durch Zytokine und Prostaglandine. Die Folge sind Knochenabbau und Knochenresorption (Birkedal et. al. 1988, van Winkelhoff et al. 1988). Dieser pathologische Prozess wird auch als "critical pathway“ bezeichnet. Diese beschriebene Zerstörung des Zahnhalteapparates kann so lange ablaufen, bis der Zahnhalteapparat völlig abgebaut ist. Zahnlockerung und Zahnverlust sind die Folgen. In diesem Modell wird deutlich, dass die Störungen innerhalb des Systems massiven Einfluss auf den weiteren Verlauf der Erkrankung haben können. Wird das balancierte Gleichgewicht zwischen Immunabwehr und bakteriellem Angriff verschoben, ist das Immunsystem nicht mehr in der Lage das Entzündungsgeschehen zu kontrollieren. In akuten Phasen führt dies zum weiteren Abbau von kollagenen Fasern und tieferliegenden Stützgeweben (Page et al. 1991).

\subsection{Koronare Herzerkankungen}

\subsection{1 Ätiologie}

Die koronare Herzkrankheit (KHK) stellt ein komplexes Krankheitsbild dar, unter das man alle morphologischen oder funktionellen Erkrankungen der Koronargefäße subsumieren kann. Die KHK ist die Manifestation der Arteriosklerose an den Herzkranzgefäßen. Nach Angaben der WHO ist die KHK derzeit die häufigste Todesursache auf der Welt (Gross et al. 1996). Die Ätiologie ist häufig unterschiedlich. Als gemeinsame Endstrecke weisen alle die Koronarinsuffizienz auf. Das bedeutet, dass ein Missverhältnis zwischen myokardialem Sauerstoffangebot und Sauerstoffbedarf besteht. In über $90 \%$ der Fälle liegt der KHK eine Arteriosklerose der extramuralen Koronararterien zugrunde. Die KHK zählt zu den häufigsten Erkrankungen in den hoch entwickelten Industrienationen und ist die häufigste Ursache des Myokardinfarktes. In 33\% aller Fälle stellt der Myokardinfarkt die klinische Erstmanifestation einer KHK dar. Bei männlichen Patienten unter 65 Jahren weist die KHK eine höhere Inzidenz auf als alle anderen arteriosklerotischen Erkrankungen dieser Patientengruppe (Lloyd-Jones et al. 1999). Das Leitsymptom der KHK ist die Angina pectoris. Typisches Merkmal ist ein plötzlich einsetzender, Sekunden bis Minuten andauernder Schmerz im Brustkorb, der meistens retrosternal gelegen ist. Der Schmerzcharakter ist dumpf und einschnürend. Charakteristisch ist die Ausstrahlung des Schmerzes in die Arme, links häufiger als rechts und meistens ulnarseitig. Hals, Unterkiefer sowie Rücken und Epigastrium können ebenfalls lokalisiert werden. Klinisch werden zwei Verlaufsformen der Angina pectoris unterschieden, die stabile und die instabile Angina pectoris. Bei der stabilen Angina pectoris klagen die Patienten vorwiegend bei Belastung über einsetzende Beschwerden, die in ihrem Charakter eher konstant sind. Bei der instabilen 
Angina pectoris rücken neu auftretende, in der Intensität zunehmende sowie in Ruhe auftretende Beschwerden in den Vordergrund. Die instabile Angina und der Non-Q-Wave Myokardinfarkt werden in Kombination als akutes Koronarsyndrom bezeichnet.

\subsubsection{Arteriosklerose}

Unter dem Begriff Arteriosklerose versteht man eine Kombination von Intimaveränderungen, die mit einer Akkumulation von Lipiden, komplexen Kohlenhydraten, Blut oder Blutbestandteilen, fibrösem Gewebe und Kalziumablagerungen einhergeht. Veränderungen der Media in großen und mittleren elastischen und muskulären Arterien sind häufig (World Health Organisation Technical Reports Series, 1958). Anhand epidemiologischer Untersuchungen konnten trotz der Komplexität arteriosklerotischer Mechanismen einige Parameter identifiziert werden, deren verstärkte oder verminderte Ausprägung das Arterioskleroserisiko erhöhen (Chamberlain et al. 1990, Miserez und Braun 1995).

Zu den wichtigsten evidenten Risikofaktoren für Arteriosklerose zählen (Isselbacher und Schmailzl 1995):

- das männliche Geschlecht

- zerebrovaskuläre Vorerkrankung oder die periphere arterielle Verschlußkrankheit (paVK)

- positive Familienanamnese

- Zigarettenkonsum (>10 Zigaretten täglich)

- Hyperlipidämie

Aufgrund der Vielfalt arteriosklerotischer Erkrankungen, die selbst in einem Individuum in verschiedenen Gefäßgebieten noch variieren können, ist anzunehmen, dass eine Vielzahl von Genen an diesen Vorgängen beteiligt sind und deshalb die individuelle genetische Prädisposition entscheidend sein kann (Isselbacher und Schmailzl 1995).

Eines der am meisten untersuchten Gebiete der Arterioskleroseforschung ist der Lipoproteinstoffwechsel mit seinen beteiligten Genen (Goldbourt et al. 1986, Schunkert et al. 1995). Bei der Entstehung einer arteriosklerotischen Läsion sind alle zellulären Komponenten einer inflammatorisch-fibroproliferativen Antwort auf eine traumatische Läsion charakterisiert. Im Rahmen der pathologischen Veränderungen spielen fünf Komponenten eine wichtige Rolle: Endothel, die glatten Muskelzellen der Arterienwand, die Monozyten/Makrophagen, die Thrombozyten und die Lipoproteine des Plasmas (Hornbostel et al. 1992). Die Response to Injury Hypothese (Verletzungstheorie) dient als Leitschnur der Pathophysiologie. Die Reaktion ist durch eine chronisch inflammatorisch-fibroproliferative Antwort der glatten Muskelzellen von Intima und Media auf eine vorher erfolgte Schädigung des Endothels gekennzeichnet. Dabei 
handelt es sich weniger um einen degenerativen, als vielmehr um einen übersteigerten proliferativen Prozess. Die Schädigung des Endothels induziert eine chronische Entzündungsreaktion. Die Folge ist eine Störung der normal gut ausgewogenen Balance verschiedener Mediatorkaskaden (Diehm et al. 2001, Ross 1999). Es kommt zu einer verminderten Freisetzung des Vasodilatators und Thrombozytenaggregationhemmers Prostacyclin sowie einer erhöhten Freisetzung des Vasokontriktors und die Aggregation fördernden Thromboxan A. Im Bereich des verletzten Endothels führt dies zu einer verstärkten Adhäsion von Thrombozyten.

Die Entstehung der arteriosklerotischen Plaque beginnt mit der aktiven Aufnahme und Einlagerung von LDL-Molekülen (Low Density Lipoproteins) in die Intima. Dieser Prozess beschreibt Veränderungen der Intima, die nach der aktuell gültigen Klassifikation der American Heart Association (AHA) dem Typ I zugeschrieben werden (Typ I Läsion nach Stary/AHA) (Stary et al. 1994). Diese ist reversibel und bei manchen Patienten schon im Alter von weniger als 20 Jahren nachweisbar. Anschließend kommt es zur Oxidation durch verschiedene Enzyme und Sauerstoffradikale. Durch die Expression verschiedener chemotaktischer Substanzen durch Endothelzellen werden im Blut zirkulierende Monozyten aktiviert und zur Adhäsion und Migration in das subepitheliale Bindegewebe angeregt. Dort angekommen, phagozytieren diese die oxidierten LDL (Diehm et al. 2000, Diehm et al. 2007). Aufgrund des Fehlens eines bestimmten Rückkopplungsmechanismusses der Scavenger-Rezeptoren, phagozytieren die Makrophagen unbegrenzt LDL-Moleküle. Dies führt innerhalb des komplexen inflammatorischen Prozesses zu einer Umwandlung der Makrophagen in Schaumzellen (Foam Like Cells), die nach Summierung die typischen Fettstreifen (Fatty Streaks) bilden (Fuster et al. 1990). Durch das komplexe Zusammenspiel von Wachstumsfaktoren und Zytokinen aus stimulierten Makrophagen, Lymphozyten und Thrombozyten kommt es zur Aktivierung und Proliferation von glatten Muskelzellen (Typ II Läsion nach Stary/AHA). Dieser Typ II kann in das Präatherom übergehen. Dabei handelt es sich morphologisch um eine Ansammlung von membrangebundenen und freiliegenden Lipidtröpfchen. Ist dieses Stadium erreicht, spricht man von einer Typ III Läsion. Diese hat bis zu diesem Punkt noch keine klinische Relevanz, wird aber als Vorstufe der Entstehung komplizierter und potenziell symptomatischer Plaques angesehen. Bei klinisch symptomatischen, fortgeschrittenen arteriosklerotischen Läsionen werden nach der AHA die Klassifikationstypen IV bis VI gewählt. Bei der Typ IV Läsion (Atherom) beschreibt man eine dichte Akkumulation von extrazellulären Lipiden in einer klar begrenzten Region innerhalb der Media (Lipidkern). Obwohl die Konzentration an Leukozyten in der proteoglykanreichen Schicht zwischen Lipidkern und Intima bis dahin schon ansteigt, sind keine strukturellen Veränderungen erkennbar. Vermutet wird, dass die Leukozyten an der bindegewebigen Umwandlung beteiligt sind. Im weiteren Verlauf wandelt sich die Intima zu einer fibrösen Kappe (fibrous cap) über dem Lipidkern um (Fuster et al 1992). Dieses Stadium des Typs Va wird als Fibroatherom 
bezeichnet. Die Typen IV und Va lassen sich lichtmikroskopisch nicht unterscheiden. Mit dem Erreichen des Stadiums IV erfährt das Lumen des Gefäßes eine erkennbare Einengung. Bei der Läsion vom Typ V lassen sich folgende Unterscheidungen definieren: a): Wird der in der Plaque befindliche Lipidkern von fibrösem Bindegewebe überdeckt, so wird die Plaque als Typ Va klassifiziert. Dabei sind nekrotische Veränderungen im Lipidkern und die Ausbildung von Cholesterinkristallen in einer amorphen Gewebemasse zu beobachten. In fortgeschrittenen Plaques wird dann von Lipid-rich/necrotic Core (LR/NC) gesprochen. b): Kommt es im Rahmen der chronischen-inflammatorischen Entzündung innerhalb der Plaque zu Kalziumphosphatablagerungen, wird die Plaque als Typ Vb bezeichnet. c): Ist kein Lipid nachweisbar und fibröses Bindegewebe dominiert die Struktur der Plaque, spricht man von einer Plaque des Typs Vc.

In den Plaques des Typs Vc kommt es häufig zu Neovaskularisationen. Durch die Einwirkung von gewebeverflüssigenden Enzymen (z.B. Matrix-Metallo-Proteinasen) oder durch die Organisation von Thromben durch leukozytäre Abräumreaktionen kommt es zur Auflockerung des Gewebes. Histopathologisch lässt sich lockeres Bindegewebe (loose matrix) mit zellulären Infiltraten von glatten Muskelzellen und Leukozyten nachweisen. In der Nähe des Lumens konnte das Vorkommen von lockerem Bindegewebe als eine Gewebereaktion auf stattgefundene Rupturen nachgewiesen werden (Burke et al. 2001). Im Rahmen von strukturellen Veränderungen sowie durch veränderte hämodynamische Faktoren kann es zu Einblutungen oder Ulzerationen kommen. Tritt eine dieser Veränderungen in Kraft, spricht man von einer komplizierten Plaque des Typs VI.

Der Befall mehrerer Stromgebiete wie koronare, zerebrale, viszerale und periphere Arterien mit Arteriosklerose ist wahrscheinlich. Die differenten Gefäße sind in verschiedenen Lebensdekaden in unterschiedlichem Ausmaß betroffen (Isselbacher und Schmailzl 1995).

In Tabelle 1 werden die verschiedenen histomorphologischen Unterschiede zusammengefasst. 
Tab. 1: Histomorphologische Klassifikation arteriosklerotischer Läsionen nach AHA (Stary et al.1994, Stary et al. 1995)

\begin{tabular}{|c|c|c|}
\hline Typ & Bezeichnung & Histomorphologische Merkmale \\
\hline I & Initialläsion & $\begin{array}{l}\text { intrazelluläre Ablagerungen, kleine Gruppen einzelner Makrophagen, } \\
\text { Akkumulation in der Tunica intima }\end{array}$ \\
\hline II & fatty streak & $\begin{array}{l}\text { Schaumzellen, Infiltration von glatten Muskelzellen mit adaptiver } \\
\text { Verdickung der Intrazellularmatrix }\end{array}$ \\
\hline III & $\begin{array}{l}\text { intermediäre } \\
\text { Läsion }\end{array}$ & Präatherom, nicht konfluierende Lipidtröpfchen \\
\hline IV & Atherom & extrazelluläre Lipidkerne \\
\hline Va & Fibroatherom & Lipidkern mit dichtem fibrösem Gewebe \\
\hline $\mathrm{Vb}$ & verkalkte Läsion & Kalzifizierung von Lipidkernen und nekrotischem Gewebe \\
\hline Vc & fibrotische Läsion & $\begin{array}{l}\text { Initima durch überwiegend fibröses Material ersetzt; Aufbruch der } \\
\text { Oberfläche und/oder Thrombus in Kontakt }\end{array}$ \\
\hline VI & $\begin{array}{l}\text { komplizierte } \\
\text { Läsion }\end{array}$ & Einblutung in den Lipidkern, Hämotombildung \\
\hline
\end{tabular}

\subsection{Ischämische Myokardzustände}

Eine späte Komplikation einer Arteriosklerose ist die Ruptur der arteriosklerotischen Plaque mit nachfolgendem Gefäßverschluss.

In 60\% der Fälle sind Plaquerupturen für die Bildung eines koronaren Thrombus, die autoptisch bei aktuen Myokardinfarkten oder plötzlichem Herztod gefunden werden, verantwortlich. Nach aktueller pathophysiologischer Vorstellung kommt es im weiteren Verlauf der Arteriosklerose innerhalb der arteriosklerotischen Plaque zu einer Dysbalance der extrazellulären Matrix, der Plaque-Angiogenese und Kalzifizierung. Die innerhalb der Plaque befindlichen Mastzellen, Lymphozyten und Schaumzellen produzieren MMPs, die zur Verjüngung der fibrösen Kappe der Plaque beitragen. Durch qualitative Unterschiede in Bezug auf Volumina und Stenosegrad kann es im Bereich der Arterienwand ebenfalls zu einer Verjüngung der Fibrinschicht (fibröse Deckplatte) kommen. Dies kann zu Rissen führen, die bis in das subendotheliale Gewebe reichen. Die Ruptur der Deckplatte führt durch einen daruntergelegenen Verkalkungsherd zu einer nicht okklusiven Thrombose. Kommt es zum Kontakt des Subendotheliums mit vorbeifließenden Thrombozyten, wird eine Gerinnungskaskade aktiviert, die eine intraluminale Thrombose auslösen kann (Rauch et al. 2001).

Ein anderer Weg der Thrombusbildung führt über die Plaqueerosion bei Endothelzellapopotose (Virmani et al. 2006, Libby et al. 2009, Ward et al.2009). Die prothrombotische Wirkung von parodontalen Pathogenen stellt hier einen wesentlichen Faktor dar. Diese können die Denudierung des programmierten Zelltods (Apoptose) von Endothelzellen verstärken und haben damit prothrombotische Eigenschaften (Kebschull et al. 2010). 
Klinisch äußert sich dies im Übergang einer stabilen koronaren Herzkrankheit (KHK) in ein instabiles Koronarsyndrom. Der sich entwickelnde Thrombus lagert sich rasch auf der geschädigten Plaque $a b$ und kann dadurch einen totalen Verschluss der Koronararterie verursachen. Als Folge tritt eine Ischämie des Myokardgewebes auf. Durch myokardiale Hypoxie und dem daraus resultierenden anaeroben Metabolismus kommt es zum Absterben unversorgter Myokardareale. Bei einigen Patienten bleiben die klinischen Parameter unauffällig, bei anderen entsteht ein Myokardinfarkt mit plötzlichem Herztod (Forrester et al. 1997). Eine Folgeerscheinung des Infarkts kann die hämodynamische Instabilität, bis hin zum Kreislaufschock oder gar die tödliche Ventrikelruptur sein. Klinisch typische Komplikationen sind Erregungsleitungstörungen und Arrythmien (Herold 2007). In der Folge der akuten Phase des Myokardinfarktes bleibt ein geschwächter Herzmuskel mit reduzierter Kontraktilität zurück. In der Folge entsteht eine Herzinsuffizienz. Nekrotische Herzmuskelareale werden durch Remodellingprozesse bindegewebig ersetzt (Narbenbildung). Dadurch wirkt die Herzwand dünner. Diese dünneren, geschwächten Areale können dem Druck und der Volumenlast des Herzens nicht den gleichen Widerstand entgegensetzen wie das gesunde Herzgewebe. Es resultiert eine Erweiterung der Herzkammer ausgehend von der Region des Infarktes. Verändert das Herz im Rahmen des Remodeling seine Form verliert es die elliptische Form und ähnelt dann eher einer Kugel. Die diastolische Funktion und die Fähigkeit des Herzens, sich zwischen den Kontraktionen zu entspannen, nehmen ab (Hasenfuss et al. 2004).

\section{$2.4 \quad$ Aortenklappenstenose (AS)}

Die Stenose der Aortenklappe stellt die dritthäufigste kardiovaskuläre Erkrankung nach der arteriellen Hypertonie und der koronaren Herzkrankheit dar. Die kalzifizierte Aortenklappe ist mit einer Prävalenz von 2-7\% der über 65-Jährigen das häufigste Herzvitium in Europa und den USA (Vahanian et al. 2007). Betroffen sind meist Patienten in höherem Lebensalter. Die Inzidenz ist aufgrund der immer älter werdenden Bevölkerung steigend (Nkomo et al. 2006). Die Ätiologie und Pathogenese der AS ist der der Arteriosklerose sehr ähnlich. Die primäre Ursache der Aortensklerose selbst ist die Folge einer Entzündungsreaktion mit Lipidablagerungen. Bei progredienten Aortenklappenstenosen können in mehr als $80 \%$ der Fälle histologisch Chondrifikationen oder Ossifikationen an den Segeln nachgewiesen werden (RenzPolster et al. 2008). Dabei handelt es sich ebenfalls um einen chronisch fibroproliferativen Entzündungenprozess, der zur Verkalkung der Klappe führt (Baumgartner 2005) (s.Kapitel 2.2.1).

Durch zunehmenden Verlust elastischer Eigenschaften der Klappe wird die linksventrikuläre Ausflussbahn verengt und hämodynamisch beeinträchtigt. Infolgedessen kommt es zu einem systolischen Druckgradienten zwischen Ventrikel und Aorta ascendens und damit zu einer Reduktion der Klappenöffnungsfläche. Physiologische Folgen sind die kompensatorische 
Linksherzhypertrophie, Steigerung des Sauerstoffbedarfs des Herzens, die Abnahme des Herzzeitvolumens und die Verringerung des koronaren Blutflusses. Die am häufigsten beobachteten klinischen Befunde sind die Belastungsdyspnoe, pektanginöse Beschwerden, Synkopen, Ermüdbarkeit, Lungenödem und Zyanose bei fortgeschrittener Erkrankung (Bonow et al. 2006, Boon und Bloomfield 2002, Freeman und Otto 2005, Vahanian et al. 2007).

Im Rahmen einer immunhistologischen Aufarbeitung einzelner kalzifizierter Klappen konnte eine vermehrte Akkumulation von Lipiden (LDL), verschiedenen inflammatorischen T-Lymphozyten und Makrophagen, Proteinen, die die Gewebekalzifizierung fördern, nachgewiesen werden. Ebenfalls konnten vermehrt inflammatorische Mediatoren, wie Interleukin-1ß und Transforming Growth Factor (TGF) sowie Adhäsionsmoleküle in Kombination mit einer verstärkten Expression der Matrixmetallproteinasen (MMP) gefunden werden (Goldbarg et al. 2007).

Goldbarg konnte zeigen, dass das Fehlen verschiedener Transkriptionsfaktoren, die Differenzierung von valvulären Zellen in osteoblastenähnliche Zellen und damit die Kalzifizierung der Klappe fördert (Goldbarg et al. 2007).

Unter Berücksichtigung dieser Aspekte kann man vermuten, dass es sich keineswegs lediglich um einen passiven Degenerationsprozess handelt, sondern vielmehr um ein aktiv reguliertes Zusammenspiel von Entzündungszellen, pro-inflammatorischen Zytokinen, Mediatoren und Adhäsionsmolekülen.

\subsection{Kausalzusammenhänge zwischen Parodontitis und Herzerkrankungen}

Im Folgenden soll ein kurzer Überblick über die potenziellen Pathomechanismen zwischen kardiovaskulären Erkrankungen und parodontalen Entzündungen gegeben werden. Schwerpunkte bilden die Effekte der parodontalen Infektion auf das Entstehen und die Progression der Arteriosklerose unter dem Einfluss von parodonthopathogenen Mikroorganismen.

In einer von Dietreich et al. publizierten Studie von 2008 wurden signifikante Zusammenhänge zwischen chronischen Parodontitiden und koronaren Herzerkrankungen unabhängig von anderen kardiovaskulären Risikofaktoren bei Männern, die jünger als 60 Jahre alt waren, beschrieben. Es wurde die Hypothese formuliert, dass sowohl direkte (z.B. Bakteriämie) und indirekte Effekte (z.B. systemische Inflammation) der Parodontitis eine bedeutende Rolle bei der Entstehung einer Arteriosklerose spielen (Abb.1) (Dietrich et al. 2008). 


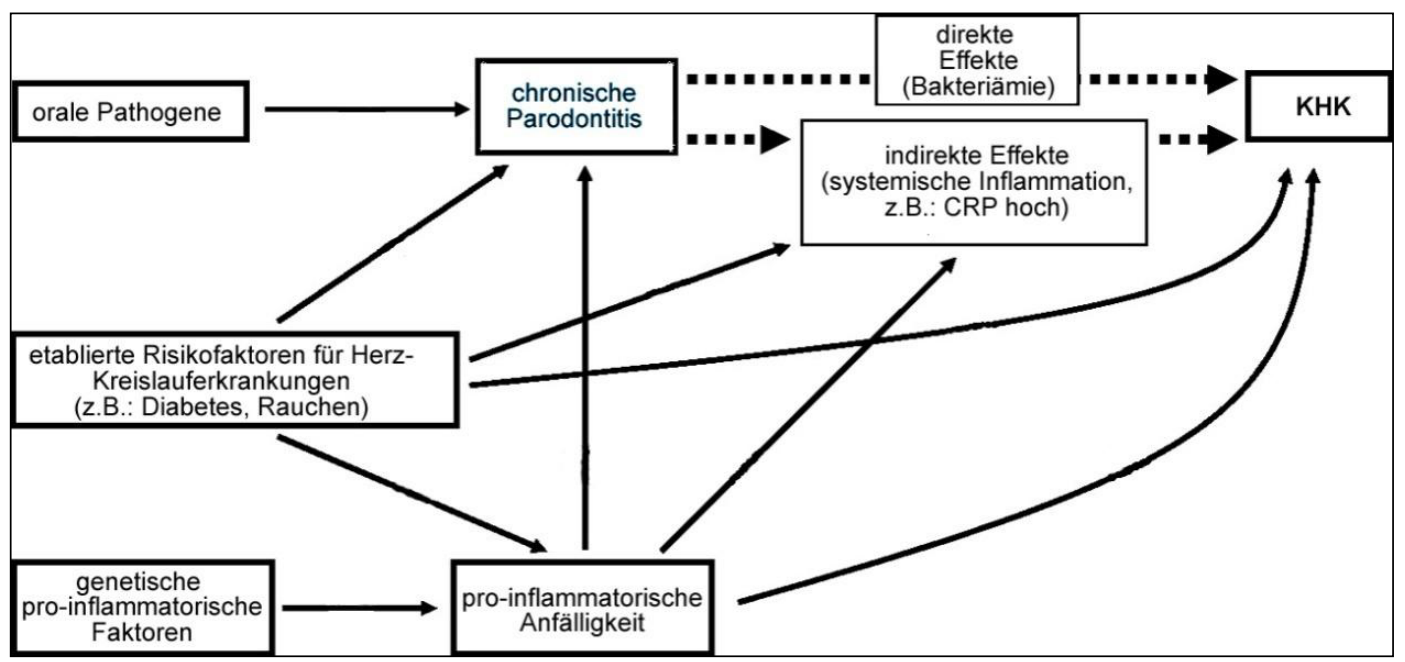

(KHK: Koronare Herzkrankheit, ---- kausaler Weg, - nicht kausaler Weg )

Abb.1: Kausalzusammenhänge von Parodontitis und koronarer Herzkrankheit nach Dietrich et al. (2008)

\subsubsection{Die Bakteriämie (direkter Effekt)}

In dem von Dietrich et al. 2008 beschrieben Modell spielt die Bakteriämie eine entscheidene Rolle (direkter Effekt) zur Klärung des kausalen Zusammenhanges zwischen parodontalen Infektionen und Arteriosklerose (Abb.1). Unter Bakteriämie versteht man das vorübergehende Vorhandensein von oralen Bakterien, deren Bestandteilen oder Stoffwechselendprodukten (Entzündungsmediatoren) im Blut.

Untersuchungen konnten zeigen, dass eine Bakteriämie vor allem bei verschiedenen Eingriffen und mechanischen Manipulationen in der Mundhöhle auftritt. Als wichtigster Ursprungsort der Bakteriämie wird das marginale Parodont angesehen (Neu 1986, Rahn 1989). Bakteriämien können nach dem Zähneputzen auftreten (Sconyers et al.1973, Schlein et al.1991), nach dem Kaugummikauen (Roberts 1999), nach Prophylaxe-Maßnahmen und nach zahnärztlich chirurgischen Eingriffen (Otten et al. 1987).

Die bakterielle Streuung in die Blutbahn beschreibt ein kurzzeitiges Phänomen. Etwa 30 Minuten nach mechanischer Manipulation des marginalen Parodonts sind die Bakterien fast vollständig eliminiert (Lautenbach und Linzenmeier 1957, Rahn et al. 1987).

Entscheidender Hauptakteur bei der Keimeliminierung aus dem Blut sind die polymorphkernigen Leukozyten und das retikuloendotheliale System der Leber (Kupffer-Sternzellen), der Milz und des Knochenmarks (Histiozyten) (Wood et al. 1951, Bennett und Beeson 1954).

\subsubsection{Zusammenhänge zwischen Parodontitis und Herzerkrankungen}

Die Frage der Zusammenhänge zwischen einer Infektion und der Entstehung von verschiedenen chronischen Erkrankungen wurde bereits in den achtziger Jahren des vergangen Jahrhunderts untersucht (Warren und Marshall 1983). So folgten in den darauffolgenden Jahren mehrere 
Studien, die die Zusammenhänge zwischen Parodontitis und kardiovaskulären Erkrankungen postulierten (Matilla et al. 1989, Syrjanen et al. 1989).

In einigen Arbeiten konnte gezeigt werden, dass es sowohl einen Zusammenhang zwischen Parodontitiden und Arteriosklerose als auch Herzerkrankungen gibt (Aldridge et al. 1995, Grossi et al. 1997, DeStefano et al 1993, Beck et al. 1996, Wimmer und Pihlstrom 2008, Offenbacher et al. 1998, Jeffcoat et al. 2001, Jepsen und Kebschull 2011). Mattila et al. konnten bereits 1989 die Hypothese einer Assoziation zwischen der parodontalen Gesundheit und dem Auftreten eines akuten Herzinfarktes aufstellen (Matilla et al. 1989). DeStefano et al. ermittelten 1993 doppelt so hohes Risiko für die Entwicklung einer koronaren Herzkrankheit (KHK) bei männlichen Parodontitispatienten im Vergleich zu einer gesunden Kontrollgruppe (DeStefano et al. 1993). Hung et al. postulierten 2004, dass Patienten mit fehlenden Zähnen ein erhöhtes Risiko haben, eine KHK zu entwickeln (Hung et al. 2004). Tang et al. konnten deutlich erhöhte Werte für Produkte des Fettstoffwechsels (z.B. Cholesterol, Triglyceride oder Lowdensity Lipoproteins (LDL)) bei Patienten mit manifester KHK und Parodontitis nachweisen (Tang et al. 2011). In derselben Studie konnten signifikant höhere Werte für die Sondierungstiefen, Attachementverlust, Sulkus-Blutungsindex und fehlende Zähne gegenüber einer gesunden Kontrollgruppe ermittelt werden (Tang et al. 2011). Die Datenlage konnte in den genannten Arbeiten und in einzelnen Metaanalysen mit dem übereinstimmenden Ergebnis, dass ein moderater Zusammenhang zwischen parodontalen Infektionen und Arteriosklerose besteht, zusammengefasst werden (Jepsen und Kebschull 2011). Demnach stellt die Parodontitis einen Risikofaktor für die KHK dar (Humphrey et al. 2008, Janket et al. 2003, Mustapha et al. 2007). In Anlehnung an Dietrich et al. 2008 konnte man bisher keinen epidemiologischen Unterschied zwischen beiden Wegen finden, sodass der Einfluss sowohl direkt als auch indirekt zu suchen ist. Zu den direkten Parametern zählt vor allem die chronische Parodontitis. Aufgrund der großen Wundfläche der Zahnfleischtaschen bei parodontal Erkrankten von bis zu $20 \mathrm{~cm}^{2}$ (Loos 2005) und der Besiedlung mit parodontalpathogenen Mikroorganismen werden bei sämtlichen mechanischen Vorgängen in der Mundhöhle Bakterien über das ulzerierte Taschenepithel des Parodontiums in die Blutbahn verschleppt (Bakteriämie). Der gingivale Sulkus wird als die Hauptquelle mit Zugang zum Blutkreislauf für orale Mikrooraganismen angesehen (BaharaniMougeot et al. 2008, Bayliss et al. 1983). Das bedeutet, dass parodontalpathogene Mikroorganismen lokal und systemisch eine Entzündungsantwort hervorrufen. Die Folge sind erhöhte Entzündungsparameter (z.B. CRP, Zytokine wie IL-1 und IL-6, TNF- $\alpha$ ) im Blut, so dass die Entzündungslast steigt (Loos et al. 2005). Bestandteile parodontaler Mikroorganismen konnten in arteriosklerotischen Plaques nachgewiesen werden (Haraszthy et al. 2000). Die Wirkung von parodontalen Pathogenen wie $P g$ auf die Endothelzellen stellt einen die Dysfunktion begünstigenden Faktor dar. Mit speziellen Fimbrien am Bakterium selbst können diese die Endothelzellen invadieren, dort überleben, sich vermehren und sich zwischen 
benachbarten Zellen bewegen (Li et al. 2008, Takahashi et al. 2006, Tonetti et al. 2007). Der Nachweis der DNA von parodontalen Keimen in atherosklerotischer Plaque beweist den ätiologischen Zusammenhang (Mahendra et al. 2013, Haraszthy et al. 2000). Durch diese Bindung wird die Aktivierung von Endothelzellen gefördert und Mediatoren ausgeschüttet, die Monozyten und Oksteoklasten rekrutieren. Endothelzellen exprimieren Oberflächenmoleküle, die die Migration von Immunzellen fördern. Spezielle Keime, z.B. Pg, können einen direkten Zelltod (Apoptose) auslösen. Der programmierte Zelltod stellt den Hauptfaktor bei der Entstehung einer endothelialen Dysfunktion dar (Hotchkiss et al. 2009, Pober et al. 2009). In der nächsten Phase der Arteriogenese, nach der Ausprägung einer endothelialen Dysfunktion, werden oxidierte Lowdensity Lipoproteins (LDL) von eingewanderten Monozyten aufgenommen. Die Aufnahme erfolgt ungehemmt und konzentrationsunabhängig über Scavenger-Rezeptoren, bis die Monozyten platzen und zu Schaumzellen werden (Giacona et al. 2004). Pg ist in der Lage die Migration von Monozyten und die Aufnahme von LDL durch proinflammatorische Zytokine (Interleukin-6, TNF- $\alpha$ ) zu steigern (Pollreisz et al. 2010). Das in der Membran von gramnegativen Bakterien vorkommende Lipopolysaccharid (LPS) steigert zusätzlich die Expression von Scavenger-Rezeptoren in der Membran der Monozyten, die die LDL Aufnahme regulieren (Lakio et al. 2006). Ein weiterer wichtiger Aspekt bei der Arterioskleroseentwicklung ist die prothrombotische Wirkung von parodontalen Pathogenen. Auf der einen Seite aktivieren nekrotische Endothelzellen, durch Membranexposition, Thrombozyten und deren Aggregation (Bombeli et al. 1997). Auf der anderen Seite wird durch systemische Inflammation die Thrombokinase aktiviert (Pober et al. 2009). Mehrere aktuelle Studien konnten Interaktionen von Antigenen mit verschiedensten Rezeptoren auf Endothelzellen, Thrombozyten und parodontalen Antigenen beschreiben und eine erhöhte Thrombosemarkerkonzentration bei Parodontitispatienten nachweisen (Nylander et al. 2008, Roth et al. 2006, Yun et al. 2005). In Folge der weiteren Entwicklung kann es zu Komplikationen im Rahmen der Arteriogenese kommen. Die Ruptur der arteriosklerotischen Plaques mit nachfolgendem Gefäßverschluss stellt eine schwerwiegende Komplikation dar (Virmani et al. 2006, Libby 2009, Ward et al. 2009).

Einige Studien evaluierten den Einfluss von parodontalen Infektionen und der Parodontitistherapie auf die endotheliale Dysfunktion. Diese wurde anhand der vasodilatatorischen Kompetenz von peripheren Gefäßen gemessen. In einzelnen Querschnittsstudien wurde Parodontitis mit einer verschlechterten Endothelfunktion assoziiert (Amar et al. 2003, Mercanoglu et al. 2004). In mehreren Interventionsstudien führte eine parodontale Therapie allein (Mercanoglu et al. 2004, Elter et al. 2006) oder in Kombination mit einer systemischen (Seinost et al. 2005) oder lokalen (Tonetti et al. 2007) antibiotischen Therapie zu einer Verbesserung der Endothelfunktion bis zu 60 Tage nach Abschluss der Therapie. Zusätzlich konnten die Entzündungsparameter (z.B. CRP, IL-6) deutlich gesenkt werden (Tonetti et al. 2007, D’Aiuto et al. 2004). 
Die Entzündungsgeschehen an Herzklappen laufen in ähnlicher Weise ab wie jene am Endothel von Blutgefäßen. Auch die Aortenklappenstenose wird einem degenerativen Entzündungsprozess zugeschrieben (Parolari et al. 2009). Die Aortenklappenstenose ist nicht nur ein Produkt des Alterungsprozesses, sie beinhaltet vorwiegend endotheliale Läsionen, Entzündungsinfiltrate und die Akkumulation von Lipiden. Die Aortenklappen solcher Entwicklungen sind verdickt, sklerosiert und häufig verkalkt. Degenerativ sklerosierende Klappenveränderungen können zu völliger Starrheit der Klappe führen. Histopathologisch äußert sich die degenerative Stenose in einem extrazellulären Matrixremodelling, kalzifizierenden Knoten und Knochengeweben (Parolari et al. 2009). Angeli et al. konnten 2003 zeigen, dass es einen signifikanten Zusammenhang zwischen linker Ventrikelmasse und dem Grad der parodontalen Erkrankung bei Patienten mit essentieller Hypertonie gibt (Angeli et al. 2003). Auch der programmierte Zelltod kann bei dem Remodellingprozess eine Rolle spielen und wurde als Einflusswert für die Herzinsuffizienz beschrieben (Narula 1999). Pg konnte als Leitkeim für die Apoptose und Hypertrophie von Kardiomyozyten identifiziert werden (Lee et al. 2005). 


\section{$3 \quad$ Material und Methoden}

\subsection{Studiendesign}

Bei der vorliegenden Arbeit handelt es sich um eine klinische Querschnittsstudie, bei der Patienten mit operationsbedürftigen Aortenklappenstenosen, akutem Myokardinfarkt und anstehenden Bypassoperationen zahnärztlich untersucht wurden. Schwerpunkt der Untersuchung war die Ermittlung des klinischen parodontalen Gesundheitszustandes und die Analyse von Biofilmproben aus den jeweilig parodontal erkrankten Regionen.

Die Durchführung der Studie wurde von der Ethikkommission der Universität Göttingen ohne ethische und rechtliche Bedenken genehmigt (Nummer 6/2/09). Da für die Untersuchung Patienten mit einer gesicherten kardialen Diagnose benötigt wurden, erfolgte im Vorfeld die interdisziplinäre Patientenauswahl mit der Klinik für Thorax-, Herz- und Gefäßchirurgie der Universitätsmedizin Göttingen unter Leitung von Herrn Prof. Dr. med. Schöndube.

Die Patienten wurden mündlich und schriftlich über das Ziel, den Ablauf und den Studienverlauf aufgeklärt. Eine entsprechende Patientenaufklärung sowie eine Einverständniserklärung zur Teilnahme an der Untersuchung und zur wissenschaftlichen Verwendung des Blutes und der ehobenen mikrobiellen Befunde wurden vom Patienten und Prüfarzt unterschrieben und dem Patienten ausgehändigt. Alle untersuchten Patienten und deren Daten wurden durchnummeriert und die entsprechenden Datenblätter pseudonymisiert.

\subsection{Patientengewinnung und Gruppeneinteilung}

Die Rekrutierung und Untersuchung der in der Studie eingeschlossenen herzkranken Patienten erfolgte im Zeitraum von Mai 2009 bis August 2010. Als Probanden dienten Patienten, die sich in der Klinik für Thorax-, Herz und Gefäßchirurgie des Universitätsklinikums Göttingen (THG) einer Bypass- oder Aortenklappenoperation unterzogen. Die Patienten ohne bekannte kardiale Vorerkrankung (Kontrollgruppe) wurden aus einer allgemeinzahnärztlichen Praxis rekrutiert. Untersuchungsort der Patienten der Kontrollgruppe war die Zahnarztpraxis Dipl.-Stom. Isante Krebs, Marschlinger Hof 11 in 06484 Quedlinburg.

Folgende Ausschlusskriterien wurden formuliert:

- Patienten, die jünger als 40 Jahre alt waren

- immunsupprimierte oder organtransplantierte Patienten

- Hepatitis A-, B- oder C- Infektion, Tuberkulose oder HIV-Infektion

- Patienten aus der Nachuntersuchung mit zwischenzeitlicher Parodontititsbehandlung

- suchtkranke Patienten

- nicht durchführbare orale Untersuchung 


\section{Gruppeneinteilung}

In die Untersuchungen sollten Patienten mit verschiedenen koronaren Herzerkrankungen einbezogen werden. Für den statistischen Vergleich wurde eine gesunde Kontrollgruppe herangezogen.

Die Einteilung erfolgte nach den Erkrankungen in 5 Gruppen:

- Gruppe 1 (Patienten mit Herzinfarkt)

- Gruppe 2 (Patienten mit Aortenklappenstenose)

- Gruppe 3 (Patienten mit koronarer Herzkrankheit (KHK))

- Gruppe 4 (Patienten mit KHK und Aortenklappenstenose)

- Gruppe 5 (gesunde Kontrollgruppe).

Um eine homogene Patientenverteilung innerhalb der Gruppen zu erreichen, erfolgte ein Matching der Teilnehmer. Dabei sollte jedem Patienten aus den Gruppen 1-4 ein herzgesunder „Zwilling“ mit ähnlichen Hauptrisikofaktoren zugeordnet werden. Die Hauptrisikofaktoren für koronare Herzerkrankungen und Parodontitis sind das Alter, das Geschlecht und der Raucherstatus. Anhand dieser Faktoren wurden die Matchingkriterien aufgestellt: Alter $( \pm 5$ Jahre), Rauchen (jedem Raucher und Nichtraucher wurde ein passender Kontrollgruppenpatient zugeordnet) und Geschlecht (gleiche Verteilung von männlichen und weiblichen Patienten in allen Gruppen).

\subsection{Kalibrierung}

Im Vorfeld erfolgte eine Kalibrierung des Untersuchers, indem die dentalen und parodontalen Befunde von 2 Untersuchern unabhängig bei 3 Patienten aufgenommen wurden. Hierbei mussten $80 \%$ der Messwerte übereinstimmen, wobei eine Abweichung um eine Einheit (=1mm) toleriert wurde. Waren die Messungen deutlich verschieden, wurden die Untersuchungen so lange wiederholt, bis die $80 \%$ erreicht wurden.

\subsection{Allgemeine Datenerfassung}

Vor Beginn der Untersuchung wurde mit den Patienten zusammen ein Anamnesebogen ausgefüllt. Ziel war es, Informationen über bisherige allgemeinmedizinische Erkrankungen und bestehende Herzerkrankungen zu erlangen. Erfragt wurden allgmeinmedizinische Parameter wie Rauchverhalten, Größe und Gewicht.

Rauchte ein Patienten mehr als 5 Zigaretten am Tag, wurde er als Raucher eingestuft. Rauchte ein Patient seit 10 Jahren nicht mehr, wurde dieser als Nichtraucher eingestuft. Um die Menge der gerauchten Zigaretten vergleichbar zu machen, wurde das Maß pack years ermittelt (Zahl 
der täglich gerauchten Zigarettenschachteln multipliziert mit der Zahl der Jahre, in denen diese Mengen konsumiert wurden $=\mathrm{x}$ pack years) (Bellamy et al. 2004).

Gewicht und Größe wurden im Bodymassindex berücksichtigt. Dieser Index stellt eine Maßzahl für die Bewertung des Körpergewichts eines Menschen in Relation zu seiner Körpergröße dar. Der BMI ist international anerkannt und kann unabhängig vom Geschlecht und Alter berechnet werden. Die Klassifikation des BMI zur Graduierung eines bestimmten Maßes an Morbiditätsoder Mortalitätsrisiko teilt sich in Normalgewicht 18,5-24,9, Übergewicht 25-29,9, Adipositas Grad I 30-34,9, Adipositas Grad II 35-39,9 und Adipositas Grad III $\geq 40$ (WHO 2006).

Blutparameter wie CRP Konzentration, Leukozyten- und Thrombozytenzahl wurden den Patientenakten entnommen. Die Mengenangaben in den Tabellen richten sich nach den Normwerten des Zentrallabors der Abteilung Klinische Chemie der Universitätsmedizin Göttingen (P-CRP in mg/l; Leukozyten in $\mu$ l; Thrombozyten in $\mu$ ). Blutwerte der Patienten der Kontrollgruppe wurden nicht berücksichtigt. Die Liste der eingenommen Medikamente (Antihypertensiva, Antikoagulantien, Antidiabetika, Herzmedikamente und Entzündungshemmer) und Daten der allgemeinmedizinischen Anamnese wie Bluthochdruck, Diabetes mellitus, Hyperlipoproteinämie oder rheumatische Arthritis wurden ebenfalls der Patientenakte entnommen.

Spezielle zahnmedizinische Angaben wie Temperaturempfindlichkeit der Zähne, Zahnfleischbluten, vorangegangene Parodontititsbehandlungen wurden erfasst.

\subsection{Kardiologische Datenerfassung}

Ausgewählt wurden Patienten, die kein Ausschlusskriterium erfüllten und einer der 4 Gruppen zugeordnet werden konnten. Die kardiale Diagnose wurde durch einen Allgemeinmediziner oder Kardiologen vor der oralen Untersuchung gestellt. Einbezogen wurden Patienten mit einem akuten Herzinfarkt mit ST-Streckenhebung (STEMI) und ohne ST-Streckenhebung (NSTEMI), Patienten mit Aortenklappenstenose und koronarer Herzkrankheit (Einteilung der Gruppen 1,2,3 und 4). Bei den Patienten mit KHK handelt es sich um arteriosklerotische Veränderungen im Herzkranzgefäßbereich mit Angina Pectoris Symptomatik oder diagnostizierter eingefäß- bis dreigefäß-KHK. Patienten mit akutem Koronarsyndrom (ACS) wurden ebenfalls erfasst.

Bei den Patienten mit Aortenklappenveränderungen handelt es sich ausschließlich um Patienten mit bevorstehender Aortenklappenoperation (Aortenklappenstenose oder kombinierte Vitien). Lediglich bei einem Patienten aus Gruppe 2 wurde eine Mitralklappenrekonstruktion vorgenommen. 


\subsection{Klinisch-zahnärztliche Untersuchung}

Die Patienten wurden einen Tag präoperativ auf der entsprechenden Station der Thorax-HerzGefäßchirurgie untersucht. In wenigen Ausnahmefällen erfolgte die Untersuchung erst postoperativ. In diesen Fällen bestimmte der gesundheitliche Zustand bzw. der Fortschritt der Genesung der Patienten den Zeitpunkt der Untersuchung.

Erhoben wurde der Zahnstatus (zahnärztlicher Befund: DMFT), Papillenblutungsindex (PBI), der Parodontalstatus und ein mikrobiologischer Befund.

\subsubsection{Zahnstatus, DMF-T}

Der DMF-T ist ein von der Weltgesundheitsorganisation (WHO) empfohlener Index, um den Zahnstatus zu erfassen und epidemiologisch zu vergleichen. Grundsätzlich beschreibt der DMF$T$ Index Zähne ( $T=$ teeth), die eine kariöse Läsion besitzen ( $D=$ decayed), fehlende Zähne ( $M=$ =missing) oder nach restaurativer Therapie gefülte Zähne (F=filled). Der Wert des DMF-T Index ergibt sich aus der Summe der einzelnen Werte. Der Maximum Wert kann demnach 28 betragen, wobei die Weisheitszähne nicht berücksichtigt werden. Für eine differenziertere Aussage ist eine Unterteilung in D-T, M-T und F-T sinnvoll und wurde bei der Ergebnisdarstellung durchgeführt.

\subsubsection{Papillen-Blutungs-Index (PBI)}

Der Papillenblutungsindex dient der Beurteilung des Entzündungsgrades der Gingiva (Saxer und Mühlemann 1975). Der Sulkus wird im Papillenbereich mit einer Parodontalsonde stumpf ausgestrichen, wobei die Sonde im Winkel von ca. $45^{\circ}$ zur Zahnachse geführt werden sollte. Nach 20 Sekunden wird die Blutung beurteilt. Der PBI-Index wird im ersten und dritten Quadranten oral und im zweiten und vierten Quadranten vestibulär erhoben.

Folgende Grade werden unterschieden (Saxer und Mühlemann 1975):

- Grad 0: keine Blutungen

- Grad 1: Auftreten eines Blutungspunktes

- Grad 2: Auftreten mehrerer Blutungspunkte oder einer Blutlinie

- Grad 3: Ausfüllen des interdentalen Dreiecks mit Blut

- Grad 4: profuse Blutung nach der Sondierung; Blut fließt über den Zahn

Der Index ist der Quotient aus der Summe der Blutungsgrade und der untersuchten Papillen. 


\subsubsection{Parodontalstatus}

Der Parodontalstatus umfasst die Erhebung der Sondierungstiefen (ST), des Attachmentlevels $(A L)$, der Furkationsbefunde (FB) und Lockerungsgrade ( $L G)$. Als Index der parodontalen Entzündung wurde zusätzlich der Bleeding on probing (BOP) erhoben.

Die Sondierungstiefen und der Attachmentlevelverlust der Patienten wurden mit Hilfe einer millimeterskalierten Parodontalsonde (PCP15, Hu-Friedy, Rottderdam, Niederlande) aufgenommen. Jeder Zahn wurde anhand einer modifizierten Vier-Punkt-Messung bewertet (Hellwig et al. 2007): mesio-vestibulär, disto-vestibulär, mesio-oral und disto-oral. Kommt es nach der Sondierung zum Auftreten von Blutungspunkten wird ein positiver BOP (bleeding on probing) notiert. Der BOP ist negativ, wenn die Blutung ausbleibt.

Nach der Sondierung erfolgte die Berechnung des Attachmentlevels aus der Summe der Rezession und der Sondierungstiefe. Klinsche Referenzpunkte sind dabei die Schmelz-ZementGrenze und der sondierbare Fundus der Zahnfleischtasche.

Die Furkationsbefunde wurden mit Hilfe einer Furkationssonde (Hu-Friedy, Rotterdam, Niederlande) gemessen.

Die Einteilung der Befunde erfolgte in 4 Grade (Hamp et al. 1975):

- Grad 0: Furkation nicht sondierbar

- Grad 1: Furkation bis $3 \mathrm{~mm}$ sondierbar

- Grad 2: Furkation über $3 \mathrm{~mm}$ sondierbar, aber nicht durchgängig

- Grad 3: Furkation durchgängig sondierbar

Die Zahnlockerungsgrade wurden mit Hilfe eines Sondengriffes und eines Fingers bestimmt. Dabei wird der jeweilige Zahn in vertikaler und horizontaler Richtung zwischen Finger und Sonde ausgelenkt. Die Auslenkung wird visuell beurteilt und in folgende Grade eingeteilt (Deutsche Gesellschaft für Parodontologie):

- Grad 0: physiologische, nicht erhöhte Zahnbeweglichkeit

- Grad 1: erhöhte Zahnbeweglichkeit, spürbar oder sichtbar bis $1 \mathrm{~mm}$ horizontal

- Grad 2: erhöhte Zahnbeweglichkeit, sichtbar über $1 \mathrm{~mm}$ horizontal

- Grad 3: erhöhte Zahnbeweglichkeit, beweglich auf Lippen- und Zungendruck und/oder in axialer Richtung 


\subsubsection{Parodontale Diagnose}

Die Einteilung der Parodontitis erfolgte in 3 Gruppen: Schwere Parodontitis, moderate Parodontitis und milde Parodonitits (Tab.2) (Page und Eke 2007).

Tab.2: Einteilung der Parodontitis nach Page und Eke (2007)

\begin{tabular}{|c|c|c|c|}
\hline \multirow[t]{2}{*}{ Grad der Parodontitis } & \multicolumn{3}{|l|}{ Definition } \\
\hline & Attachmentlevel (AL) & & Sondierungstiefe (ST) \\
\hline schwere Parodontitis & $\begin{array}{l}\geq 2 \text { approximale Messpunkte } \\
\text { mit } \geq 6 \mathrm{~mm}\end{array}$ & und & $\begin{array}{l}\geq 1 \text { approximaler Messpunkt } \\
\text { mit einer ST } \geq 5 \mathrm{~mm}\end{array}$ \\
\hline leichte Parodontitis & $\begin{array}{l}\geq 2 \text { approximale Messpunkte } \\
\text { mit } A L \geq 4 \mathrm{~mm}\end{array}$ & oder & $\begin{array}{l}\geq 2 \text { approximale Messpunkte } \\
\text { mit einer ST } \geq 5 \mathrm{~mm} \text { (nicht } \\
\text { am selben Zahn) }\end{array}$ \\
\hline keine oder milde Parodontitis & $\begin{array}{l}\text { Weder leichte noch schwere } \\
\text { Parodontitis }\end{array}$ & & \\
\hline
\end{tabular}

Dritte Molaren ausgenommen

\subsubsection{Mikrobiologische Analyse}

Nach der Entfernung von supragingivaler weicher Plaque wurden mit sterilen Papierspitzen der Größe ISO 50 (Hain Lifescience $\mathrm{GmbH}$, Nehren, Deutschland) mindestens 2 bis maximal 5 subgingivalen Plaque-Biofilmproben aus den jeweiligen tiefsten Zahnfleischtaschen entnommen. Die Proben wurden anschließend gepoolt. Mit einem kommerziell erhältlichen semiquantitativen Nachweis von 11 verschiedenen Bakterien wurde die bakterielle Besiedelung der Zahnfleischtaschen mit Hilfe der Polymerase-Kettenreaktion (PCR) bestimmt (micro-IDent®plusTest, Hain Lifesience GmbH, Nehren, Deutschland). Der Keimnachweis wurde in dem Labor der Poliklinik für Präventive Zahnmedizin, Parodontologie und Kariologie im Zentrum Zahn-, Mundund Kieferheilkunde der Universitätsmedizin Göttingen durchgeführt.

Die Bestimmung beschränkte sich hierbei auf folgende Bakterien (Nachweisgrenze: $<10^{3} \mathrm{~g} / \mathrm{l}$ ). Die Einteilung erfolgte in den von Socransky et al. (1989) beschrieben Komplexen.

- Violetter-Komplex: Aggregatibacter actinomycetemcomitans (Aac)

- Roter Komplex: Porphyromonas gingivalis (Pg), Tanerella forsythia (Tf), Tre-ponema denticola $(T d)$

- Oranger Komplex: Prevotella intermedia (Pi), Peptostreptococcus micros (Pm), Fusobacterium nucleatum (Fn)

- Gelber Komplex: Campylobacter rectus (Cr), Eubacterium nodatum (En)

- Grüner Komplex: Eikanella corrodens (EC),Capnocytophaga species (Cs) 


\subsection{Auswertung der Ergebniss und statistische Methode}

In der deskriptiven und analysierenden Statistik wurden verschiedene Verfahren der Häufigkeitsverteilungen, parametrischer Outcomes und nicht parametrischer Outcomes verwendet. Bei den Häufigkeitsverteilungen wurde vorwiegend die Anzahl (n) und Prozentangabe (\%) verwendet. Verteilungen einzelner Parameter wie Bluthochdruck, Diabetes mellitus, Hyperlipoproteinämie und rheumatische Arthritis innerhalb der Gruppen wurden mit dem Chi-Quadrat-Test verglichen. Die parametrischen Outcomes der getesteten Variablen (DMFT, BOP, ST, AL, Sondierungstiefen $\geq 4 \mathrm{~mm}$ (ST $\geq 4 \mathrm{~mm}$ ) und Sondierungstiefen $\geq 6 \mathrm{~mm}$ (ST $\geq 6 \mathrm{~mm})$ ) stellt vor allem der Mittwelwert mit Standardabweichung dar. Das parametrische Verfahren der OneWayAnova wird zur statistischen Auswertung bei ST, AL, PBI, BOP, ST $\geq 4$ $\mathrm{mm}, \mathrm{ST} \geq 6 \mathrm{~mm}$ und der zahnärztlichen Befunde (DMFT) verwendet.

Statistische Tests ohne Kovariablen werden im ersten Vergleich als „p“ bezeichnet. Das verwendete statistische Verfahren ist die OneWayAnova. Im zweiten Test, als „p*“ bezeichnet, werden weitere Kovariablen berücksichtigt. Als Einflussgrößen berücksichtigt sind hier das Alter, Geschlecht, BMI, Bluthochdruck, Rauchen und Hyperlipidämie. Als statistisches Verfahren wird die Rückwärtsselektion gewählt.

Nicht parametrische Variablen wie Furkationsbefunde, PBI und Lockerungsgrade werden als Median mit Minima und Maxima dargestellt. Gruppenvergleiche wurden bei nicht parametrischen Daten mit dem Kruskall-Wallis-Test durchgeführt (Parodontitisgrad). Im weiteren statistischen Vergleich stellt sich für die p-Werte vom BOP-Index und der Furkationsbefunde ein Gruppenvergleich an. Im Gruppenvergleich bezieht sich der p-Wert immer auf das Verhältnis zur Kontrollgruppe. Es findet ein direkter Gruppenvergleich im Sinne 1 gegen 5, 2 gegen 5, 3 gegen 5, 4 gegen 5 statt. Das Signifikanzniveau wurde aufgrund des multiplen Testens bezüglich mehrerer Gruppenvergleiche mit der Referenzgruppe 5, von 5\% auf 1,25\% adjustiert. Für pWerte größer gleich 0,0125 wäre adjustiert keine Signifikanz mehr erkennbar (BonferroniAdjustierung). Das statistische Verfahren ist die multivariable logistische Regression. Die multivariable Regression wird ebenfalls bei den Gruppenvergleichen für die Keime Aac und $P g$ verwendet. Das Signifikanzniveau wird hier auf 5/11 adjustiert. Für $p$-Werte größer gleich 0,0045 wäre adjustiert keine Signifikanz mehr erkennbar.

Das Signifikanzniveau liegt, sofern keine Adjustierung vorgenommen wurde, bei $5 \%$. Die statistische Auswertung erfolgte in Zusammenarbeit mit dem Institut für Medizinische Statistik der Universitätsmedizin Göttingen. Die Analyse wurde mit Hilfe des Programms Statistica, Version 9 der Firma StatSoft®, Hamburg durchgeführt. Einige Auswertungen im Bereich der Gruppenvergleiche unter Berücksichtigung diverser Kovariablen wurden mit Hilfe des statistischen Programms SAS 9.3, Cary, North Carolina, gemacht. Die Darstellung der deskriptiven Statistik erfolgte mit Microsoft Excel und Word 2007 (Office Windows). 


\section{$4 \quad$ Ergebnisse}

\subsection{Beschreibung des Patientenkollektivs}

Insgesamt konnten in die Studie 128 herzkranke Patienten aufgenommen werden. Neben diesen wurden weitere 30 Patienten für die gesunde Kontrollgruppe 5 nach den Matchingkriterien Alter, Geschlecht, und Rauchverhalten untersucht. Insgesamt konnten 158 Patienten in die Studie auf aufgenommen werden.

Das Durchschnittsalter über die Gruppen 1-4 beträgt 67,3 Jahre, davon waren 94 Männer und 34 Frauen. In Tabelle 3 wird ein kurzer Überblick über die Verteilung anamnestischer Daten abgebildet.

Tab.3: Patienten- und Probandencharakteristik nach Alter, Geschlecht und anamnestischen Daten

\begin{tabular}{|c|c|c|c|c|c|c|}
\hline Anamnestische Parameter & $\begin{array}{l}\text { Gruppe } 1-4 \\
(n=128)\end{array}$ & $\begin{array}{l}\text { Gruppe } 1 \\
(n=30)\end{array}$ & $\begin{array}{l}\text { Gruppe } 2 \\
(n=37)\end{array}$ & $\begin{array}{l}\text { Gruppe } 3 \\
(n=25)\end{array}$ & $\begin{array}{l}\text { Gruppe } 4 \\
(n=36)\end{array}$ & $\begin{array}{l}\text { Gruppe } 5 \\
(n=30)\end{array}$ \\
\hline Alter (Jahre, SD) & 67,3 & $68 \pm 9,6$ & $66,43 \pm 11,8$ & $64,2 \pm 9$ & $70,7 \pm 8,4$ & $65 \pm 12,3$ \\
\hline Geschlecht (männlich) (n) & 94 & 23 & 19 & 22 & 30 & 17 \\
\hline Bluthochdruck $(n=\%)$ & $98(76 \%)$ & $23(77 \%)$ & $22(59 \%)$ & $19(76 \%)$ & $27(75 \%)$ & $7(23 \%)$ \\
\hline Diabetes mellitus $(\mathrm{n}=\%)$ & $25(19 \%)$ & $5(16 \%)$ & $6(16 \%)$ & $6(24 \%)$ & $8(22 \%)$ & $4(13 \%)$ \\
\hline $\begin{array}{l}\text { Rheumatische Arthritis } \\
(n=\%)\end{array}$ & $3(2 \%)$ & $2(6 \%)$ & $0(0 \%)$ & $0(0 \%)$ & $1(2 \%)$ & $1(3 \%)$ \\
\hline Hyperlipidämie ( $n=\%)$ & $42(32 \%)$ & $13(43 \%)$ & $10(27 \%)$ & $11(44 \%)$ & $8(22 \%)$ & - \\
\hline $\mathrm{BMI}\left[\mathrm{kg} / \mathrm{m}^{2}\right] \pm \mathrm{SD}$ & $26,5 \pm 0,97$ & $30 \pm 0,87$ & $28,4 \pm 1$ & $28,1 \pm 0,88$ & $27,9 \pm 0,96$ & $27,9 \pm 0,96$ \\
\hline Raucher in $(n=\%)$ & $42(32 \%)$ & $12(40 \%)$ & $12(32 \%)$ & $9(36 \%)$ & $9(25 \%)$ & $14(47 \%)$ \\
\hline pack years, $[\mathrm{MW} \pm S D]$ & - & $16,9 \pm 26,8$ & $11,1 \pm 21,5$ & $11,3 \pm 17,9$ & $4,7 \pm 10,2$ & $12,7 \pm 16,5$ \\
\hline
\end{tabular}

(Gruppe 1: Herzinfarkt, Gruppe 2: Aortenstenose, Gruppe 3:Koronare Herzkrankheit (KHK), Gruppe 4: (KHK und Aortenstenose, Gruppe 5: gesunde Kontrollgruppe, SD: Standardabweichung; BMI: Body-mass-index; CRP: Creaktives Protein, MW: Mittelwert, SD: Standardabweichung, BMI: Body-Mass-Index

Unter den Probanden der Gruppe 1 befanden sich 12 Raucher (40\%), der Gruppe 212 Raucher (32\%), der Gruppe 39 Raucher (36\%), der Gruppe 49 Raucher (25\%) und der Gruppe 514 Raucher (47\%) (Tab.3). Die Zahl der Raucher ist in den Gruppen 2, 3 und 4 annähernd gleich verteilt. In der Gruppe 1 lag der Anteil der Raucher bei 40\%, in der Kontrollgruppe bei 47\%. Über alle Gruppen betrachtet rauchten 56 (35\%) der Patienten.

Die errechneten Werte des Body-Mass-Index bewegen sich über alle Gruppen betrachtet zwischen 26,5 und 30 (Präadipositas). Der niedrigste Mittelwert trat mit 26,5 in Gruppe 1 auf. Der höchste mit 30 in Gruppe 2 (Tab.3).

Auffälligkeiten der statistischen Auswertung zeigten sich vorallem beim Bluthochdruck und der Hyperlipidämie. Beide Erkrankungen sind im angewendeten statistischen Verfahren signifkant für die Gruppen. Der Einfluss dieser Erkrankungen auf die Entwicklung einer koronaren 
Herzerkrankung ist für alle Gruppen bedeutsam. Das Rauchen stellt sich als nicht signifikante Einflussgröße für die Gruppen dar $(p=0,45)(T a b .4)$.

Tab.4: Statistik der anamnestischen Parameter

\begin{tabular}{l|l}
\hline Anamnestische Parameter & $\mathbf{p}$ \\
\hline Alter & 0,097 \\
Rauchen & 0,45 \\
Bluthochdruck & 0,00002 \\
Diabetes mellitus & 0,82 \\
Rheumatische Arthritis & 0,44 \\
Hyperlipidämie & 0,00065 \\
BMl & 0,12 \\
\hline
\end{tabular}

Blutparameter wurden nur in den Gruppen 1-4 erhoben. Blutwerte der Kontrollgruppe sind nicht vorhanden. Die Werte des C-reaktiven Proteins waren in allen Gruppen erhöht. Deutlich erhöhte P-CRP Werte $>100 \mathrm{mg} / \mathrm{l}$ waren vor allem in Gruppe 4 und Gruppe 3 zu finden. Aber auch in Gruppe 1 lagen die Werte im Mittel knapp über 100mg/l. Die Zahl der Leukozyten war in Gruppe

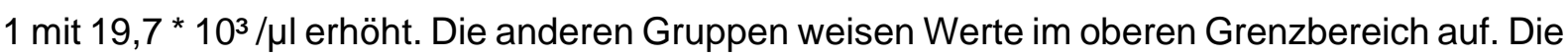
Thrombozyten bewegten sich überwiegend im Bereich der Normwerte (Tab.5).

Tabelle 5 gibt einen Überblick über die Blutparameter der Gruppen 1-4.

Tab.5: Durchschnittswerte der Blutparameter

\begin{tabular}{|c|c|c|c|c|c|c|}
\hline Blutparameter & $\begin{array}{l}\text { Gruppe } 1 \\
\mathrm{n}=30\end{array}$ & $\begin{array}{l}\text { Gruppe } 2 \\
\mathrm{n}=37\end{array}$ & $\begin{array}{l}\text { Gruppe } 3 \\
n=25\end{array}$ & $\begin{array}{l}\text { Gruppe } 4 \\
n=36\end{array}$ & $\begin{array}{l}\text { Gruppe5 } \\
\mathrm{n}=30\end{array}$ & Normbereich ${ }^{1)}$ \\
\hline P-CRP mg/l & $100,4 \pm 71$ & $75,3 \pm 59,2$ & $102,9 \pm 77,2$ & $108 \pm 73,6$ & - & $\leq 8,0$ \\
\hline 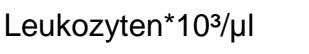 & $19,7 \pm 43,8$ & $9,7 \pm 4,0$ & $10,6 \pm 3,6$ & $10,3 \pm 3,8$ & - & $4,0-11,0$ \\
\hline 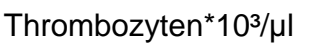 & $242,8 \pm 137,8$ & $195 \pm 0,80$ & $231,2 \pm 132,5$ & $179,2 \pm 5,89$ & - & $150-350$ \\
\hline
\end{tabular}

"Normwerte des Zentrallabors, Abteilung Klinische Chemie, Universitätsmedizin Göttingen

In der Liste der eingenommen Medikamente fällt auf, dass antihypertensiv wirkende Pharmazeutika in allen Gruppen verstärkt eingenommen wurden. In Gruppe 3 und Gruppe 4 sind 100\% der untersuchten Probanden antihypertensiv eingestellt. In der Gruppe 1 sind 96,7\% der Probanden und in Gruppe 2 83,78\% gegen Bluthochdruck eingestellt. Die Einnahme von Antidiabetika betraf 7 Patienten der Gruppe 1. Die Zahl der Patienten die Antikoagulantien einnahmen, war ebenfalls gleichmäßig verteilt (Tab.6). 
Die Aufstellung der eingenommenen Medikamente wird in Tabelle 6 verdeutlicht.

Tab. 6: Liste der eingenommen Medikamente

\begin{tabular}{llllll}
\hline Medikamente & $\begin{array}{l}\text { Gruppe 1 } \\
\mathrm{n}=\mathbf{3 0}\end{array}$ & $\begin{array}{l}\text { Gruppe 2 } \\
\mathrm{n}=\mathbf{3 7}\end{array}$ & $\begin{array}{l}\text { Gruppe 3 } \\
\mathrm{n}=\mathbf{2 5}\end{array}$ & $\begin{array}{l}\text { Gruppe 4 } \\
\mathrm{n}=36\end{array}$ & $\begin{array}{l}\text { Gruppe 5 } \\
\mathrm{n}=\mathbf{3 0}\end{array}$ \\
\hline Antihypertensiva & $\mathrm{n}=29[97 \%]$ & $\mathrm{n}=31[84 \%]$ & $\mathrm{n}=25[100 \%]$ & $\mathrm{n}=36[100 \%]$ & $\mathrm{n}=12[40 \%]$ \\
Antikoagulantien & $\mathrm{n}=20[22 \%]$ & $\mathrm{n}=23[25 \%]$ & $\mathrm{n}=18[20 \%]$ & $\mathrm{n}=27[29 \%]$ & $\mathrm{n}=4[4 \%]$ \\
Antidiabetika & $\mathrm{n}=7[23 \%]$ & $\mathrm{n}=5[14 \%]$ & $\mathrm{n}=2[8 \%]$ & $\mathrm{n}=6[16 \%]$ & $\mathrm{n}=2[6 \%]$ \\
Herzmedikamente & $\mathrm{n}=2[6 \%]$ & $\mathrm{n}=1[3 \%]$ & $\mathrm{n}=0[0 \%]$ & $\mathrm{n}=2[5 \%]$ & $\mathrm{n}=0[0 \%]$ \\
Entzündungshemmer & $\mathrm{n}=0[0 \%]$ & $\mathrm{n}=2[5 \%]$ & $\mathrm{n}=0[0 \%]$ & $\mathrm{n}=1[3 \%]$ & $\mathrm{n}=0[0 \%]$ \\
\hline
\end{tabular}

Der Schwerpunkt der kardialen Erkrankungen lag über die Gruppen 1-4 mit 90 Patienten bei den Herzklappenveränderungen und mit 103 Patienten bei denen mit akutem Koronarsyndrom oder instabiler Angina pectoris Symptomatik. Die Schwerpunkte bei den Herzklappenveränderungen bildeten hierbei die Aortenklappenstenose und die kombinierten Vitien. Von Eingefäß-KHK waren 53 Patienten, von Zweigefäß-KHK waren 10 und von Dreigefäß-KHK waren 16 Patienten betroffen. Bei 3 Patienten aus Gruppe 3 stellte die Indikation zur Operation nicht die koronare Herzkrankheit dar. Von allen untersuchten Patienten gaben 19 an, bereits schon einen Herzinfarkt gehabt zu haben. 12 dieser Patienten sind aus Gruppe 1.

Bei 18 Patienten aus Gruppe 1 wurde ein Infarkt ohne ST-Strecken Hebung diagnostiziert. Bei weiteren 12 Patienten lag ein Infarkt mit ST-Strecken Hebung vor.

26 Patienten mit Myokardinfarkt gaben an bereits im Vorfeld an Angina pectoris Symptomen gelitten zu haben. In Gruppe 2 konnte bei 30 Patienten eine Angina pectoris Symptomatik diagnostiziert werden. In der Gruppe 3 wurde bei 21 Patienten eine Eingef.-KHK und bei 1 Patienten eine Zweigef.-KHK diagnostiziert. Bei 3 Patienten aus Gruppe 3 konnte keine KHK befundet werden. Diese Patienten litten nach eigenen Anhgaben an Angina pectoris Symptomen und hatten arteriosklerotische Vorerkrankungen. In der Gruppe 4 werden sowohl Patienten mit KHK und Aortenstenose betrachtet. Hier wird bei 11 Patienten eine Eingef.- KHK und bei 14 eine Dreigef.-KHK diagnostiziert. 25 Patienten gaben an bereits vorher an Angina pectoris Symptomen gelitten zu haben. 3 Patienten aus Gruppe 4 hatten bereits vorher einen Myokardinfarkt. In der Gruppe 4 waren 35 Patienten von einer Aortenklappeninsuffizienz betroffen, bei 1 Patienten wurde die Mitralklappe rekonsturiert, so dass dies in der weiteren Betrachtung vernachlässigt wurde. 
Tabelle 7 gibt einen Überblick über die Verteilung der kardialen Diagnosen innerhalb der Gruppen 1-4.

Tab.7: Verteilung kardialer Erkrankungen

\begin{tabular}{|c|c|c|c|c|}
\hline Kardiale Diagnose & $\begin{array}{l}\text { Gruppe } 1 \\
\mathrm{n}=30\end{array}$ & $\begin{array}{l}\text { Gruppe } 2 \\
\mathrm{n}=37\end{array}$ & $\begin{array}{l}\text { Gruppe } 3 \\
\mathrm{n}=25\end{array}$ & $\begin{array}{l}\text { Gruppe } 4 \\
n=36\end{array}$ \\
\hline Herzklappenerkrankungen & 10 & 37 & 9 & 35 \\
\hline Eingef.- KHK & 21 & 0 & 21 & 11 \\
\hline Zweigef.- KHK & 4 & 0 & 1 & 5 \\
\hline Dreigef.- KHK & 1 & 1 & 0 & 14 \\
\hline STEMI & 12 & 0 & 0 & 0 \\
\hline NSTEMI & 18 & 0 & 0 & 0 \\
\hline $\begin{array}{l}\text { ACS, AP Symptomatik, } \\
\text { instabile AP, }\end{array}$ & 26 & 30 & 22 & 25 \\
\hline Mitralklappenrekonstruktion & 0 & 0 & 0 & 1 \\
\hline Zustand nach Infarkt & 12 & 0 & 4 & 3 \\
\hline
\end{tabular}

Gruppe1: Herzinfarkt, Gruppe2: Herzklappenerkrankung, Gruppe3: Koronare Herzkrankheit (KHK), Gruppe4: (KHK und Herzklappenerkrankung), Ein-Dreigef.-KHK: 1-3 Gefäß-Koronare Herzkrankheit; STEMI: ST-elevation myocardial infarction; NSTEMI: Non-ST-elevation myocardial infarction; ACS: Acute coronary syndrome; AP: Angina pectoris

\subsection{Ergebnisse der klinischen Untersuchung}

\subsubsection{Zahnstatus, DMF-T und Papillen-Blutungs-Index (PBI)}

Tabelle 8 gibt einen Überblick über die Verteilung des DMFT, D-T, F-T und M-T, innerhalb der Gruppen. Der Anteil der fehlenden Zähne (M-T) war in allen Gruppen am höchsten. Der mittlere DMF-T der Patienten in Gruppe 1 lag bei 21,8 $\pm 6,2$, in Gruppe 2 bei 22,1 $\pm 4,8$, in Gruppe 3 bei $20,2 \pm 5,9$, in Gruppe 4 bei 22,5 $\pm 5,65$ und in Gruppe 5 bei 21,93 $\pm 6,8$.

Tab.8: Mittelwert und Standardabweichung des DMF-T

\begin{tabular}{l|l|llll|l}
\hline & Gruppe 1-5 & Gruppe 1 & Gruppe 2 & Gruppe 3 & Gruppe 4 & Gruppe 5 \\
\hline DMFT [MW \pm & $21,79 \pm 5,8$ & $21,8 \pm 6,2$ & $22,1 \pm 4,8$ & $20,2 \pm 5,9$ & $22,5 \pm 5,65$ & $21,93 \pm 6,8$ \\
SD] & $1,5 \pm 3,4$ & $3 \pm 4,7$ & $1,3 \pm 3,5$ & $2 \pm 3,4$ & $1,3 \pm 3$ & $0,3 \pm 0,7$ \\
D-T [MW \pm & SD] & $14 \pm \mathbf{1 0 , 4}$ & $\mathbf{1 2 , 7} \pm \mathbf{8 , 4}$ & $\mathbf{1 0 , 1} \pm \mathbf{8}$ & $\mathbf{1 5} \pm \mathbf{9}$ & $\mathbf{1 2} \pm \mathbf{8 , 2}$ \\
M-T [MW \pm & $\mathbf{1 2 , 8 9} \pm 8,8$ & $\mathbf{1 4}$ & $\mathbf{8}$ & \\
SD] & $7,3 \pm 5,8$ & $4,9 \pm 5,8$ & $8,1 \pm 6,1$ & $8 \pm 5,2$ & $6,2 \pm 5,6$ & $9,6 \pm 5,6$ \\
F-T [MW \pm & SD]
\end{tabular}

MW: Mittelwert, SD: Standardabweichung; D-T: Decayed Teeth; M-T: Missing Teeth; F-T: Filled Teeth

Die Ergebnisse für den Schweregrad der gingivalen Entzüdnung $(\mathrm{PBI})$ stellen sich wie folgt dar (Tab.9). Der Mittelwert mit Standardabweichung ergab für die Patienten aus Gruppe 1 den Wert 1,3, aus Gruppe 2 1,1, aus Gruppe 3 1,3, aus Gruppe 4 1,4 und aus Gruppe 5 1,1. Der Median stellt in allen Gruppen den Wert 1 dar. Die Maxima Werte sind in Gruppe 13 , in Gruppe 2 3, in Gruppe 3 4, in Gruppe 44 und in Gruppe 5 3. Die Minima Werte sind in allen Gruppen 0 . Der Grad der gingivalen Entzündung stellt sich als ausgeprägte Gingivitis dar. 
Tabelle 9 gibt einen Überblick über die Verteilung des PBI.

Tab.9: PBI als Mittelwert mit Standardabweichung und Median mit Minimum und Maximum

\begin{tabular}{l|l|llll|l}
\hline PBI & Gruppe 1-5 & Gruppe 1 & Gruppe 2 & Gruppe 3 & Gruppe 4 & Gruppe 5 \\
\hline MW \pm SD & $1 \pm 0,95$ & $1,3 \pm 1$ & $1,1 \pm 1,1$ & $1,3 \pm 0,8$ & $1,4 \pm 1,1$ & $1,1 \pm 0,8$ \\
Median & 1 & 1 & 1 & 1 & 1 & 1 \\
Max & 4 & 3 & 3 & 4 & 4 & 3 \\
Min & 0 & 0 & 0 & 0 & 0 & 0 \\
\hline
\end{tabular}

MW \pm SD: Mittelwert \pm Standardabweichung; Max: Maximum; Min: Minimum

\subsubsection{Parodontalstatus}

Es werden die Sondierungswerte, der BOP, das klinische Attachmentlevel (AL), die Furkationsbefunde und Lockerungsgrade vorgestellt (Tab.10). Der höchste Mittelwert der Sondierungstiefen liegt mit 3,64 mm $\pm 0,93$ in der Gruppe 3. Der niedrigste Mittelwert liegt mit 3,2 $\mathrm{mm} \pm 0,69$ in der Gruppe 5. Der höchste durchschnittliche klinische Attachmentlevelverlust beträgt 6,2 $\mathrm{mm} \pm 2,2$ in Gruppe 3 und der niedrigste mit 5,6 $\mathrm{mm} \pm 1,23$ in Gruppe 5 .

Bei den Werten für $\mathrm{ST} \geq 4 \mathrm{~mm}$ und $\mathrm{ST} \geq 6 \mathrm{~mm}$ handelt es sich um die prozentuale Verteilung der Zahnflächen mit Sondiertiefen $\geq 4 \mathrm{~mm}$ und $\geq 6 \mathrm{~mm}$. In Gruppe 3 konnten die meisten Zahnflächen, $45 \%$, mit Sondiertiefen $\geq 4 \mathrm{~mm}$ gemessen werden. Die niedrigsten Werte für Sondiertiefen $\geq 4 \mathrm{~mm}$ waren mit 34\% in Gruppe 5 zu finden. Der BOP konnte in Gruppe $1 \mathrm{mit}$ einem Wert von $40 \% \pm 28 \%$, in Gruppe 2 von $43 \% \pm 35 \%$, in Gruppe 3 von $49 \% \pm 33 \%$, in Gruppe 4 von $31 \% \pm 33 \%$ und in Gruppe 5 von $66 \% \pm 31 \%$ ermittelt werden. Die BOP Werte der Kontrollgruppe sind im Vergleich zu den anderen erhöht (Tab.10).

Tab.10: Parodontale Parameter

\begin{tabular}{lllll|l}
\hline Variable & Gruppe 1 & Gruppe 2 & Gruppe 3 & Gruppe 4 & Gruppe 5 \\
\hline ST [MW \pm SD] & $3,3 \pm 0,78$ & $3,5 \pm 0,81$ & $3,64 \pm 0,93$ & $3,2 \pm 0,95$ & $3,2 \pm 0,69$ \\
AL [MW \pm SD] & $5,98 \pm 1,71$ & $5,94 \pm 1,78$ & $6,20 \pm 2,2$ & $5,70 \pm 1,97$ & $5,60 \pm 1,23$ \\
ST $\geq 4 \mathrm{~mm}[\mathrm{MW}$ in \%] & $36 \%$ & $45 \%$ & $45 \%$ & $35 \%$ & $34 \%$ \\
ST $\geq 6 \mathrm{~mm}[\mathrm{MW}$ in \%] & $5 \%$ & $7 \%$ & $10 \%$ & $7 \%$ & $3 \%$ \\
BOP [MW in \%] & $40 \%$ & $43 \%$ & $49 \%$ & $31 \%$ & $66 \%$ \\
\hline
\end{tabular}

ST: Mittlere Sondierungstiefe in $\mathrm{mm}$; AL: Clinical attachment level; ST $\geq 4 \mathrm{~mm}$ : gemittelter Wert der Zahl der sondierbaren Flächen $\geq 4 \mathrm{~mm}$, ST $\geq 6 \mathrm{~mm}$ : gemittelter Wert der Zahl der sondierbaren Flächen $\geq 6 \mathrm{~mm}$, MW: Mittelwert, SD: Standardabweichung in \%, BOP: Bleeding on probing 
In Tabelle 11 werden die Furkationsbefunde dargestellt, eine Graduierung (I-III) erfolgte nicht.

Tab.11: Furkationsbefunde

\begin{tabular}{lllll}
\hline Gruppe & $\mathbf{n}$ & Median & Min & Max \\
\hline Gruppe 1 & 19 & 1 & 0 & 3 \\
Gruppe 2 & 27 & 1,3 & 0 & 2,5 \\
Gruppe 3 & 22 & 1 & 0,37 & 2,5 \\
Gruppe 4 & 27 & 1,3 & 0 & 3 \\
Gruppe 5 & 26 & 0,7 & 0 & 2 \\
\hline \multicolumn{5}{c}{ n=Zahl der mehrwurzeligen Zähne }
\end{tabular}

Tabelle 12 zeigt die Lockerungsgrade, eine Angabe der Lockerungsgrade (1-3) erfolgte nicht.

Tab.12:Lockerungsgrade

\begin{tabular}{lllll}
\hline Gruppe & $\mathbf{n}$ & Median & Min & Max \\
\hline Gruppe 1 & 24 & 0,18 & 0 & 3 \\
Gruppe 2 & 36 & 0,26 & 0 & 3 \\
Gruppe 3 & 25 & 0,25 & 0 & 2,2 \\
Gruppe 4 & 32 & 0,27 & 0 & 1,7 \\
Gruppe 5 & 30 & 0,36 & 0 & 3 \\
\hline \multicolumn{5}{c}{ n=Anzahl der untersuchten Zähne }
\end{tabular}

\subsubsection{Parodontale Diagnose}

In Tabellle 13 wird die Verteilung der parodontalen Diagnosen innerhalb Gruppen dargestellt. Die Verteilung der parodontalen Diagnosen verschiebt sich deutlich in den Bereich der schweren Parodontitis. In Gruppe 1 sind 23, in Gruppe 2 30, in Gruppe 3 24, in Gruppe 425 und in Gruppe 5 sind 25 Patienten an einer schweren Parodontitis erkrankt. Von einer moderaten Parodontitis sind in Gruppe 10 Patienten, in Gruppe 24 Patienten, in Gruppe 31 Patient, in Gruppe 45 Patienten und in Gruppe 55 Patienten betroffen.

Tab.13: Verteilung der parodontalen Diagnose

\begin{tabular}{llllll}
\hline PA-Diagnose & Gruppe 1 & Gruppe 2 & Gruppe 3 & Gruppe 4 & Gruppe 5 \\
\hline Milde/keine Parodontitis & $7(23 \%)$ & $3(8 \%)$ & $0(0 \%)$ & $6(17 \%)$ & $0(0 \%)$ \\
Moderate Parodontitis & $0(0 \%)$ & $4(11 \%)$ & $1(4 \%)$ & $5(14 \%)$ & $5(17 \%)$ \\
Schwere Parodontitis & $23(77 \%)$ & $30(81 \%)$ & $24(96 \%)$ & $25(69 \%)$ & $25(83 \%)$ \\
\hline
\end{tabular}

\subsubsection{Statistik der parodontalen Parameter}

Im folgenden Kapitel erfolgt die statistische Auswertung der parodontalen Parameter (Tab. 14). Der Wert $p$ bezieht sich auf einen nicht adjustierten statistischen Test (OneWayAnova), bei dem getestet wird, ob die Varianz zwischen den Gruppen größer ist, als innerhalb einer Gruppe. Im zweiten Test $\mathrm{p}^{*}$ werden weitere Parameter, die Einfluss auf die Gruppen haben können 
berücksichtigt. Selektiert wurden hier das Alter, Geschlecht, BMI, Bluthochdruck, Rauchen und Hyperlipidämie. Als statistisches Verfahren wird die Rückwärtsselektion gewählt. Das Signifikanzniveau liegt bei $p=0,05$.

Die statistische Auswertung zeigt einen Einfluss der parodontalen Parameter Furkationsbefund und BOP auf die Gruppen. Die $p$ - und $p^{*}$ - Werte sind für die jeweiligen Furkationsbefunde mit $p=0,04$ und $p^{*}=0,03$ und dem BOP mit $p=p^{*}=0,0011$ signifikant (Tab.14).

Tab.14: Statistische Auswertung parodontaler Parameter und Entzündungsindizes

\begin{tabular}{lll}
\hline Variable & $\mathbf{p}$ & $\mathbf{p}^{*}$ \\
\hline BOP & $\mathbf{0 , 0 0 1 1}$ & $\mathbf{0 , 0 0 1 1}$ \\
PBI & 0,62 & 0,78 \\
DMFT & 0,65 & 0,81 \\
Lockerungsgrad & 0,54 & 0,41 \\
Furkationsbefund & $\mathbf{0 , 0 4}$ & $\mathbf{0 , 0 3}$ \\
ST & 0,24 & 0,24 \\
AL & 0,76 & 0,71 \\
ST $\geq 4 \mathrm{~mm}$ & 0,27 & 0,3 \\
ST $\geq 6 \mathrm{~mm}$ & 0,16 & 0,38
\end{tabular}

BOP: Bleeding on probing, PBi: Papillenblutungsindex, DMFT: Decayed-Missing-Filled Teeth, ST:Sondierungstiefen, AL: Attachmentlevel, ST $\geq 4 \mathrm{~mm}$ : gemittelter Wert der Zahl der sondierbaren Flächen $\geq 4 \mathrm{~mm}, S T \geq 6 \mathrm{~mm}$ : gemittelter Wert der Zahl der sondierbaren Flächen $\geq 6 \mathrm{~mm}$

Im weiteren statistischen Vergleich stellt sich für die $p$-Werte vom BOP und der Furkationsbefunde ein Gruppenvergleich an. Im Gruppenvergleich bezieht sich der p-Wert immer auf das Verhältnis zur Kontrollgruppe. Für p-Werte größer gleich 0,0125 ist adjustiert keine Signifikanz mehr vorhanden (Bonferroni-Adjustierung) (Tab.15).

Tab.15: Gruppenvergleich zur Referenzgruppe

\begin{tabular}{llllll}
\hline Variable & Gruppe 1 & Gruppe 2 & Gruppe 3 & Gruppe 4 & Gruppe 5 \\
\hline BOP & $\mathbf{p}=\mathbf{0 , 0 0 4}$ & $\mathbf{p}=\mathbf{0 , 0 0 7}$ & $\mathrm{p}=0,061$ & $<\mathbf{0 , 0 0 0 1}$ & Referenz \\
$\mathrm{F}$ & $\mathrm{p}=0,054$ & $\mathbf{p = 0 , 0 0 2}$ & $\mathbf{p}=\mathbf{0 , 0 0 4}$ & $\mathbf{p = 0 , 0 0 0 2}$ & Referenz
\end{tabular}

BOP: Bleeding on probing; F: Furkationsgrad

Im direkten Gruppenvergleich sind die $p$-Werte für die Variable BOP in Gruppe 1 ( $p=0,004)$, in Gruppe $2(p=0,007)$, Gruppe $4(p=0,0001)$ zur Referenzgruppe 5 signifikant (Tab.15). Der Grad der parodontalen Entzündung, über die Gruppen 1,2 und 4 im Vergleich zur Gruppe 5, ist für diese Herzerkrankung statistisch relevant. Patienten dieser Gruppen zeigen statistisch also geringere Entzündungsgrade als herzgesunde Patienten. Der statistische Vergleich der Furkationsbefunde zeigt für die Gruppe $2(p=0,002)$, Gruppe $3(p=0,004)$ und Gruppe $4(p=$ $0,0002)$ einen statistischen Einfluss. Der Grad der sondierbaren Furkation durch entzündlich bedingten Knochenabbau hat in diesen Gruppen einen höheren Einfluss. 
Im Testverfahren mit weiteren Risikofaktoren zeigte das Rauchen, der Bluthochdruck und Diabetes mellitus eine signifikante Bedeutung für die parodontalen Parameter (Tab.16). Sowohl das Rauchen, der Bluthochdruck und Diabetes mellitus haben Einfluss auf die jeweiligen Hauptparameter (ST, ST $\geq 4 \mathrm{~mm}$, ST $\geq 6 \mathrm{~mm}$ ). Die p-Werte liegen in dem Bereich 0,028-0,047 (Tab.16). Man schreibt innen aufgrund der Größe des p-Wertes eher explorativen Charakter zu, da der negative Einfluss dieser Covariablen zu erwarten war.

Tab.16: Einfluss der Covariablen

\begin{tabular}{lll}
\hline Variable & Covariable & p-Wert \\
\hline ST & Rauchen & 0,028 \\
ST $\geq 4 \mathrm{~mm}$ & Diabetes mellitus & 0,039 \\
& Rauchen & 0,038 \\
ST $\geq 6 \mathrm{~mm}$ & Bluthochdruck & 0,047 \\
& Rauchen & 0,038 \\
\hline
\end{tabular}

ST: Mittlere Sondierungstiefe; ST $\geq 4 \mathrm{~mm}$ : gemittelter Wert der Zahl der sondierbaren Flächen $\geq 4 \mathrm{~mm}$ in $\%$, $\mathrm{ST} \geq 6 \mathrm{~mm}$ : gemittelter Wert der Zahl der sondierbaren Flächen $\geq 6 \mathrm{~mm}$ in \%,

Die statistische Auswertung des Einflusses des Grades der Parodontitis auf eine spezifische Herzerkrankung wurde mittels Kruskal-Wallis-Test durchgeführt. Das Signifikanzniveau liegt bei $p=0,05$. Der Grad der Parodontitis ist nicht signigfikant $\left(p=0,13, p^{*}=0,38\right)$ und hat demnach keinen statistisch relevanten Einfluss auf die einzelnen Gruppen.

\subsubsection{Mikrobiologie}

Im Rahmen der klinischen Untersuchungen konnte nicht von allen Patienten eine mikrobiologische Auswertung vorgenommen werden. Aufgrund mangelnder Probenqualität wegen zu starker parodontaler Blutung war bei Einzelnen keine Entnahme von Plaqueproben möglich. Tabelle 17 gibt einen Überblick über die Zahl der zahnlosen Patienten und derer, bei denen keine Entnahme möglich war.

Tab.17: Zahnlose Patienten und fehlende mikrobiologische Auswertung

\begin{tabular}{cccccc}
\hline Parameter & $\begin{array}{c}\text { Gruppe 1 } \\
\mathbf{n = 3 0}\end{array}$ & $\begin{array}{c}\text { Gruppe 2 } \\
\mathbf{n = 3 7}\end{array}$ & $\begin{array}{c}\text { Gruppe 3 } \\
\mathbf{n = 2 5}\end{array}$ & $\begin{array}{c}\text { Gruppe 4 } \\
\mathbf{n = 3 6}\end{array}$ & $\begin{array}{c}\text { Gruppe 5 } \\
\mathbf{n = 3 0}\end{array}$ \\
\hline zahnlose & 6 & 1 & 0 & 4 & 0 \\
Patienten & 1 & 2 & 3 & 0 & 0 \\
Mibi fehlt & 7 & 3 & 3 & 4 & 0 \\
\hline Gesamt & & & & & \\
\hline
\end{tabular}

Mibi: Mikrobiologie

Insgesamt wurden in Gruppe 1 bei 7 Patienten, in Gruppe 2 bei 3, in Gruppe 3 bei 3 und in Gruppe 4 bei 4 Patienten keine mikrobiologische Auswertung durchgeführt. In der Kontrollgruppe wurde bei allen Patienten eine mikrobiologische Auswertung vorgenommen.

Sowohl bei allen Patienten aus den Gruppen 1-4 und den Patienten aus der Kontrollgruppe 5 konnten die 11 parodontalpathogenen Bakterien nachgewiesen werden (Nachweisgrenze $<10^{3}$ ). 
Auffällig war, dass der Brückenkeim Fusobacterium nucleatum ( $F n)$ in den Gruppen 1 und 5 bei allen Patienten nachgewiesen werden konnte. In den Gruppen 2-4 konnte Fn bei über $90 \%$ der Patienten dedektiert werden. Aac war in der Infarktgruppe mit 17\% und $P g$ mit $70 \%$ zu finden (Tab.18). Eine deutlichere Tendenz für Aac lag in Gruppe 5 vor. Hier konnte Aac mit 30\% nachgewiesen werden. Die Bakterien aus dem roten Komplex waren für $P g$ mit 63\%, für $T f$ mit 87\% und $T d$ mit $63 \%$ ebenfalls erhöht. Der Biofilm ist in allen Gruppen mit herzkranken Patienten eher gleichermaßen verteilt, so dass keinem Krankheitsbild ein bestimmter mikrobiologischer Befund zugeordnet werden kann. Im Gegenteil, die Belastung mit parodontalpathogenen Baktierien ist bei den Patienten der Kontrollgruppe gegenüber den kardial Erkrankten erhöht. Auch die Bakterien aus dem grünen und orangenen Komplex sind sehr stark vertreten (Tab.18).

Tab.18: Prävalenz der Bakterienkomplexe

\begin{tabular}{|c|c|c|c|c|c|c|}
\hline Komplexe & Bakterien & Gruppe 1 & Gruppe 2 & Gruppe 3 & Gruppe 4 & Gruppe 5 \\
\hline $\begin{array}{l}\text { Violetter } \\
\text { Komplex }\end{array}$ & Aac & $17 \%$ & $9 \%$ & $14 \%$ & $3 \%$ & $30 \%$ \\
\hline \multirow{3}{*}{$\begin{array}{l}\text { Roter } \\
\text { Komplex }\end{array}$} & $\mathrm{Pg}$ & $70 \%$ & $35 \%$ & $59 \%$ & $69 \%$ & $63 \%$ \\
\hline & $\mathrm{Tf}$ & $26 \%$ & $73 \%$ & $91 \%$ & $84 \%$ & $87 \%$ \\
\hline & $\mathrm{Td}$ & $52 \%$ & $65 \%$ & $59 \%$ & $66 \%$ & $63 \%$ \\
\hline \multirow{3}{*}{$\begin{array}{l}\text { Oranger } \\
\text { Komplex }\end{array}$} & $\mathrm{Pi}$ & $26 \%$ & $32 \%$ & $32 \%$ & $31 \%$ & $27 \%$ \\
\hline & $\mathrm{Pm}$ & $56 \%$ & $79 \%$ & $59 \%$ & $72 \%$ & $63 \%$ \\
\hline & $\mathrm{Fn}$ & $100 \%$ & $97 \%$ & $95 \%$ & $91 \%$ & $100 \%$ \\
\hline \multirow{2}{*}{$\begin{array}{l}\text { Gelber } \\
\text { Komplex }\end{array}$} & $\mathrm{Cr}$ & $61 \%$ & $74 \%$ & $72 \%$ & $72 \%$ & $73 \%$ \\
\hline & En & $17 \%$ & $38 \%$ & $27 \%$ & $25 \%$ & $20 \%$ \\
\hline \multirow{2}{*}{$\begin{array}{l}\text { Grüner } \\
\text { Komplex }\end{array}$} & Ec & $65 \%$ & $82 \%$ & $82 \%$ & $63 \%$ & $57 \%$ \\
\hline & Csp. & $70 \%$ & $68 \%$ & $45 \%$ & $75 \%$ & $70 \%$ \\
\hline
\end{tabular}

Aac: Aggregatibacter actinomycetemcomitans, Pg: Porphyromonas gingivalis, Tf: Tanerella forsythia, Td:Treponema denticola, Pi: Prevotella intermedia, Pm: Peptostreptococcus micros, Fn: Fusobacterium nucleatum, Cr: Campylobacter rectus, En: Eubacterium nodatum, Ec: Eikanella corrodens, Cs: Capnocytophaga species, Nachweisgrenze: $<10^{3}$ 


\subsubsection{Statistische Auswertung der Mikrobiologie}

Es ist für die Keime $A a c$ und $P g$ ein signifikanter Zusammenhang innerhalb der Gruppen zu erkennen. Das beudeutet das $A a c$ und $P g$ Einfluss auf die Gruppen haben und das Unterschiede in der Keimverteilung bestehen. Sowohl nicht adjustiert, als auch adjustiert, liegen die Werte für Aac bei $\mathrm{p}=0,034$ und $\mathrm{p}^{*}=0,076$ im signifikanten Bereich. Die $\mathrm{p}$-Werte für $\mathrm{Pg}$ liegen bei $p=0,035$ und $p^{*}=0,042$ und haben statistisch Einfluss auf alle Gruppen (Tab. 19). Für die anderen untersuchten Bakterien war dies nicht festzustellen.

Tab.19: Statistischer Vergleich ( $\mathrm{p}^{*}$-Werte adjustiert)

\begin{tabular}{lll}
\hline Bakterien & $\mathrm{p}$ & $\mathrm{p}^{*}$ \\
\hline Aac & $\mathbf{0 , 0 3 4}$ & $\mathbf{0 , 0 7 6}$ \\
$\mathrm{Pg}$ & $\mathbf{0 , 0 3 5}$ & $\mathbf{0 , 0 4 2}$ \\
$\mathrm{Tf}$ & 0,42 & 0,49 \\
$\mathrm{Td}$ & 0,86 & 0,88 \\
$\mathrm{Pi}$ & 0,97 & 0,96 \\
$\mathrm{Pm}$ & 0,32 & 0,15 \\
$\mathrm{Fn}$ & 0,26 & 0,89 \\
$\mathrm{Cr}$ & 0,85 & 0,93 \\
$\mathrm{En}$ & 0,39 & 0,28 \\
Ec & 0,11 & 0,13 \\
Csp. & 0,22 & 0,53 \\
\hline p: Auswertung ohne Covariablen; $\mathrm{p}^{*}$ : Auswertung mit Covariablen
\end{tabular}

Für die Keime $P g$ und $A a c$ wurde ein weiterer Gruppenvergleich angestellt. Gruppe 5 dient als Referenzgruppe.

Das Signifikanzniveau wurde aufgrund des multiplen Testens wegen mehrerer Gruppenvergleiche mit der Referenzgruppe 5, auf 5/11 adjustiert. Für p-Werte größer gleich 0,0045 wäre adjustiert keine Signifikanz mehr vorhanden ( $p \geq 0,0045)$.

Tab.20: Gruppenvergleich zur Referenzgruppe

\begin{tabular}{llllll}
\hline Variable & Gruppe 1 & Gruppe 2 & Gruppe 3 & Gruppe 4 & Gruppe 5 \\
\hline Aac & 0,29 & 0,04 & 0,18 & 0,02 & Referenz \\
$\mathrm{Pg}$ & 0,81 & 0,02 & 0,88 & 0,99 & Referenz \\
\hline
\end{tabular}

Aac: Aggregatibacter actinomycetemcomitans, Pg: Porphyromonas gingivalis

Es gibt keine signifikante Bedeutung für einen speziellen Keim im Vergleich zur Kontrollgruppe. Keiner der beiden Keime hat im statistischen Vergleich zur Kontrollgruppe einen besonderen Einfluss auf eine Gruppe der herzkranken Patienten. 


\subsubsection{Parodontale Parameter unter der Anwesenheit von Pg und Aac}

In der weiteren statistischen Auswertung werden die mittleren Sondierungstiefen in Bezug auf die Anwesenheit der Keime Pg und Aac dargestellt. Die Anwesenheit von Aac scheint bei denen in der Studie involvierten Patienten lediglich in Gruppe 1 und Gruppe 5 einen Einfluss auf die mittlere Sondierungstiefe zu haben. Der Mittelwert liegt in Gruppe $1 \mathrm{mit}$ 0,23 mm weniger bei den Patienten ohne Aac deutlich unterhalb des Mittelwertes derer mit Aac Befall. In Gruppe 5 liegt der Mittelwert mit 0,27 mm mehr bei den Patienten mit Aac Befall deutlich oberhalb des Wertes derer ohne Aac Befall. In den restlichen Gruppen zeichnet sich ein umgekehrtes Bild ab. Die mittleren Sondierungswerte in Abwesenheit der Baktierien des violetten Komplexes liegen deutlich oberhalb derer mit Keimbelastung. In Abbildung 4 wird im Boxplot Diagramm eine graphische Darstellung der Sondierungswerte unter Berücksichtigung der Anwesenheit von Aac gegeben.

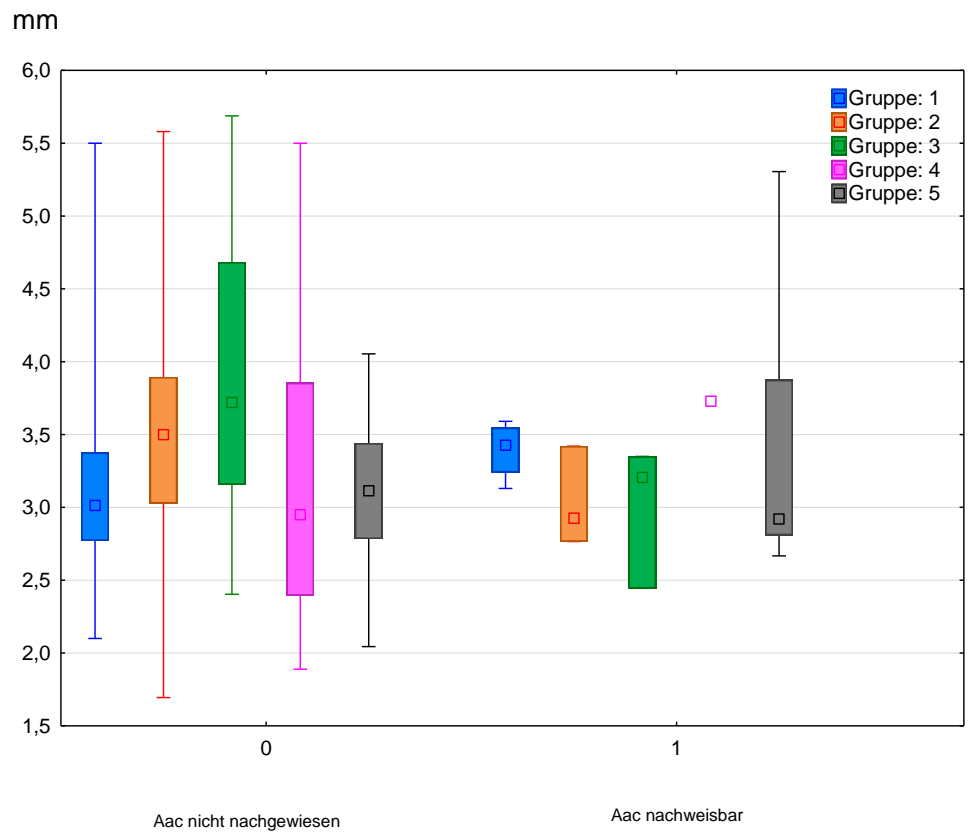

Abb.2: Darstellung der mittleren Sondierungstiefen in Abhängigkeit von Aac 
In Tabelle 21 werden die Mittelwerte, Median mit Minima und Maxima der mittleren Sondierungswerte angegeben.

Tab.21: Mittlere Sondierungstiefen in Abhängigkeit von Aac

\begin{tabular}{cccccc}
\hline Gruppe & $\begin{array}{c}\text { Anwesenheit } \\
\text { Aac }\end{array}$ & $\begin{array}{c}\text { Mittelwert } \pm \text { SD } \\
\text { ST }\end{array}$ & $\begin{array}{c}\text { Median } \\
\text { ST }\end{array}$ & $\begin{array}{c}\text { Min } \\
\text { ST }\end{array}$ & $\begin{array}{c}\text { Max } \\
\text { ST }\end{array}$ \\
\hline Gruppe 1 & nein & $3,16 \pm 0,73$ & 3,01 & 2,10 & 5,5 \\
Gruppe 2 & nein & $3,50 \pm 0,84$ & 3,50 & 1,69 & 5,58 \\
Gruppe 3 & nein & $3,85 \pm 0,94$ & 3,72 & 2,40 & 5,69 \\
Gruppe 4 & nein & $3,23 \pm 0,96$ & 2,95 & 1,89 & 5,5 \\
Gruppe 5 & nein & $3,09 \pm 0,58$ & 3,11 & 2,04 & 4,05 \\
\hline Gruppe 1 & ja & $3,39 \pm 0,20$ & 3,43 & 3,13 & 3,6 \\
Gruppe 2 & ja & $3,04 \pm 0,34$ & 2,92 & 2,76 & 3,42 \\
Gruppe 3 & ja & $3,00 \pm 0,48$ & 3,21 & 2,44 & 3,35 \\
Gruppe 4 & ja & $3,73 \pm 0,00$ & 3,73 & 3,73 & 3,73 \\
Gruppe 5 & ja & $3,36 \pm 0,89$ & 2,92 & 2,67 & 5,3 \\
\hline
\end{tabular}

SD: Standardabweichung

Tabelle 22 gibt eine Übersicht über die Verteilung der mittleren Sondierungstiefen als Mittelwert und Median mit Minima und Maxima unter Berücksichtigung der Anwesenheit von Pg. Die Anwesenheit von $P g$ scheint im Vergleich zu Aac einen deutlicheren, aber nicht signifkanten Einfluss auf die Sondierungswerte der Patienten zu haben. Die Mittelwerte der Sondierungstiefe steigen bei Anwesenheit des Keims in der Gruppe 1 um 0,59 mm, in Gruppe 2 um 0,23 mm, in Gruppe 3 um 0,72 mm, in Gruppe 4 um 0,41 mm und in Gruppe 5 um 0,41 mm mehr als in der gleichen Gruppe ohne Keimbelastung. Auffällig ist die deutliche Diskrepanz vor allem in der Infarktgruppe (Gruppe 1) (Tab.22). In Abbildung 5 erfolgt die Darstellung im Boxplotdiagramm. 
Tab.22: Mittlere Sondierungstiefen in Abhängigkeit von $P g$

\begin{tabular}{cccccc}
\hline Gruppe & $\begin{array}{c}\text { Anwesenheit } \\
\text { Pg }\end{array}$ & $\begin{array}{c}\text { Mittelwert } \pm \text { SD } \\
\text { ST }\end{array}$ & $\begin{array}{c}\text { Median } \\
\text { ST }\end{array}$ & $\begin{array}{c}\text { Min } \\
\text { ST }\end{array}$ & $\begin{array}{c}\text { Max } \\
\text { ST }\end{array}$ \\
\hline Gruppe 1 & nein & $2,79 \pm 0,44$ & 2,73 & 2,10 & 3,37 \\
Gruppe 2 & nein & $3,38 \pm 0,85$ & 3,40 & 1,69 & 5,58 \\
Gruppe 3 & nein & $3,31 \pm 0,85$ & 3,15 & 2,40 & 5,02 \\
Gruppe 4 & nein & $2,96 \pm 0,81$ & 2,83 & 1,89 & 4,62 \\
Gruppe 5 & nein & $2,92 \pm 0,66$ & 2,96 & 2,04 & 4,05 \\
\hline Gruppe 1 & ja & $3,38 \pm 0,68$ & 3,18 & 2,77 & 5,50 \\
Gruppe 2 & ja & $3,61 \pm 0,76$ & 3,70 & 2,44 & 5,10 \\
Gruppe 3 & ja & $4,03 \pm 0,90$ & 3,87 & 2,44 & 5,69 \\
Gruppe 4 & ja & $3,37 \pm 2,1$ & 3,37 & 2,10 & 5,50 \\
Gruppe 5 & ja & $3,33 \pm 0,67$ & 3,11 & 2,67 & 5,30 \\
\hline
\end{tabular}

SD: Standardabweichung, ST: Sondierungstiefe

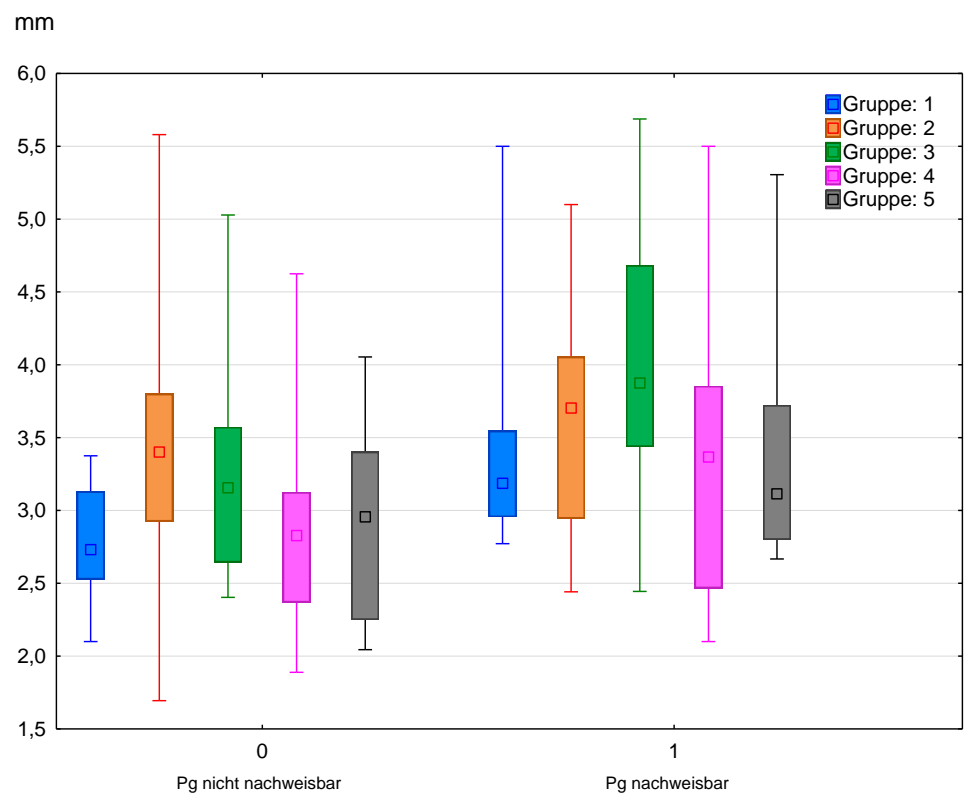

Abb.3: Darstellung der mittleren Sondierungstiefen in Abhängigkeit von $\mathrm{Pg}$

Es gibt einen validen Zusammenhang zwischen den Sondierungswerten und der Anwesenheit von $P g$ innerhalb der Gruppen. Die Zuordnung eines mikrobiologischen Befundes zu einer bestimmten Herzerkrankung ist nicht möglich.

Aufgrund einer eindeutigen Signifikanz der BOP Werte, sowohl adjustiert $\left(p^{*}=0,0011\right)$ als auch nicht adjustiert ( $p=0,0011)$ und eines Zusammenhanges der mittleren Sondierungswerte unter der Anwesenheit des Keimes Pg wird die Abhängigkeit der BOP Werte unter Berücksichtung der Nachweisbarkeit von $P g$ dargestellt (Tab.23). 
Auch in dieser Darstellung mittels Boxplot-Diagramm (Abb.4) wird deutlich, dass der Entzündungsgrad der Gingiva unter Anwesenheit des Bakteriums steigt. Auffällig sind mit einer Differenz der Mittelwerte besonders die Werte in Gruppe 3 mit 0,16; in Gruppe 4 mit 0,31 und in Gruppe 5 mit 0,16. Das bedeutet, dass die Zahl der Blutungspunkte nach Sondierung unter Anwesenheit von Pg im Mittel in Gruppe 3 um 16\%, in Gruppe 4 um 31\% und in Gruppe 5 um $16 \%$ steigt.

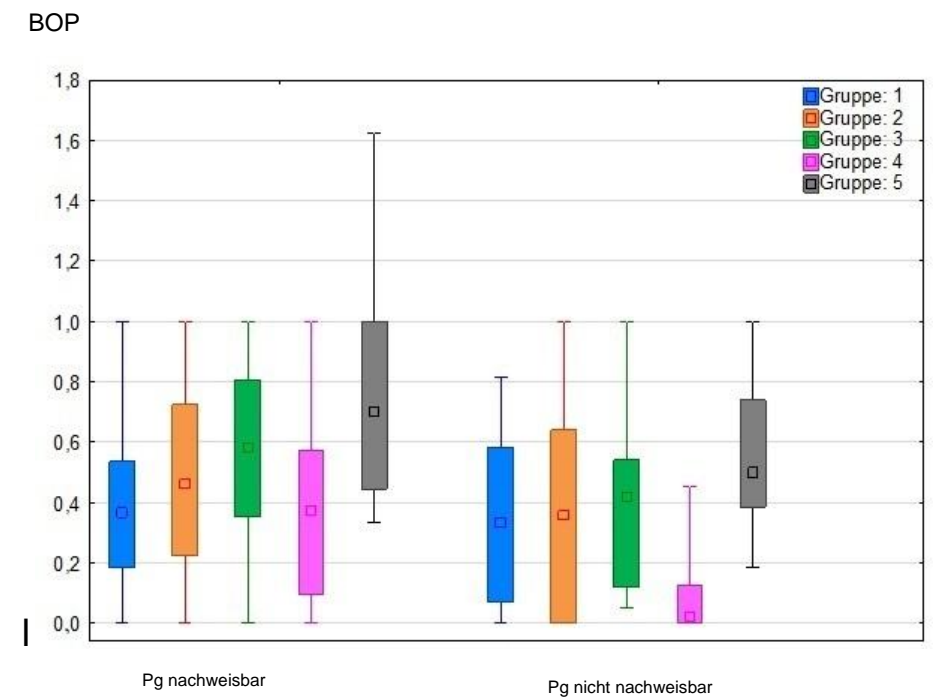

Abb.4: Graphische Darstellung des BOP in Abhängigkeit von $\mathrm{Pg}$

Tab.23: BOP in Abhängigkeit von $P g$

\begin{tabular}{|c|c|c|c|c|c|}
\hline Gruppe & Anwesenheit & BOP in \% & $\begin{array}{c}\text { Median } \\
\text { BOP }\end{array}$ & $\begin{array}{l}\text { Min } \\
\text { BOP }\end{array}$ & $\begin{array}{l}\text { Max } \\
\text { BOP }\end{array}$ \\
\hline Gruppe 1 & nein & $34 \%$ & 0,33 & 0 & 0,81 \\
\hline Gruppe 2 & nein & $38 \%$ & 0,36 & 0 & 1 \\
\hline Gruppe 3 & nein & $39 \%$ & 0,42 & 0,05 & 1 \\
\hline Gruppe 4 & nein & $9 \%$ & 0,2 & 0 & 0,45 \\
\hline Gruppe 5 & nein & $56 \%$ & 0,5 & 0,18 & 1 \\
\hline Gruppe 1 & ja & $38 \%$ & 0,36 & 0 & 1 \\
\hline Gruppe 2 & ja & $48 \%$ & 0,45 & 0 & 1 \\
\hline Gruppe 3 & ja & $55 \%$ & 0,58 & 0 & 1 \\
\hline Gruppe 4 & ja & $40 \%$ & 0,37 & 0 & 1 \\
\hline Gruppe 5 & ja & $72 \%$ & 0,7 & 0,33 & 1,63 \\
\hline
\end{tabular}

BOP: Bleeding on probing 


\subsection{Zusammenfassung der Ergebnisse}

Bei der vorliegenden Arbeit handelt es sich um eine klinische Querschnittsstudie. Schwerpunkt der Arbeit ist die Untersuchung von Patienten mit verschiedenen koronaren Herzerkrankungen und deren Vergleich mit einer kardial gesunden Kontrollgruppe. Erfasst wurden der Zahnstatus, der Parodontalzustand und der orale mikrobiologische Befund.

Die wichtigsten Ergebnisse lassen sich wie folgt zusammenfassen:

1. Das Patientenkollektiv besteht insgesamt aus 158 Patienten (128 Patienten mit koronaren Herzerkrankungen und 30 Patienten in der Kontrollgruppe).

Die Einteilung erfolgte in 5 Gruppen. Die Gruppen 1-4 stellen die Gruppen der herzkranken Patienten dar. Die Gruppe 5 ist die Kontrollgruppe.

- Gruppe 1: 30 Patienten mit Herzinfarkt

- Gruppe 2: 25 Patienten mit Aortenstenose

- Gruppe 3: 37 Patienten mit koronarer Herzkrankheit (KHK)

- Gruppe 4: 36 Patienten mit KHK und Arotenstenose

- Gruppe 5: 30 Patienten ohne Herzerkrankung

Das Durchschnittsalter über die Gruppen 1-4 liegt bei 67,3 Jahren. Die allgemeinanamnestischen Parameter wie Bluthochdruck $(p=0,0002)$ und Hyperlipidämie $(p=0,00065)$ sind in allen Gruppen vertreten und sind statistisch signifikant für die Gruppen.

Die CRP Werte (mg/l) sind in allen Gruppen erhöht (Gruppe 1 100,4 \pm 71 ; in Gruppe 2 75,3 \pm 59,2; in Gruppe $3102 \pm$ 77,2 und in Gruppe $4108 \pm 73,6$ ). Die Zahl der Leukozyten $\left(x * 10^{3} / \mu l\right)$ ist in der Infarktgruppe mit 19,7 $\pm 43,8$ deutlich erhöht.

2. Im Schnitt lag der BOP in Gruppe 5 bei $0,66 \pm 0,3$; in Gruppe 1 bei $0,4 \pm 0,28$; in Gruppe 2 bei $0,43 \pm 0,35$; in Gruppe 3 bei $0,49 \pm 0,33$ und in Gruppe 4 bei $0,31 \pm 0,33$. Der $p$ Wert liegt bei $p=0,0011$.

Im Gruppenvergleich ist der BOP für die Gruppe 1 mit $p=0,004$; für die Gruppe 2 mit $p=$ 0,007 und für die Gruppe 4 mit $p=0,001$ signifikant verschieden zur Kontrollgruppe.

Die Häufigkeit der Diagnose schwere Parodontitis ist über alle Gruppen ähnlich verteilt (Gruppe $1=77 \%$, Gruppe $2=81 \%$, Gruppe $3=96 \%$, Gruppe $4=69 \%$, Gruppe $5=$ 83\%). Der $p$-Wert für den Parodontitisgrad liegt bei $p=0,13$.

Für die Furkationsbefunde konnte eine Signifkanz von $p=0,04$ ermittelt werden.

3. Die Ergebnisse der mikrobiologischen Auswertung zeigen, dass Fn in den Gruppen 1 - 5 bei über 90\% der Proben über der Nachweisgrenze liegt. In Gruppe 1 (Infarktgruppe) ist 
$P g$ mit 70\% stark vertreten. Aackonnte vorallem in der Gruppe 5 mit 30\% nachgewiesen werden.

Die statistische Auswertung des Einflusses der Bakterien auf die Gruppen ergibt einen signifikanten Einfluss für $P g(p=0,034)$ und für Aac $(p=0,035)$. Auch unter Berücksichtigung diverser Confounder kann für $\operatorname{Pg}(p=0,076)$ und für $\operatorname{Aac}(p=0,042)$ eine signifikante Bedeutung für die Gruppen ermittelt werden.

Im Gruppenvergleich ( $\mathrm{Aac}$ und $\mathrm{Pg}$ ) in Bezug zur Kontrollgruppe 5 kann kein statisitsch relevanter Einfluss ermittelt werden. Ein Unterschied zwischen beiden Keimen war festzustellen.

4. Die Korrelation der Sondierungstiefe (ST) in Bezug auf die Anwesenheit von Pg ergibt deutlich höhere Sondierungstiefen bei Anwesenheit von Pg. Im Mittel liegt die Sondierungstiefe in Gruppe 1 um 0,59 mm, in Gruppe 2 um 0,23 mm, in Gruppe 3 um 0,72 mm, in Gruppe 4 um 0,41 mm und in Gruppe 5 um 0,41 mm über den Werten derer, wo $P g$ nicht über der Nachweisgrenze lag. Auffällig ist die Diskrepanz in der Infarktgruppe mit 0,59 mm.

5. Die Anwesenheit von Aac scheint lediglich in Gruppe 1, Gruppe 4 und Gruppe 5 einen Einfluss auf die mittlere Sondierungstiefe zu haben. Der Mittelwert der Sondierungstiefe in Gruppe 1 liegt mit 0,23 mm, in Gruppe 4 mit 0,5 mm und in Gruppe 5 mit 0,27 mm oberhalb der mittleren Sondierungstiefe bei den Patienten ohne Aac Nachweis. In den Gruppen 2 und 3 liegt der Mittelwert bei Anwesenheit von Aac unterhalb des Mittelwertes bei Fehlen des Bakteriums. In Gruppe 2 liegt die mittlere Sondierungstiefe 0,44 mm und in Gruppe 3 0,85 mm unterhalb der Mittelwerte ohne Aac. 


\section{Diskussion}

Basierend auf der Hypothese, dass parodontopathogene Mikroorganismen, die in einem subgingivalen Biofilm organisiert sind, einen Einfluss auf die Entstehung von koronaren Herzerkrankungen haben, wurden in dieser Arbeit 128 herzkranke Patienten auf parodontale Entzündung und auf orale mikrobiologische Befunde untersucht und mit einer kardial gesunden Kontrollgruppe verglichen.

In mehreren Übersichtsarbeiten (Sanz et al. 2010, Meurmann et al. 2004) und Metaanalysen (Blaizot et al. 2009, Humphrey et al. 2008, Janket et al. 2003, Mustapha et al. 2007), in denen die klinische Manifestation der Arteriosklerose und das Auftreten von parodontalen Infektionen (Auftreten von parodontalpathogenen Bakterien) untersucht wurde, konnte kein eindeutiges Ergebnis formuliert werden. Es wurde lediglich gezeigt, dass der Zusammenhang dezent vorhanden ist und immer wieder in einzelnen Studien belegt werden kann (DeStefano et al. 1993, Beck und Offenbacher 2002).

In einer von Kebschull et al. publizierten Übersichtsarbeit wird sehr deutlich gezeigt, welche kausalen Zusammenhänge zwischen parodontalen Infektionen und Arteriosklerose bestehen (Kebschull et al. 2010). Es konnte gezeigt werden, dass durch parodontale Infektion die lokalen und systemischen Entzündungsparameter steigen und damit die Entstehung einer Arteriosklerose begünstigt wird (Blaizot et al. 2009, Humphrey et al. 2008, Janket et al.2003). Interventionsstudien konnten den Einfluss einer parodontalen Therapie auf die verbesserte endotheliale vasodilatatorische Kapazität deutlich machen (Blum et al. 2007, Elter et al. 2006, Higashi et al. 2009, Mercanoglu et al. 2004, Tonetti et al. 2009). In einer Arbeit von Piconi et al. wurde gezeigt, dass die Verdickung der Intima Media der Arteria carotis durch die parodontale Therapie verringert wurde (Piconi et al. 2009). Der Einfluss der Behandlung einer Parodontitis führte zur Verbesserung von kardiovaskulären Risikofaktoren (endotheliale Dysfunktion, Entzündungsparameter, Dicke der Intima Media) (Tonetti et al. 2009, Mercanoglu et al. 2004, Offenbacher et al. 2009). Bisher ungeklärt ist der Einfluss einer Parodontitistherapie auf eine fortgeschrittene Arteriosklerose bzw. einen Herzinfarkt (Beck et al. 2007).

So wurde die Hypothese aufgestellt, dass parodontopathogene Bakterien und ihre Toxine eine entscheidende Rolle auf die Pathogenese der Arteriosklerose und damit auf die Entwicklung einer koronaren Herzkrankheit, eines Myokardinfarktes und der Aortenstenose haben könnten (Hoppe et. al 2005). In Folge der koronaren Herzkrankheit entsteht bei vielen Patienten ein Herzinfarkt. So konnte von Schaefer und Kollegen ein gemeinsamer genetischer Risikolokus für die Entwicklung einer aggressiven Parodontitis und eines Herzinfarktes identifiziert werden, dessen Bedeutung für dargestellten Assoziationen aber noch völlig unklar ist (Schaefer et al. 2009).

Die Entstehung einer Parodontitis wird von einer qualitativen Veränderung im subgingivalen Biofilm bis zu einer Dominanz gramnegativer Bakterien begleitet. Eine vermehrte Anzahl dieser 
parodontalpathogenen Bakterien konnte sowohl in den Zahnfleischtaschen als auch in arteriosklerotischen Plaques bei Patienten mit KHK nachgewiesen werden (Haraszty et al. 2000, Kozarov et al. 2005, Padilla et al. 2006). In anderen Untersuchungen konnten diese Ergebnisse nicht geteilt werden (Cairo et al. 2004, Romano et al. 2007). Cairo und Kollegen untersuchten die Prävalenz parodontopathogener Bakterien im Mund und in arteriosklerotischen Plaques der Arteria carotis bei 52 Patienten. Es konnte keine Korrelation zwischen diesen Bakterien und arteriosklerotischen Plaques gefunden werden (Cairo et al. 2004).

Die Grundlage der Auswahl des Patientenkollektivs stellten die vorab festgelegten Ausschlusskriterien dar. Entscheidendes Kriterium war die Diagnose eine der 3 untersuchten Krankheitsbilder (akuter Myokardinfarkt, koronare Herzkrankheit (KHK), Aortenklappenstenose). Die kardiale Diagnose wurde von einem in der Klinik für Thorax-Herz-Gefäß Chirurgie arbeitenden Kardiologen erstellt und so in die Patientenanamnese übernommen. Die Gruppenstärke sollte über alle Gruppen etwa gleich sein. Die Gruppe 4 ist mit 36 Patienten die größte.

Die Gruppengröße der Kontrollgruppe wurde auf 30 Patienten festgelegt. Eine günstigere statistische Auswertung wäre möglich, wenn die Zahl der Kontrollgruppenpatienten genau der Zahl der Teilnehmer aus allen anderen Gruppen entsprochen hätte. Da es sich bei dieser Arbeit aber nicht um eine Fallkontrollstudie handelt, war es nicht das primäre Ziel, so viele Patienten in die Kontrollgruppe aufzunehmen. Der Vorteil der limitierten Gruppengröße ist, dass so ein besserer Gruppenvergleich möglich war. Man kann jetzt unterschiedliche kardiale Symptome (Herzdiagnose) mit einer parodontalen Diagnose vergleichen.

Um eine homogene Patientenstruktur zu erreichen, erfolgte ein Matching der Patienten nach Alter ( \pm 5 Jahre), Geschlecht und dem Rauchverhalten. Die Patienten der Kontrollgruppe waren ihrem Wissen nach kardial gesund. Das Rauchen stellt einen Risikofaktor für beide Erkrankungen dar (Hyman 2006).

Das Durchschnittsalter der Patienten der Gruppen 1-4 lag bei 67,3 Jahren. Sowohl für die Parodontitis (Micheelis und Schiffner 2006) als auch für Herzerkrankungen (D'Agostino et al. 2000, McMurray und Stewart 2000) lässt sich in diesem Altersabschnitt ein erhöhtes Risiko erkennen. In dieser Alterskategorie ähneln sich die Risikofaktoren sowohl für Herzerkrankungen und Parodontitis (Armitage 2000). Die Hypertonie $(p=0,00002)$ und die Hyperlipidämie ( $p=0,00065)$ stellen sich in dieser Studie als signifikanter Risikofaktor dar und wurden als Confounder in den multivariablen Analysen berücksichtigt. Die Hypertoniker kamen in den Gruppen mit Herzerkrankungen häufiger vor als in der Kontrollgruppe. Die Raucher waren in allen Gruppen gleich verteilt. Statistisch konnte keine Signifikanz ermittelt werden $(p=0,45)$. Die Teilnehmer unserer Studie hatten erhöhte CRP-Werte. Da bei keinem Patienten gastrointestinale, urogenitale oder andere allgemeine Entzündungen diagnostiziert werden konnten, sind die erhöhten Werte der chronischen Inflammation des Herzens und ggf. des 
Parodonts geschuldet. In einigen Studien, die den Zusammenhang zwischen KHK und Parodontitis untersuchten, konnte eine höhere CRP Konzentration nachgewiesen werden (Amar et al. 2003, Tonetti et al. 2007). Andere Arbeiten konnten diese Korrelation wiederrum nicht bestätigen (Androsz-Kowalska et al. 2013, Yakob et al. 2012).

\subsection{Zahn- und Parodontalstatus}

Die Auswertung des DMF-T Index zeigt, dass die Patienten der Kontrollgruppe deutlich geringere Zahlen kariöser oder zerstörter Zähne aufweisen. Die Zahl der fehlenden Zähne ist in der Infarktgruppe (Gruppe1) mit 14 und in der KHK/Aortenstenose (Gruppe 4) mit 15 Zähnen im Vergleich zu den anderen Gruppen etwas erhöht. Der DMF-T oder die Zahl der fehlenden Zähne hat auf die Gruppen keinen signifikanten Einfluss (Tab.8, Tab.14). In einer Untersuchung von Ziebolz et al. konnte ebenfalls kein signifikanter Zusammenhang zwischen der Zahl der fehlenden Zähne bei Patienten mit akutem Koronarsyndrom im Vergleich zu einer gesunden Kontrollgruppe gefunden werden (Ziebolz et al. 2012). In einer von Aminzadeh 2013 pubilizierten Studie wurde bei 2 Patientengruppen mit akutem Myokardinfarkt mit und ohne ST Streckenhebung kein signifikanter Einfluss des DMF-T gefunden $(p=0,84)$ (Aminzadeh et al. 2013). In anderen Studien konnte dagegen ein Zusammenhang bei Patienten mit akutem Koronarsyndrom und der Zahl der fehlenden Zähne gefunden werden (López et al. 2002, Meurmann et al. 2003, Willerhausen et al. 2009). In Untersuchungen von Gürkan et al. konnte der Zusammenhang bei Patienten mit Gefäßektasien wiederrum nicht bestätigt werden (Gürkan et al. 2014). Ein Vergleich der ermittelten Werte des DMF-T der Patienten dieser Studie mit denen der Deutschen Mundgesundheitsstudie (DMS IV) ist aufgrund eines ähnlichen Durchschnittsalters (ca. 67 Jahre) sinnvoll. Der ermittelte durchschnittliche DMF-T der Probanden lag bei 21,79 und entspricht annähernd dem in der DMS IV für die Senioren ermittelten Wert von 22,1 (Micheelis und Schiffner 2006). Betrachtet man die einzelnen Komponenten D (decayed=zerstört), M (missing=fehlt) und $\mathrm{F}$ (filled=versorgt), wird deutlich, dass der hohe DMF-T der Studienteilnehmer der DMS IV auf der großen Anzahl fehlender (M$T=14,1)$ und konservierend bzw. prothetisch $(F-T=7,7)$ versorgter Zähne basiert (Micheelis und Schiffner 2006). Diese Tendenz spiegelt sich auch in dieser Arbeit wieder. Der durchschnittliche Anteil der fehlenden Zähne lag bei 12,89 und der der gefüllten Zähne bei 7,3.

Die klinische Bewertung der parodontalen Situation (gesund, milde Parodontitis, schwere Parodontitis) der Teilnehmer unserer Studie konnte keine direkten Zusammenhänge zu den bewerteten Herzerkrankungen erkennen lassen $(p=0,13)$. Die parodontale Diagnose ist für die Gruppen nicht signifikant. Diese Zusammenhänge konnten speziell für die KHK von einigen Autoren mehrfach belegt werden (DeStefano et al. 1993, Emingli et al. 2000, Renvert et al. 2004, Dogan et al. 2005). Auffällig ist, dass in Gruppe 4 die Zahl der schweren Parodontitiden mit 69\% im Vergleich zu den anderen geringer ausfällt. 
Vor allem in Gruppe 3 (KHK) sind 96\% der Patienten von einer schweren Parodontitis betroffen. In einer Arbeit von Aminzedah konnte für die Sondierungstiefen ebenfalls kein signifikanter Zusammenhang bei Patienten mit akutem Myokardinfarkt (mit und ohne ST Streckenhebung) gefunden werden (Aminzedah et al. 2013).

Untersuchungen von Gürkan et al. zeigen einen signifikanten Zusammenhang der Sondierungswerte, des Gingivaindex (Gl) und des BOP bei Patienten mit koronaren Gefäßektasien im Vergleich zu einer gesunden Kontrollgruppe (Gürkan et al. 2014).

Zahnfleischtaschen mit Sondierungstiefen $\geq 4 \mathrm{~mm}$ und $\geq 6 \mathrm{~mm}$ haben einen deutlich höheren Befall an parodontopathogenen Bakterien. Dadurch kommt es im Rahmen der Bakteriämie zu einer erhöhten systemischen Belastung. Aus diesem Grunde wurden diese in der statistischen Auswertung gesondert betrachtet. Andere Forschungsgruppen konnten bei der Untersuchung der prozentual erhöhten Sondierungstiefen (ST $\geq 4 \mathrm{~mm}$ und ST $\geq 6 \mathrm{~mm}$ ) einen signifikanten Einfluss nachweisen (Stein et al 2009). Eine höhere Prävalenz schwererer Formen der Parodontitis konnten im Zusammenhang mit akutem Myokardinfarkt nachgewiesen werden (Emingli et al. 2000, Nonnenmacher et al. 2007). In dieser Studie waren weder die prozentual erhöhten Sondiertiefen $\geq 4 \mathrm{~mm}$, noch $\geq 6 \mathrm{~mm}$ signifikant für die Gruppen. Multivariable Analysen mit diversen Confoundern zeigten einen signifikanten Einfluss von Diabetes mellitus, Rauchen und Bluthochdruck. Der erklärende Charakter ist aufgrund der Größe des p-Wertes eher explorativ zu suchen, da alle gleichermaßen einen Risikofaktor für Parodontitis und Herzerkrankungen darstellen. In einer Arbeit von Renvert und Kollegen wurde der röntgenologische und sondierbare Attachmentlevelverlust an 4 Messpunkten bei Patienten mit akutem Myokardinfarkt bestimmt. Bei den Patienten mit akutem Myokardinfarkt konnten deutlich höhere Werte für den BOP und für einen cut-off Wert von $50 \%$ der Meßstellen für Sondierungstiefen $\geq 4 \mathrm{~mm}$ gefunden werden. Bei den Patienten der Kontrollgruppe konnte dagegen ein höheres Verhältnis an Sondierungstiefen $\geq 6 \mathrm{~mm}$ bestimmt werden (Renvert et al. 2004). In der Studie von Renvert et al. 2004 wurden röntgenologische Parameter zur Bestimmung des Attachmentverlustes verwendet. In unserer Arbeit dagegen wurde Parodontitis anhand klinisch messbarer Parameter bestimmt. Vorteil der röntgenologischen Bestimmung ist die erhöhte Reproduzierbarkeit gemessener Werte.

Der Grad der gingivalen Entzündung wurde mit Hilfe des PBI bestimmt. Um falsch positive Messungen zu vermeiden, wurde der PBI vor der Messung der Sondierungstiefe bestimmt. Der Median des PBI ist in allen Gruppen 1. Diese Aussage steht im Widerspruch mit der hohen Prävalenz an schweren Parodontitiden. Aufgrund des hohen Durchschnittsalters der Patienten deutet alles auf ein chronisches Stadium der Erkrankungen hin. Ziebolz et al. konnten bei Patienten mit akutem Koronarsysndrom eine deutliche signifikante Bedeutung für den Gingivaindex (Gl) im Vergleich zu einer gesunden Kontrollgruppe finden (Ziebolz et al. 2012). 
Anders stellt sich die Situation der parodontalen Entzündung dar. Der BOP ist in der Kontrollgruppe deutlich höher als in den Gruppen 1-4. Im Schnitt lag der BOP in Gruppe 5 bei 0,66 \pm 0,3. Im Gruppenvergleich ist der BOP für die Gruppen 1, 2 und 4 signifikant. Vor allem in der Gruppe 4 (KHK und Herzklappenerkrankung) in der 2 Erkrankungen berücksichtigt wurden, ist der BOP mit 0,31 am niedrigsten. In einer Studie von Dogan et al. wurde ebenfalls in einer gesunden Kontrollgruppe ein deutliche höherer Wert für die parodontale Entzündung ermittelt, als in einer Infarktgruppe (Dogan et al. 2005). In einer Arbeit von Renvert et al. wurden dagegen deutliche höhere Werte für die parodontale Entzündung (BOP) bei Patienten mit akutem Myokardinfarkt ermittelt (Renvert et al. 2004).

\section{$5.2 \quad$ Mikrobiologie}

In der vorliegenden Arbeit wurden parodontopathogene Bakterien bei allen Patienten mit Herzerkrankungen und der Kontrollgruppe bestimmt. Bei einigen Patienten konnte aufgrund profuser Blutung keine mikrobiologische Bestimmung erfolgen. Die Patienten ohne mikrobiologischen Befund wurden nicht in die statistische Auswertung einbezogen. Untersucht wurden 11 parodontopathogene Bakterien, bei einer Nachweisgrenze $<10^{3}$.

Nähere Angaben über die Rolle von $A a c$ und $P g$ bei Patienten mit kardiovaskulären Herzerkrankungen wurden bereits in mehreren Studien ausführlich untersucht (Stein et al. 2009, Dogan et al. 2005, Sakurai et al. 2007, Nonnemacher et al. 2007). Beide Bakterien sind bekannt für eine erhöhte parodontale Pathogenität und die Fähigkeit, in das parodontale Gewebe einzudringen (Haffajee et al. 1998, Van Winkelhoff et al. 2000). Entzündlich bedingte epitheliale Desintegrität parodontaler Gefäße unterstützt die Verschleppung von parodontopathogenen Bakterien in den Blutkreislauf und damit die Verschleppung, bis hin zur Invasion peripherer Endothelzellen. Nicht alle Studien konnten in arteriosklerotischen Plaques parodontale Pathogene nachweisen (Romano et al. 2007, Aimetti et al. 2007). In einer Studie wurde die Prävalenz von parodontopathogenen Keimen in der Mundhöhle und in arteriosklerotischen Plaques untersucht. Der Zusammenhang konnte nicht ausreichend bestätigt werden (Cairo et al. 2004). Andere Studien konnten positive Zusammenhänge bestätigen (Haraszthy et al. 2000, Kozarov et al. 2005, Padilla et al. 2006).

Auffällig ist, dass bei allen Patienten aus den Gruppen 1-4 und den Patienten der Kontrollgruppe alle 11 parodontalpathogenen Bakterien über der Nachweisgrenze lagen (Nachweisgrenze $<10^{3}$ ). Insbesondere Fusobacterium nucleatum (Fn) konnte in den Gruppen 1 und 5 bei allen Patienten gefunden werden. In allen anderen Gruppen sind ebenfalls über $90 \%$ der Patienten betroffen. Aac aus dem violetten Komplex konnte vor allem in der Infarktgruppe mit $17 \%$ und in der Kontrollgruppe mit 30\% dedektiert werden. In einer Arbeit von Stein et al. (2009) wurde die Prävalenz von Aac, Pg, Tf, und Ti bei Patienten mit akutem Myokardinfarkt untersucht. Bei 44\% der Betroffenen Patienten mit Infarkt konnte ebenfalls Aac nachgewiesen werden. In der 
gleichen Gruppe konnte $P g$ mit 42\%, Tfmit 40\% und Pi mit 42\% gegenüber einer Kontrollgruppe gefunden werden. In unserer Studie konnte $\mathrm{Pg}$ bei 70\% der Patienten aus Gruppe 1, bei 35\% der Betroffenen aus Gruppe 2, bei 59\% aus Gruppe 3 und bei 69\% aus Gruppe 4 nachgewiesen werden. In der Kontrollgruppe waren 63\% betroffen. Die anderen Spezies des roten Komplexes ( $T f, T d$ lagen vor allem in Gruppen 2-5 über der Nachweisgrenze. In der Gruppe 1 waren hingegen nur $26 \%$ von Tf und $52 \%$ von Td betroffen. Ein wichtiger Aspekt ist der hohe Befall der Brückenkolonisierer $(F n)$ in allen Gruppen. Letztlich wurde bei allen Patienten ein mikrobiologischer Befund ermittelt, der die Basis für die Entwicklung eines hochkomplexen pathologischen Biofilms ermöglicht. Die statistische Auswertung ist für die Keime $\mathrm{Aac}$ und $\mathrm{Pg}$ signifikant. Die nicht adjustierte Auswertung ergab für Aac eine Signifikanz von $p=0,034$ und für $P g \mathrm{p}=0,035$. In der adjustierten statistischen Auswertung sind die Bakterien ebenfalls bedeutungsunterscheidend ( $A a c p=0,076$ und $P g p=0,042)$. Im Gruppenvergleich konnte keine signifikante Bedeutung für ein spezielles Bakterium ermittelt werden. Also im Vergleich zur Kontrollgruppe weicht der mikrobiologische Befund für eine valide Aussage nicht ausreichend $a b$, um den Einfluss eines mikrobiologischen Befundes einer spezifischen Herzerkrankung zuordnen zu können. Unseren Ergebnissen nach zu urteilen, scheint es keinen signifikanten Zusammenhang für die untersuchten drei Herzerkrankungen mit parodontalen Pathogenen zu geben.

Im Vergleich zu anderen Arbeiten wurde in unserer Arbeit der Zusammenhang einer Bakterienpopulation auf eine der 3 Herzerkrankungen untersucht. Akute und chronische Formen der KHK unterscheiden sich hinsichtlich ihres parodontalen mikrobiologischen Befundes (Renvert et al. 2004, Spahr et al. 2006). Bestätigt wurde dies in einer Studie von Sakurai et al. (2007). Im Gegensatz zu der Arbeit von Stein et al. (2009) konnte von Nonnemacher et al. (2007) eine signifikante Bedeutung für Pibei Patienten mit KHK gefunden werden. Renvert et al. konnten bei Patienten mit akutem Myokardinfarkt eine höhere Bakterienlast für $P g, T f$ und $T d$, nicht aber für Aac finden (Renvert et al. 2006). Die statistische Auswertung der Prävalenz von Keimkombinationen (z.B. $A a c+P g$ ) wurde in dieser Studie nicht ausgewertet. Stein und Kollegen konnten für das Vorhandensein beider Spezies ein signifikant höheres Risiko bei Patienten mit Myokardinfarkt nachweisen (Stein et al. 2009). Eine weniger ausgeprägte, aber stets signifikante Assoziation konnte für die Keimkombination $(\mathrm{Aac}+\mathrm{Pg}+\mathrm{Tf})$ gefunden werden. Die Prävalenz der Keime $(A a c+P g+T f)$ korrelierte stets mit den klinischen Befunden für Sondierungstiefen (ST) und klinischem Attachmentverlust (Stein et al. 2009). In unserer Studie hat im Vergleich zur Anwesenheit des Keims Aac, die Anwesenheit des Keims Pg einen deutlicheren Einfluss auf die Sondierungswerte der Studienteilnehmer. Die Mittelwerte der ST steigen bei Anwesenheit des Keims an. Auffällig ist vor allem der Anstieg des Mittelwertes um 0,59 mm in der Gruppe 1 (Infarktgruppe) und in der Gruppe 3 (Aortenklappenstenose) um $0,72 \mathrm{~mm}$, als in der jeweiligen gleichen Gruppe ohne Keimbelastung. Die Anwesenheit von Aac 
hat in dieser Studie lediglich einen Einfluss auf steigende Sondierungstiefen in den Gruppen 1 (Infarktgruppe), Gruppe 4 (KHK und Herzklappen) und 5 (Kontrollgruppe). Die Mittelwerte für Sondierungstiefen bei Patienten mit Keimbelastung liegen in Gruppe 10,23 mm, in Gruppe 4 0,5 $\mathrm{mm}$ und in Gruppe $50,27 \mathrm{~mm}$ über den Mittelwerten der gleichen Gruppe ohne Keimnachweis. Diese Ergebnisse entsprechen in etwa der Annahme, das akute und chronische Formen der KHK in ihrem mikrobiologischen Befund voneinander abweichen. Ähnliche Ergebnisse konnten von Sakurai et al. gefunden werden (2007). Bei 33\% der Patienten mit akutem Koronarsyndrom konnte Aac nachgewiesen werden. Bei denen mit chronischen Verlaufsformen der KHK wurde dagegen kein Aac gefunden. Die Werte der Serum Immunglobuline G, gegen Aac waren ebenfalls bei den Patienten mit akutem Koronarsyndrom deutlicher erhöht, als bei denen mit chronischem Verlauf. Keine signifikanten Unterschiede zwischen chronischen und akuten Zuständen wurden dagegen bei den Keimen $P g, T f$ und $T d$ gefunden (Sakurai et al. 2007). Diese drei Mikroorganismen sind im roten Komplex definiert, mit einer chronischen Parodontitis verbunden und treten meistens zusammen auf. In einer Studie wurde publiziert, dass $\mathrm{Pg}$ und $\mathrm{Td}$ die am häufigsten gefunden parodontalpathogenen Keime in abdominalen Aortenaneurysmen sind (Kurihara et al. 2004). Auch andere Erkrankungen wie Hirnabszesse, Endokarditis, Perikarditis, Frühgeburten, rheumatische Arthritis und Sepsis werden im Zusammenhang mit parodontalen Pathogenen gesehen (Deschner et al. 2011, DeStefano et al 1993, Wimmer und Pihlstrom 2008).

In einer anderen Arbeit wurde gezeigt, dass sich der qualitative Biofilm bei Patienten mit akutem Myokardinfarkt und chronischer Parodontitis kaum von den Patienten ohne chronische Parodontitis unterscheidet (Dogan et al. 2005). In der Gruppe mit chronischer Parodontitis und akutem Myokardinfarkt fand man ca. 8-mal so viele Bakterien wie in der der anderen Gruppe. Keime des roten Komplexes wie z.B. $P g$ und $T f$ fand man vorwiegend in der Gruppe ohne chronische Parodontitis. Keime wie Aac und M.micros konnten in der Infarktgruppe mit chronischer Parodontitis in 9-mal höherer Konzentration gefunden werden. Die Zahl der bakteriellen Pathogene in der Gruppe mit chronischer Parodontitis zeigt, dass die Patienten mit aktuem Myokardinfarkt einer deutlich höhreren Bakterienlast ausgesetzt waren als jene ohne chronische Parodontitis (Dogan et al. 2005). 


\section{$6 \quad$ Zusammenfassung}

Das Ziel dieser klinischen Querschnittsstudie war es, die bisher vorliegenden epidemiologischen Daten zu unterstützen, Determinanten und Mechanismen des Krankheitsbildes Parodontitis mit den Auswirkungen auf die vaskuläre Gesundheit zu stärken und parodontale Infektionen als Risikofaktor für Arteriosklerose und kardiovaskuläre Herzerkrankungen darzustellen.

Die am Anfang gestellten Hypothesen sollten klären, ob es einen direkten Zusammenhang verschiedener kardiovaskulärer Herzerkrankungen mit parodontaler Gesundheit (gesund, Gingivitis, Parodontitis) gibt. Herzkranke Patienten sollten auf eine erhöhte parodontale Bakterienlast untersucht werden und die Qualität des bakteriellen Biofilms sollte bestimmt werden. Die untersuchten Herzerkrankungen sind der akute Myokardinfarkt, die koronare Herzkrankheit (KHK) und die Aortenklappenstenose. Patienten der Kontrollgruppe wurden nach Alter, Geschlecht und Raucherstatus gematcht und waren anamnestisch kardial gesund.

Herzkranke Probanden wurden in der Klinik der Thorax-Herz-Gefäß Chirurgie der Universität Göttingen aufgesucht und auf Ausschlusskriterien überprüft. Anschließend erfolgte die Aufklärung und Einverständniserklärung. Gegebenenfalls wurden die Patienten antibiotisch abgeschirmt. Die klinischen Befunde der Parodontitis wie Sondierungstiefen, BOP, Attachmentlevel, Lockerungsgrade und Furkationsbefunde sollten neben Entzündungsparametern bestimmt werden. Den Index der gingivalen Entzündung stellt der PBI dar, den der parodontalen Entzündung der BOP. Um die mikrobiologische Besiedlung der Zahnfleischtaschen zu analysieren, wurden in die jeweils tiefsten Taschen Papierspitzen eingebracht und Plaqueproben entnommen. Es wurden 11 parodontalpathogene Bakterien untersucht. Die Proben wurden gepoolt und anschließend im Labor mittels PCR-Methode auf bakterielle DNA untersucht. Insgesamt wurde 158 Patienten untersucht, 30 davon gehören zur Kontrollgruppe. Das Durchschnittsalter der Gruppen 1-4 liegt bei 67,3 Jahren.

Der BOP ist in der Gruppe 5 mit 0,66 am höchsten und ist im Gruppenvergleich zur Kontrollgruppe für die Gruppe 1 mit $p=0,004$, für die Gruppe 2 mit $p=0,007$ und für die Gruppe 4 mit $p=0,001$ signifikant geringer.

Der Parodontitisgrad stellt sich als nicht signifikante Einflussgröße für die Gruppen dar $(p=0,13)$. Die Diagnose schwere Parodontitis ist über alle Gruppen ähnlich verteilt (Gruppe $1=$ 77\%, Gruppe $2=81 \%$, Gruppe $3=96 \%$, Gruppe $4=69 \%$, Gruppe $5=83 \%$ ). Die Furkationsbefunde stellen sich im statistischen Test $(p=0,04)$ als signifikant dar.

Die Ergebnisse der mikrobiologischen Auswertung zeigen, dass Fn in den Gruppen 1-5 bei über $90 \%$ der Proben über der Nachweisgrenze liegt.

In Gruppe 1 (Infarktgruppe) ist $P g$ mit 70\% stark vertreten. Aac konnte vor allem in der Kontrollgruppe mit 30\% und in Gruppe 1 mit 17\% nachgewiesen werden. Tfkonnte in Gruppe 3 (Aortenstenose) bei 91\% gefunden werden. Generell waren die Erreger aber in allen Gruppen vertreten. Die statistische Auswertung des Einflusses der Bakterien auf die Gruppen ergibt einen 
signifikanten Einfluss für $P g(p=0,034)$ und für $\operatorname{Aac}(p=0,035)$. Auch unter Berücksichtigung diverser Confounder kann für $P g(p=0,076)$ und für $\operatorname{Aac}(p=0,042)$ eine signifikante Bedeutung ermittelt werden. Im Gruppenvergleich (für $A a c$ und $P g$ ) zur Kontrollgruppe 5, konnte keine statistisch charakteristisch relevante Bedeutung nachgewiesen werden. In Anwesenheit des Keims $P g$ konnten vor allem in Gruppe 1 deutlich höhere Werte für die mittlere Sondierungstiefe ermittelt werden (Diskrepanz 0,59 mm). Die Anwesenheit von Aac scheint lediglich in Gruppe 1, 4 und Gruppe 5 einen Einfluss auf die mittlere Sondierungstiefe zu haben. Hier steigen die mittleren Sondierungstiefen bei Anwesenheit des Keims an. Eine Signifikanz konnte im Gruppenvergleich nicht gefunden werden.

\section{Schlussfolgerung}

Die Assoziation parodontaler Gesundheit mit verschiedenen kardiovaskulären Herzerkrankungen kann auf Grundlage dieser Ergebnisse nicht hinreichend beantwortet werden. Weder die nachgewiesenen Bakterien noch eine klinische parodontale Situation lassen Rückschlüsse auf den Zusammenhang mit einer der untersuchten Herzerkrankungen zu. Es gibt eine Vielzahl von Studien mit Patienten unterschiedlicher Populationen und unterschiedlicher Kriterien, nach denen die Parodontitis und verschiedene kardiovaskuläre Herzerkrankungen bewertet werden. Einer der Gründe für die aktuell uneinheitliche Meinung über die Zusammenhänge von Zahnfleischerkrankungen und Herzerkrankungen sind die unterschiedlichen Parameter der Diagnostik des Grades der Parodontitis und die uneinheitliche Bewertung von Risikofaktoren für Parodontitis und Herzerkrankungen. Ein anderer, nicht berücksichtigter Aspekt ist der bidirektionale Einfluss von parodontalen Pathogenen auf Parodontitis und kardiovaskuläre Ereignisse. Diese Tatsache wurde erst seit Kurzem in Studien involviert (Dogan et al. 2005, Spahr et al. 2006).

Deshalb war es in dieser Studie wichtig, sich an klar definierte, evidenzbasierte Definitionen für Parodontitis und Richtlinien bei der Verwendung der mikrobiologischen Parameter zu halten. Bei der Diagnosefindung wurden die Empfehlungen der Arbeitsgruppe Page und Eke (2007) verwendet. Um eine Vergleichbarkeit von Studien zu erreichen, wurde der Grad der Parodontitis an der Sondierungstiefe (ST) und dem klinischen Attachmentlevel (AL) gemessen. In vielen Interventionsstudien konnte gezeigt werden, dass die Therapie einer parodontalen Entzündung zu einer deutlichen Verbesserung von klinischen Markern der Arteriosklerose führt. Der Zusammenhang zwischen Mundgesundheit und Herzerkrankungen ist trotz der hohen Anzahl von Untersuchungen nicht ausreichend belegt. Gegenwärtig fehlt es an Arbeiten, die belegen, dass die präventive Behandlung von parodontalen Infektionen kardiovaskulären Ereignissen vorbeugen kann. In Zukunft werden weitere große und exakt kontrollierte Patienten- und Interventionsstudien nötig sein. 


\section{$7 \quad$ Anhang}

\subsection{Formulare}

\subsubsection{Anamnesebogen}

\section{$\begin{aligned} \text { UNIVERSITÄTSMEDIZIN } & =1 \mathbf{M G} \\ \text { GÖTTINGEN } & =0 \mathbf{G}\end{aligned}$}

Prof. Dr. med. dent. Rainer F. Mausberg; Georg-August-Universität Göttingen, ZentrumZahn-, Mund- und Kieferheilkunde; Abteilung Zahnerhaltung und Präventive Zahnheilkunde und Parodontologie; Robert-Koch-Str. 40,37075 Göttingen; Tel.: 0551/3922877

\section{Anamnesebogen}

${ }_{\text {K}}$ Klinisch - Experimentelle Studie zur möglichen Assoziation parodontaler Gesundheit und verschiedenen Herzerkrankungen ${ }^{a}$

Pat.-Nr.

Datum:

Bitte beantworten Sie die folgenden Fragen bzw. kreuzen Sie Zutreffendes an.

Mehrfachantworten sind möglich. Die gewissenhafte Beantwortung ist eine Voraussetzung für den Erfolg der Studie!

1. Sind Sie in ständiger ärztlicher Behandlung?

ja nein

Wenn ja, weswegen?

[ ] [ ]

2. Leiden Sie an einer Herzerkrankung? (z.B.A. pectoris, Endokarditis, Klappenfehler)

3. Müssen Sie ständiq Medikamente einnehmen?

[ ] [ ]

Wenn ja, welche?

[ ] [ ]

(z.B. zur Blutzuckersenkung; gegen Herzbeschwerden, Bluthochdruck; zur Hemmung der Blutgerinnung; Rheumamittel; Beruhigungs-/Schlaftabletten)

4. Sind Sie zur Zeit in ärztlicher Behandlung?

Wenn ja, weswegen?

5. Wann sind Sie zum letzten Mal zahnärztlich untersucht worden?

6. Sind Ihre Zähne temperaturempfindlich?

7. Blutet Ihr Zahnfleisch?

8. Bemerken Sie Stellungsveränderungen Ihrer Zähne?

[ ] [ ]

9. Haben Sie manchmal einen schlechten Geschmack im Mund?

[ ] [ ]

[ ] [ ]

10. Haben Sie wegen Zahnlockerung bzw. Zahnfleischbeschwerden schon einmal einen Zahnarzt aufgesucht?

Wenn ja, was wurde gemacht?

11. Wurde bei Ihnen bereits eine "Parodontose"-Behandlung durchgeführt? Wenn ja, wann?

12. Rauchen Sie oder haben Sie geraucht?

[ ] [ ]

13. Wie viel Zigaretten/Schachteln pro Tag etwa? Zigaretten/Tag, Schachteln/Tag 


\subsubsection{Patientenaufklärung}

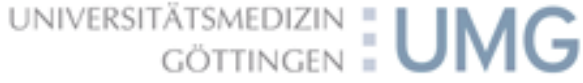

Prof. Dr. med. dent. Rainer F. Maus berg; Georg-August-Universität Göttingen, Zentrum Zahn-, Mund- und Kieferheilkunde; Abteilung Zahnerhaltung und Präventive Zahnheilkunde und Parodontologie; Robert-KochStr. 40, 37075 Göttingen; Tel.: 0551/3922877

Patientenaufklärung - Studienteilnahme

„Klinisch - Experimentelle Studie zur möglichen Assoziation parodontaler Gesundheit und verschiedenen Herzerkrankungen ${ }^{\alpha}$

Sehr geehrte Patientin, sehr geehrter Patient!

Hiermit möchten wir Sie um die freiwillige Teilnahme an der klinisch-wiss enschaftlichen Untersuchung:

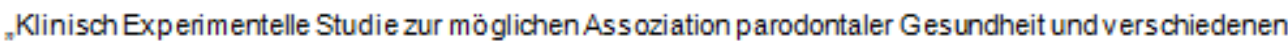
Herzerkrankungen ${ }^{a}$ bitten.

Parodontitis ist eine Erkrankung von Zahnfleisch und zahnumgebenden Knochen, dem so genannten Zahnhaltapparat; bis hin zum Verlust des Zahnhalteapparates und Abbau des Kieferknochens. Als Folge können betroffene Zähne verloren gehen. Einer Entzündung des gesamten Zahnhalteapparates geht in der Regel eine Entzündung des Zahnfleisches voraus. Dabei spielenviele verschiedene Faktoren eine Rolle: Zahnbelag (Plaque), bestimmte Bakterien, körpereigene Abwehr, aber auch Allgemeinerkrankungen ( $z$.B. Diabetes mellitus, HIV) oder Medikamente. Die Entzündung des Zahnhalteapparates lässt sich durch MessungvonZahnfleischtaschen und Beurteilung des Knochenabbaus aufzeigen und diagnostizieren. Zahnfleischblutenund zunehmende Lockerung des Zahnes können weitere Hinweise geben. Mikrobielle Untersuchungen zur Bestimmung der Menge und Art der in der Zahnfleischtasche befindlichen Bakterien können zudem eine genauere Auskunft über Krankheitszustand und den Verlauf geben.

Grund dieser Studie ist die Uberprüfung der klinischen Zusammenhänge von Allgemeinerkrankungen (in diesem Fall Erkrankungen am Herzen) mit Erkrankungen des Zahnhalteapparates. Ziel dieser rein wissenschaftlichen Untersuchung soll es sein, Patienten mit Herzerkrankung hinsichtlich möglicher Zusammenhänge zwischen der Parodontitis und der Herzerkrankungenzu untersuchen. Mit Ihrer Teilnahme können Sie uns helfen herauszufinden ob und welche Zusammenhänge zwischen den beiden Erkrankungen existieren.

Um Aussagenüber denjeweiligen Mundhygiene-und Entzündungszustand zutreffen zu können, werden spezielle Befunde erhoben, die sich aus einem Kariesbefund, der Messung der Entzündung des Zahnfleischs und aus Feststellung des Zustands des Zahnhalteapparates (Messungred Zahnfleischtaschen; Feststellung der Zahnlockerung) zusammensetzen. Zusätzlich erfolgt eine Bestimmung von vorhandenen Bakterien aus der Zahnfleischtasche. Die Untersuchungen an IhrenZähnen und an Ihrem Zahnfleisch führt ein Doktorand (9. Semester Zahnheilkunde) der Abt. Zahnerhaltung, Präventiven Zahnheilkunde uns Parodontologie der Universitätsmedizin Göttingen nach Absprache mit Ihrem betreuendem Arzt durch. 


\section{$\begin{aligned} \text { UNIVERSITÄTSMEDIZIN } & =1 \mathbf{M G} \\ \text { GÖTTINGEN } & =\mathbf{O}\end{aligned}$}

Des Weiteren bitten wir Sie, einige Fragen zu Ihrem Allgemeinzustand, Lebensgewohnheiten und Mund gesundheitszustand zu beantworten. Bitte versuchen Sie diese Fragenwahrheitsgemäß und möglichst genau zu beantworten.

Der Zeitraum der Untersuchung ist ein Tag vor oder nach der Operation geplant und wird bei Ihnen auf Station am Bett durchgeführt. Der Mehraufwand an Zeit pro Untersuchung beträgt ca. 15 Minuten; es entstehen für Sie keine zusätzlichen Kosten. Risiken und Nebenwirkungen bei der Durchführung der Untersuchung sind nicht zu erwarten bzw. bestehen nicht, da keine Medikamente, operative Eingriffe oder Anfertigungenvon Röntgenaufnahmen notwendig sind; jedoch kann die Untersuchung ggf. unangenehm sein und möglicherweise geringfügige Blutungen provozieren. Um mögliche Unannehmlichleiten zu verhindern, wird lhr Zustand nach der Operation berücksichtigt und g gf. auf die Untersuchung verzichtet. Auf Im Rahmen der postoperativen Maßnahmen sind Sie antibiotisch abgedeckt und es erübrigt sich eine eventuell notwendige Endokarditisprophylaxe.

Ihre personenbezogenen Daten unterliegen dem Datenschutz und werdcn vom Leiter der Prüfung nicht weitergegeben. Sie werden pseudnymisiert behandelt (anstelle von Namen und Geburtsdatum wird ein Zahlencode verwendet), nur zu Untersuchungszwecken verwendet und nach der Auswertung vernichtet.

Wir bitten um die freiwillige Teilnahme an der Studie. Sie können jederzeit die Teilnahme widerrufen, ohne Angabe von Gründen und ohne Nachteile erwartenzu müssen. Nach Ihrem Widerruf erfol gt unverzüglich die Vernichtung Ihrer personenbezogenen Daten.

Für Rückfragen stehen Ihnen der Studienleiter und der durchführende Zahnarzt unter o.g. Telefonnummem zur Verfügung.

Vielen Dank für Ihre Teilnahme.

Ort und Datum

Unterschrift 
7.1.3 Einverständniserklärung

\section{$\begin{aligned} \text { UNIVERSITÄTSMEDIZIN } & =1 / \mathrm{V} \\ \text { GÖTTINGEN } & =0\end{aligned}$}

Prof. Dr. med. dent. Rainer F. Maus berg; Georg-August-Universität Göttingen, Zentrum Zahn-, Mund- und Kieferheilkunde; Abteilung Zahnerhaltung; Präventive Zahnheilkunde und Parodontologie; Ro bert-Koch-Str. 40, 37075 Göttingen; Tel.: 0551/3922877

\section{Einverständniserklärung - Teilnahme an Untersuchung}

„Klinisch - Experimentelle Studie zur möglichen Assoziation parodontaler Gesundheit und verschiedenen Herzerkrankungen ${ }^{\alpha}$

Ich, wurde von meinem Arzt vollständig über Wesen, Bedeutung und Tragweite der klinischen Untersuchung mit dem Titel:

„Klinisch - Experimentelle Studie zur möglichen Assoziation parodontaler Gesundheit und verschiedenen Herzerkrankungen ${ }^{\alpha}$

aufgeklärt.

Mir ist bekannt, dass bei dieser Untersuchung personenbezogene Daten, insbesondere der medizinische Befund über mich erhoben, gespeichert und ausgewertet werden sollen. Die Verwendung der Angaben über meine Gesundheit erfolgt nach gesetzlichen Bestimmungen und setzt vor der Teilnahme an der Klinischen Prüfung die folgende freiwillig abgegebene Einwilligungserklärung voraus.

Ich hatte ausreichend Zeit, mich zur Teilnahe an dieser Untersuchung zu entscheiden und weiß, dass die Teilnahme freiwillig ist.

Mir ist bekannt, dass ich jederzeit und ohne Angaben von Gründen diese Zustimmung widerrufen kann, ohne dass sich dieser Entschluss nachteiliq auf meine weitere Behandlung auswirkt. Ich habe eine Kopie der Patienteninformation und dieser Einwilligungserklärung erhalten.

Ich erkläre hiermit meine freiwillige Teilnahme an dieser Studie.

Ort und Datum

Unterschrift des Teilnehmers

Ort und Datum

Unterschrift des Prüfarzt 


\subsubsection{Ethikvotum}

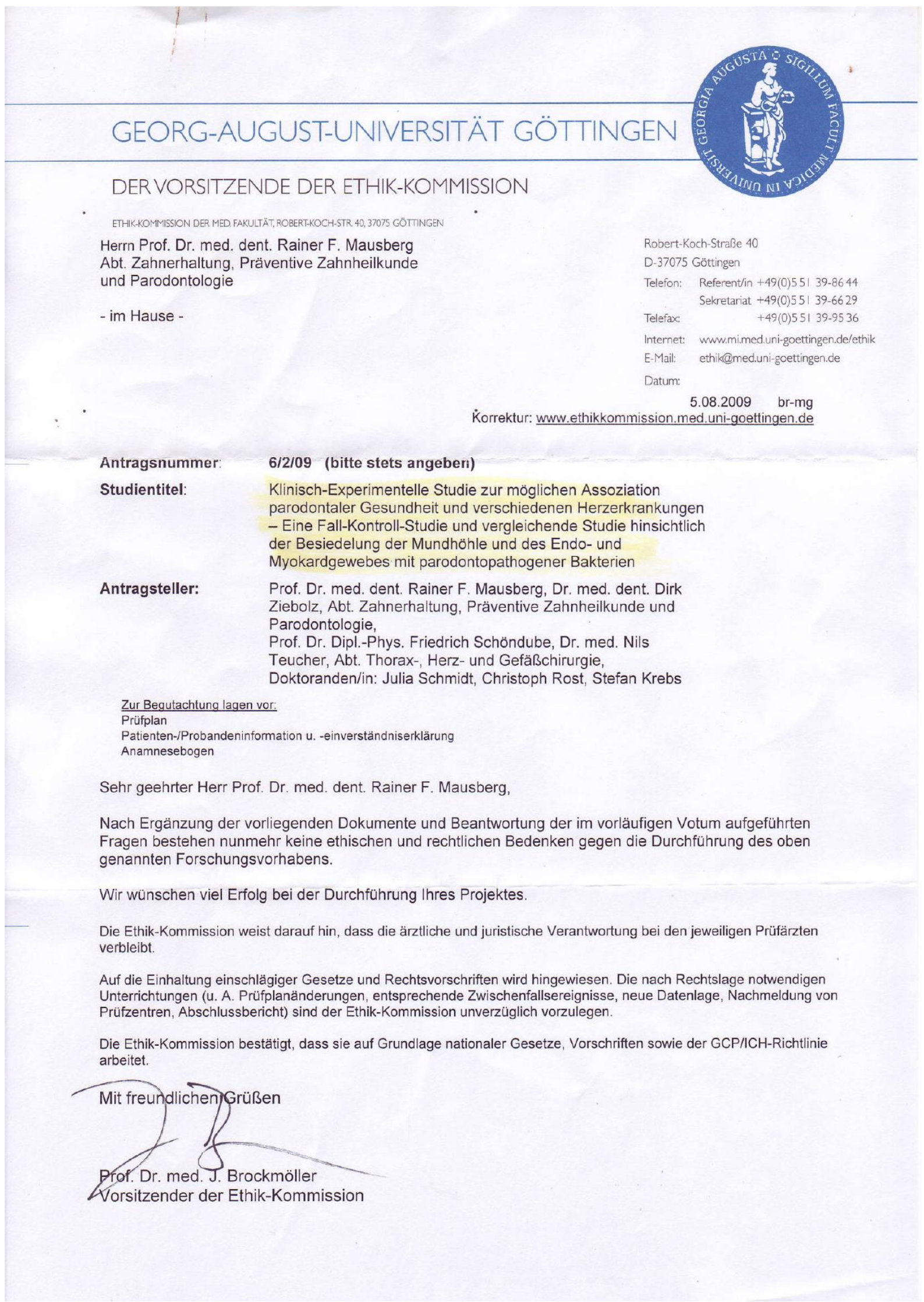




\subsection{Abbildungsverzeichnis}

Abb.1: Kausalzusammenhänge von Parodontitis und koronarer Herzkrankheit nach Dietrich et al. (2008)

Abb.2: Darstellung der mittleren Sondierungstiefen in Abhängigkeit von Aac

Abb.3: Darstellung der mittleren Sondierungstiefen in Abhängigkeit von $\mathrm{Pg}$

Abb.4: Graphische Darstellung des BOP in Abhängigkeit von $\mathrm{Pg}$

\subsection{Tabellenverzeichnis}

Tab. 1: Histomorphologische Klassifikation arteriosklerotischer Läsionen nach AHA (Stary et al. 1994, Stary et al. 1995)

Tab.2: Einteilung der Parodontitis nach Page und Eke (2007)

Tab. 3: Patienten- und Probandencharakteristik nach Alter,

Geschlecht und anamnestischen Daten

Tab.4: Statistik der anamnestischen Parameter

Tab.5: Durchschnittswerte der Blutparameter

Tab.6: Liste der eingenommenen Medikamente

Tab.7: Verteilung kardialer Erkrankungen

Tab.8: Mittelwert und Standardabweichung des DMF-T

Tab.9: PBI als Mittelwert mit Standardabweichung und Median mit Minimum und Maximum

Tab.10: Parodontale Parameter

Tab.11: Furkationsbefunde

Tab.12: Lockerungsgrade

Tab.13: Verteilung der parodontalen Diagnose

Tab.14: Statistische Auswertung parodontaler Parameter und Entzündungsindizes

Tab.15: Gruppenvergleich zur Referenzgruppe

Tab.16: Einfluss der Covariablen

Tab.17: Zahnlose Patienten und fehlende mikrobiologische Auswertung

Tab.18: Prävalenz der Bakterienkomplexe

Tab.19: Statistischer Vergleich ( $\mathrm{p}^{*}$-Werte adjustiert)

Tab.20: Gruppenvergleich zur Referenzgruppe

Tab.21: Mittlere Sondierungstiefen in Abhängigkeit von Aac

Tab.22: Mittlere Sondierungstiefen in Abhängigkeit von $P g$

Tab.23: BOP in Abhängigkeit von $P g$ 


\section{$8 \quad$ Literaturverzeichnis}

Abbas AK, Lichtman AH, Pober JS (1996) Immunologie. Verlag Hans Huber, Bern

Acar J, Elias J, Luxereau P (1995): Aortic stenosis and mixed aortic valve disease. In: Acar J, Bodnar E (Hrsg.): Textbook of acquired heart valve disease. Volume I. 454-486 ICR Publishers, London 1995

Aimetti M, Romano F, Nessi F (2007): Microbiologic analysis of periodontal pockets and carotid atheromatous plaques in advanced chronic periodontitis patients.

J Periodontol $\underline{78}(9), 1718-1723$

Albandar JM (2002): Global risk factors and risk indicators for periodontal diseases. Periodontol $2000 \underline{29}, 177-206$

Albandar JM, Brown LJ, Löe H (1997): Putative Periodontal Pathogens in Subgingival Plaque of Young Adults with and without early-onset periodontitis.

J Periodontol $\underline{68}(10), 973-981$

Albandar JM, Streckfus CF, Adesanya MR, Winn DM (2000): Cigar, pipe, and cigarette smoking as risk factors for periodontal disease and tooth loss.

J Periodontol $\underline{71}$ (12), 1874-1881

Albandar JM, DeNardin AM, Adesanya MR, DiehI SR, Winn DM (2001): Associations between serum antibody jevels to periodontal pathogens andearly-onset periodontitis. J Periodontol $\underline{72}(11), 1463-1469$

Albandar JM, Rams TE (2002): Global epidemiology of periodontal diseases: an overview. Periodontology $2000 \underline{29}, 7-10$

Aldridge JP, Lester V, Watts TL, Collins A, Viberti G, Wilson RF (1995): Single-blind studies of the effects of improved periodontal health on metabolic control in type 1 diabetes mellitus. J Clin Periodontol 22(4), 271-275

Allenspach-Petrzilka GE, Guggenheim B (1983): Bacterial invasion of the periodontium, an important factor in the pathogenesis of periodontitis? J Clin Periodontol 10(6), 609-617

Amar S, Gokce N, Morgan S, Loukideli M, Van Dyke TE, Vita JA (2003): Periodontal disease is associated with brachial artery endothelial dysfunction and systemic inflammation.

Arterioscler Thromb Vasc Biol 23(7), 1245-1249

Aminzadeh A, Ahmadi M, Hosseini SM (2013): Relation between Oral Health Status and Electrocardiogram ST Segment Changes in a Group of Patients with Myocardial Infarction.

J Dent Res Dent Clin Dent Prospects $\underline{7}(3), 169-73$

Androsz-Kowalska O, Jankowski K, Rymarczyk Z, Kowalski J, Pruszczyk P, Górska R (2013): Correlation between clinical parameters of periodontal disease and mean platelet volume in patients with coronary artery disease: a pilot study. Kardiol Pol 71(6), 600-5 
Angeli F, Verdecchia P, Pellegrino C, Pellegrino RG, Pellegrino G, Prosciutti L, Giannoni C, Cianetti S, Bentivoglio M (2003): Association between disease and left ventricle mass in essential hypertension. Hypertension 41(3), 488-492

Arbes SJ, Slade GD, Beck JD (1999): Association between extent of periodontal attachment loss and self-reported history of heart attack: an analysis of NHANES III data.

J Dent Res $\underline{78}(12), 1777-1782$

Armitage GC (1999): Development of a classification system for periodontal disease and conditions. Ann Periodontol $\underline{4}(1), 1-6$

Armitage GC (2000): Periodontal infections and cardiovascular disease-how strong is the association? Oral Disease $\underline{6}(6), 335-350$

Arnett DK, Baird AE, Barkley RA, Basson CT, Boerwinkle E, Ganesh SK, Herrington DM, Hong $Y$, Jaquish C, McDermott DA (2007): Relevance of genetics and genomics for prevention and treatment of cardiovascular disease: a scientific statement from the American Heart Association Council on Epidemiology and Prevention, the Stroke Council, and the Functional Genomics and Translational Biology Interdisciplinary Working Group.

Circulation 115(22), 2878-2901

Bahrani-Mougeot FK, Paster BJ, Coleman S, Ashar J, Barbuto S, Lockhart PB (2008): Diverse and novel oral bacterial species in blood followingdental procedures.

J Clin Microbiol 느(6), 2129-2132.

Baumgartner $\mathrm{H}$ (2005): Aortic stenosis: medical and surgical management. Heart $\underline{91}(11), 1483-1488$

Bayliss R, Clarke C, Oakley CM, Somerville W, Whitfield AG, Young SE (1983): The microbiology and pathogenesis of infective endocarditis. Br Heart J $\underline{50}(6), 513-519$

Beck JD, Garcia R, Heiss G, Vokonas PS, Offenbacher S (1996): Periodontal disease and cardiovascular disease. J Periodontol $\underline{67}$ (10 Suppl), 1123-1137

Beck JD, Offenbacher S (2002): Relationships among clinical measures of periodontal disease and their associations with systemic markers. Ann Periodontol $\underline{7}(1), 79-89$

Beck JD, Couper DJ, Falkner KL, Graham SP, Grossi SG, Gunsolley JC, Madden T, Maupome G, Offenbacher S, Stewart DD, Trevisan M, Van Dyke TE, Genco RJ (2008): The Periodontitis and Vascular Events (PAVE) pilot study: adverse events. J Periodontol 79(1), 90-96

Bellamy D, Booke R (2004): Chronic Obstructive Pulmonary Disease in Primary Care. Class Publishing ISBN 1-859-59104-3, S. $31 \mathrm{f}$

Bennett IL, Beeson PB (1954): Bacteremia. A consideration of some experimental and clinical aspects. Yale J Biol Med 26 (4), 241-262 
Blaizot A, Vergnes JN, Nuwwareh S, Amar J, Sixou M: Periodontal diseases and cardiovascular events (2009): meta-analysis of observational studies. Int Dent J $\underline{59}, 197-209$

Blum A, Kryuger K, Mashiach Eizenberg M, Tatour S, Vigder F, Laster Z, Front E (2007): Periodontal care may improve endothelial function. Eur J Intern Med 18(4), 295-298

Bombeli T, Karsan A, Tait JF, Harlan JM (1997): Apoptotic vascular endothelial cells become procoagulant. Blood $\underline{89}(7), 2429-2442$

Bonow RO, Carabello BA, Chatterjee K, de Leon AC, Faxon DP, Freed MD, Gaasch WH, Lytle BW, Nishimura RA, O'Gara PT, O'Rourke RA, Otto CM, ShahP M, ShanewiseJ S(2006): ACC/AHA 2006 Guidelines for the Management of Patients With Valvular Heart Disease: A Report of the American College of Cardiology/American Heart Association Task Force on Practice Guidelines (Writing Committee to Revise the 1998 Guidelines for the Management of Patients With Valvular Heart Disease): Developed in Collaboration With the Society of Cardiovascular Anesthesiologists: Endorsed by the Society for Cardiovascular Angiography and Interventions and the Society of Thoracic Surgeons.

Circulation 114(5), e84-23

Boon NA, Bloomfield P (2002): The medical management of valvar heart disease. Heart $\underline{87}(4), 395-400$

Brunner M, Salvi GE, Lang NP (2002): Aggressive Parodontitis.

Parodontologie 13/4, 321-343

Burke AP, Kolodgie FD, Farb A, Weber DK, Malcom GT, Smialek J, Virmani R (2001): Healed plaque ruptures and sudden coronary death: evidence that subclinical rupture has a role in plaque progression. Circulation $\underline{103}(7)$, 934-40

Cairo F, Gaeta C, Dorigo W, et al. (2004): Periodontal pathogensin atheromatous plaques. A controlled clinical and laboratory trial. J Periodontal Res 39(6), 442-446

Caldwell DE, Lawrence JR (1986): Growth kinetics of Pseudomonas fluorescens microcolonies within the hydrodynamic boundary layers of surface microenvironments. Microb Ecol $\underline{12}, 299$ 312

Chamberlain J, Galton DJ (1990): Genetic susceptibility to atherosclerosis.

British Medical Bulletin 느(4), 917-940

Christersson LA, Albini B, Zambon JJ, Wikesjo UM, Genco RJ (1987): Tissue localization of Actinobacillus actinomycetemcomitans in human periodontitisl Light, immunofluorescence and electron microscopic studies. J Periodontol $\underline{58}(8), 529-53$

Costerton JW, Cheng KJ, Geesy GG, Ladd T, Nickel JC, Dasgupta M, Marie TJ (1987): Bacterial biofilms in nature and disease. Annu Rev Mikrobiol 41, 435-464

D'Agostino RB, Russell MW, Huse DM, Ellison RC, Silbershatz H, Wilson PW, Hartz SC (2000): Primary and subsequent coronary risk appraisal: new results from the Framingham Study. Am Heart J 139(2Pt 1), 272-281 
D'Aiuto F, Parkar M, Andreou G, Suvan J, Brett PM, Ready D, Tonetti MS (2004): Periodontitis and systemic inflammation: control of the local infection is associated with a reduction in serum inflammatory markers. J Dent Res $\underline{83}(2), 156-160$

Dahlén G, Lindhe J, Sato K (1992): The effect of supragingival plaque control on the subgingival microbiota in subjects with periodontal disease.

J Clin Periodontol 19(10), 802-809

Dalla Vecchia CF, Susin C, Rösing CK, Oppermann RV, Albandar JM (2005): Overweight and obesity as risk indicators for periodontitis in adults. J Periodontol $\underline{76}(10), 1721-1728$

Dennison DK, Van Dyke TE (1997): The acute inflammatory response and the role of phagocytic cells in periodontal health and disease. Periodontol 2000 14(1), 54-78

Deschner J, Haak T, Jepsen S, Kocher T, Mehnert H., Meyle J, Schumm-Draeger P-M, Tschöpe D (2011): Diabetes mellitus und Parodontitis. Bidirectional relationship and clinical implications. A consensus document. Internist Berl $\underline{52}(4)$, 466-77

DeStefano F, Anda RF, Kahn HS, Williamson DF, Russell CM (1993): Dental disease and risk of coronary heart disease and mortality. British Medical Journal 306(6879), 688-691

Deutsche Gesellschaft für Parodontologie e. V. (Hrsg.):

Klassifikationen der Parodontalerkrankungen. Quintessenz Verlags-GmbH, Berlin 2002

Diehm C, Weiss T (2000): AVK-Fibel. 3. Auflage, LinguaMed-Verlag, Neu-Isenburg 2000

Diehm C, Heidrich H, Schulte K, Spengel FA, Theiss W, Dt. Gesellschaft für Angiologie, Gesellschaft für Gefäßmedizin (2001): Leitlinien zur Diagnostik und Therapie der arteriellen Verschlusskrankheit der Beinarterien. VASA 30(Suppl 57), 1-20

Diehm C, Allenberg J-R, Haberl R, Darius H, Mahn M, Tepohl G, Holland-Letz T, Pittrow D, Trampisch H-J (2007): High All-Cause Mortality in Patients with Peripheral Arterial Disease in Primary Care: Five-Year Results of the getABI Study. Circulation 116, II 841

Dietrich T, Jimenez M, Krall Kaye EA, Vokonas PS, Garcia RI (2008): Age-dependent associations between chronic periodontitis/edentulism and risk of coronary heart disease.

Circulation 117(13), 1668-1674

Dogan B, Buduneli E, Emingil G, et al. (2005): Characteristics of periodontal microflora in acute myocardial infarction. J Periodontol $\underline{76}(5), 740-748$

Eckmann L, Jung H, Yang S, Panja A, Fierer J, Morzycka-Wrob-Lewska E, Kagnoff MF (1995): A distinct array of proinflammatory cytokines is expressed in human colon epithelial cells in response to bacterial invasion. J Clin Invest 95(1), 55-65

Elter JR, Hinderliter AL, Offenbacher S (2006): The effects of periodontal therapy on vascular endothelial function: a pilot trial. Am Heart J 151(1), 47 
Emingil G, Buduneli E, Aliyev A, Akilli A, Atilla G (2000): Association between periodontal disease and acute myocardial infarction. J Periodontol $\underline{71}$ (12), 1882-1886

Flemming HC, Wingender J (2001): Biofilme - die bevorzugte Lebensform der Mikroorganismen. Biologie in unserer Zeit $\underline{31}$, 2-13

Folt SC, Bramanti TE (1991): Factors in virulence expression and their role in periodontal diseases pathogenesis. Crit Rev Oral Biol Med 2(2), 177-281

Forrester S, Shah K (1997): Using Serum Cholesterol as a ScreeningTest for Preventing Coronary Heart Disease: The Five Fundamental Flaws of the American College of Physicians Guidelines. Am J Cardiol 79(6), 790-792

Freeman RV, Otto CM (2005): Spectrum of Calcific Aortic Valve Disease: Pathogenesis, Disease Progression, and Treatment Strategies. Circulation 111(24), 3316-3326

Fuster V, Stein B, Ambrose JA, Badimon L, Badimon JJ, Chesebro JH(1990): Atherosclerotic plaque rupture and thrombosis. Evolving concepts. Circulation $\underline{82}$ (3 Suppl), II 47-59

Fuster V, Badimon L, Badimon JJ, Chesebro JH (1992): The pathogenesis of coronary artery disease and the acute coronary syndromes I. New Engl J Med 326(5), 242-250

Gängler P, Arnold WH (2005): Ätiologie und Pathogenese - Parodontalerkrankungen im ZahnMund-Kieferheilkunde - Konservierende Zahnheilkunde und Parodontologie, hrsg. Gängler P, Hoffmann T u.a.; 2. Auflage. Georg Thieme Verlag, Stuttgart 2005, 251-298

Gemmell E, RI Marshall and GJ Seymour (1997): Cytokines and prostaglandins in immune homeostasis and tissue destruction in periodontal disease. Periodontol 2000 14, 112-143

Genco RJ (1992): Host responses in periodontal diseases: current concepts.

J Periodontol $\underline{63}(4), 338-55$

Genco RJ, HO AW, Grossi SG, Dunford RG, Tedesco LA (1999): Relationship of stress, distress and inadequate coping behaviors to periodontal disease. J Periodontol $\underline{70}(7), 711-723$

Giacona M B, Papapanou PN, Lamster IB (2004): Porphyromonas Gingivalis induces its uptake by human makrophages and promotes foam cell formation in vitro. FEMS Microbiol Lett. 241(1), 95-101

Goldbarg SH, Elmariah S, Miller MA, Fuster V (2007): Insights into degenerative aortic valve disease. J Am Coll Cardiol 50(13), 1205-1213

Goldbourt U, Neufeld HN (1986): Genetic aspects of arteriosclerosis.

Arteriosclerosis $\underline{6}(4), 357-377$

Goodson JM, Tanner AC, Haffajee AD, Sornberger GC, Socransky SS (1982): Patterns of progression and regression of advanced destructive periodontal disease.

J Clin Periodontol $\underline{9}(6), 472-481$ 
Gross R, Schölmerich P, Gerok W (1996): Die Innere Medizin. Hrsg. von R Gross, P Schölmerich, W Gerok 9, neubearbeitete Auflage. Stuttgart, New York: Schattauer 13-19, 28, 205-229, 323-324, 367-368

Grossi SG, Skrepcinski FB, DeCaro T, Robertson DC, Ho AW, Dunford RG, Genco RJ (1997): Treatment of periodontal disease in diabetics reduces glycated hemoglobin. J Periodontol $\underline{68}(8), 713-719$

Gürkan U, Yağmur S, Akgöz H, Aksoy S, Oz D, Akyüz S, Yılmaz H, Karataş MB, Bolca O (2014): Severity of periodontitis in patients with isolated coronary artery ectasia. Int Heart J $\underline{55}(4), 296-300$

Haffajee AD, Socransky SS (1994): Microbial etiological agents of destructive periodontal diseases. Periodontol 2000 5, 78-111

Haffajee AD, Cugini MA, Tanner A, et al. (1998): Subgingival microbiota in healthy, wellmaintained elder and periodontitissubjects. J Clin Periodontol 25(5), 346-353

Hamp SE, Nyman S, Lindhe J (1975): Periodontal treatment of multirooted teeth. Results after 5 years. J Clin Periodontol $\underline{2}(3), 126-135$

Haraszthy VI, Zambon JJ, Trevisan M, Zeid M, Genco RJ (2000): Identification of periodontal pathogens in atheromatous plaques. J Periodontol $\underline{71(10), 1554-1560}$

Hasenfuss G, Hermann HP, Pieske B (2004): Dyspnea and normal systolic function. Herz $\underline{29}(6), 602-8$

Hellström MK, Ramberg P, Krok L, Lindhe J (1996): The effect of supragingival plaque control on the subgingival microflora in human periodontitis.

J Clin Periodontol 23(10), 934-940

Hellwig E, Klimek J, Attin T: Einführung in die Zahnerhaltung. 4. Auflage; Urban\&Fischer Verlag, München 2007

Herold G. Innere Medizin. Köln, 2007

Higashi Y, Goto C, Hidaka T, Soga J, Nakamura S, Fujii Y, Hata T, Idei N, Fujimura N, Chayama $\mathrm{K}$, Kihara Y, Taguchi A (2009): Oral infection-inflammatory pathway, periodontitis, is a risk factor for endothelial dysfunction in patients with coronary artery disease. Atherosclerosis 206(2), 604610

Hoppe UC, Böhm M, Dietz R, Hanrath P, Kroemer HK, Osterspey A, Schmaltz AA, Erdmann E (2005): Leitlinien zur Therapie der chronischen Herzinsuffizienz.

Z Kardiol 94(8), 488-509

Hornbostel H, Kaufmann W, Siegenthaler W: Innere Medizin in Praxis und Klinik. 4. Auflage. Georg Thieme Verlag, Stuttgart 1992 
Hotchkiss RS, Strasser A, McDunn JE, Swanson PE (2009): Cell death.

N Engl J Med $\underline{361}(16), 1570-1583$

Humphrey LL, Fu R, Buckley DI, Freeman M, Helfand M (2008): Periodontal disease and coronary heart disease incidence: a systematic review and meta-analysis.

J Gen Intern Med 23 (12), 2079-2086

Hung HC, Joshipura KJ, Colditz G, Manson JE, Rimm EB, Speizer FE, Willett WC (2004):

The association between tooth loss and coronary heart disease in men and women.

J Public Health Dent Fall $\underline{64}$ (4), 209-15

Hyman J (2006): The importance of assessing confounding and effect modification in research involving periodontal disease and systemic diseases.

J Clin Periodontol 33(2), 102-103

Isselbacher KJ, SchmailzI KJG (1995): Harrisons Innere Medizin. Band 1. Hrsg. v. Schmailzl Deutsche Ausgabe der 13. Auflage. Blackwell Wissenschafts-Verlag Berlin, 1995

Janket SJ, Baird AE, Chuang SK, Jones JA. (2003): Meta-analysis of periodontal disease and risk of coronary heart disease and stroke.

Oral Surg Oral Med Oral Pathol Oral Radiol Endod 95(5), 559-569

Jeffcoat MK, Geurs NC, Reddy MS, Cliver SP, Goldenerg RL, Hauth JC (2001): Periodontal infection and preterm birth: results of a prospective study. J Am Dent Assoc 132(7), 875-880

Jepsen S, Kebschull M, Deschner J (2011): Wechselwirkungen zwischen Parodontitis und systemischen Erkrankungen. Bundesgesundheitsbl 4, 1089-1096

Jimenez M, Krall EA, Garcia RI, Vokonas PS, Dietrich T (2009): Periodontitis and incidence of cerebrovascular disease in men. Ann Neurol $\underline{66}(4), 505-512$

Kazor CE, Mitchell PM, Lee AM, Stokes LN, Loesche WJ, Dewhirst FE, Paster BJ (2003):

Diversity of bacterial populations on the tongue dorsa of patients with halitosis and healthy patients. J Clin Microbiol 41(2), 558-563

Kebschull M, Demmer RTm Papapanou PN (2010): „Gum bug, leave my heart alone! "Epidemiologic and mechanistic evidence linking periodontal infections and atherosclerosis.

J Dent Res $\underline{89}(9)$, 879-902

Khoury AE, Lam K, Ellis B, Costerton JW (1992): Prevention and control of bacterial infections associated with medical devices. Am Soc Artif Intern Organs $\underline{38}(3), 174-178$

Kinane DF, Adonogianski E, Moughal N, Winstanley FP, Mooney J, Thornhill M (1991): Immunocytochemical characterization of cellular infiltrate, related endothelial changes and determination of GCF acute phase proteins during human experimental gingivitis.

J Periodont Res $\underline{26}$ (3 Pt 2), 286-288

Kleber BM: Parodontologie - Kompendium für Studierende und Zahnärzte.

Deutscher Ärzteverlag, Köln 1998 
Kleber BM (2000): Parodontologie - ein Leitfaden für die Praxis WM-Colleg, Aalen 2000

Kohal RJ, Dennison DK (2000): Neue Paradigmen in der Pathogenese parodontaler Erkrankungen. Dtsch Zahnarztl Z $\underline{55}$, 660-666

Kornman KS, Crane A, Wang, HY, di Giovane FS, Newman MG, Pirk FW, Wilson TG, Higginbottom FL, Duff GW (1997): The interleukin-1 genotype as a severity factor in adult periodontal disease. J Clin Periodontol 24 (1), 72-77

Kornman KS, Page RC, Tonetti S (2000): The host response to the microbial challenge in periodontitis: assembling the Players. Periodontol $\underline{14}, 33-53$

Koulouri O, Lappin DF, Radvar M, Kinane DF (1999): Cell division, synthetic capacity and apoptosis in periodontal lesions analysed by in situ hybridisation and immunohistochemistry. J Clin Periodontol 26(8), 5528-559

Kozarov EV, Dorn BR, Shelburne CE, Dunn WA Jr, Progulske-Fox A (2005): Human atherosclerotic plaque contains viable invasive Actinobacillus actinomycetemcomitans and Porphyromonas gingivalis. Arterioscler Thromb Vasc Biol 25(3), e17-18

Kurihara N, Inoue Y, Iwai T, Umeda M, Huang Y, Ishikawa I. (2004): Detection and localization of periodontopathic bacteria in abdominal aortic aneurysms.

Eur J Vasc Endovasc Surg 28(5), 553-558

Lakio L, Lehto M, Tuomainen AM, Jauhiainen M, Malle E, Asikainen S, et al. (2006): Proatherogenic properties of lipopolysaccharide from the periodontal pathogen Actinobacillus actinomycetemcomitans. J Endotoxin Res 12(1), 57-64

Lautenbach E, Linzenmeier G (1957): Zur Frage der Bakteriämie nach Zahnextraktion. Dtsch Zahnärztl Z 12, 980-992

Lee SD, Kuo WW, Lin DY, Chen TH, Kuo WH, Hsu HH, Chen JZ, Liu JY, Yeh YL, Huang CY (2005): Role of calcineurin in Porphyromonas gingivalis-induced myocardial cell hypertrophy and apoptosis. J Biomed Sci 13(2), 251-260

Li L, Michel R, Cohen J, Decarlo A, Kozarov E (2008): Intracellular survival and vascular cell-tocell transmission of Porphyromonas gingivalis. BMC Microbiol $\underline{8}, 26$

Libby P (2009): Molecular and cellular mechanisms of the thrombotic complications of

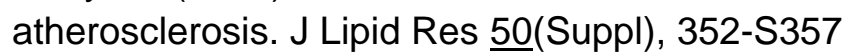

Lindhe J, Haffajee AD, Socransky SS (1983): Progression of periodontal disease in adult subjects in the absence of periodontal therapy. J Clin Periodontol 10(4), 433-42

Listgarten, M (1994): The structure of dental plaque. Periodontol $2000 \underline{5}, 52-65$ 
Lloyd-Jones DM, Larson MG, Beiser A, Levy D (1999): Lifetime risk of developing coronary heart disease. Lancet $\underline{353}(9147), 89-92$

Löe H, Theilade E, Jensen B (1965): Experimental Gingivitis in Man. J Periodontol $\underline{36}, 177-187$

Löe H, Anerud A, Boysen H, Morrison E (1986): Natural history of periodontal disease in man. Rapid, moderate and no loss of attachment in Sri Lankan laborers 14 to 46 years of age. $\mathrm{J}$ Clin Periodontol 13(5), 431-440

Loos BG (2005): Systemic markers of inflammation in periodontitis.

J Periodontol $\underline{76}$ (11Suppl), 2106-2115

López R, Oyarzún M, Naranjo C, Cumsille F, Ortiz M, Baelum V (2002): Coronary heart disease and periodontitis - a case control study in Chilean adults.

J Clin Periodontol 29 (5), 468-73

Loppnow H, Brade H, Dürrbaum I, Dinarello CA, Kusukoto S, Rietschel ET, Flad HD (1989): IL-1 induction-capacity of defined lipopolysaccharide partial structures.

J Immunol 142(9), 3229-3238

Lux R, Miller JN, Park NH, Shi W (2001): Motility and chemotaxis in tissue penetration of oral epithelial cell layers by Treponema denticola.

Infect Immun 69(10), 6276-6283

Mahendra J, Mahendra L, Felix J, Romanos G (2013): Prevelance of periodonto-pathogenic bacteria in subgingival biofilm and atherosclerotic plaques of patients undergoing coronary revascularization surgery. J Indian Soc Periodontol 17(6), 719-24

Marsh P, Martin MV (2003): Orale Mikrobiologie. Georg Thieme Verlag, Stuttgart 2003

Massie BM, Shah NB (1996): The heart failure epidemic: magnitude of the problem and potential mitigating approaches. Current Opinion Cardiol 11(3), 221-226

Mattila KJ, Nieminen MS, Valtonen VV, Rasi VP, Kesäniemi YA, Syrjälä SL, Jungell PS, Isoluoma M, Hietaniemi K, Jokinen MJ (1989): Association between dental health and acute myocardial infarction. BMJ $\underline{\text { 298}}(6676), 779-781$

McMurray JJ, Stewart S (2000): Epidemiology, aetiology and prognosis of heart failure. Heart 83(5):596-602

Mercado FB, Marshall RI, Bartold PM (2003): Inter-relationships between rheumatoid arthritis and periodontal disease. A review. J Clin Periodontol $\underline{30}$, 761-772

Mercanoglu F, Oflaz H, Oz O, Gokbuget AY, Genchellac H, Sezer M, Nisanci Y, Umman S (2004): Endothelial dysfunction in patients with chronic periodontitis and its improvement after initial periodontal therapy. J Periodontol $\underline{75}(12), 1694-1700$ 
Meurman JH, Qvarnström M, Janket SJ, Nuutinen P (2003): Oral health and health behavior in patients referred for open-heart surgery.

Oral Surg Oral Med Oral Pathol Oral Radiol Endod $\underline{95}$ (3), 300-7

Meurman JH, Sanz M, Janket SJ (2004): Oral health, atherosclerosis, and cardiovascular disease. Crit Rev Oral Biol Med 15(6), 403-413

Meyer DH, Sreenivasan PK, Fives-Taylor PM (1991): Evidence for invasion of a human oral cell line by Actinobacillus actinomycetemcomitans. Infect Immun $\underline{59}(8), 2719-2726$

Michalowicz BS (1994): Genetic and heritable risk factors in periodontal disease.

J Periodontol $2000 \underline{65}$ Suppl(5), 479-488

Michalowicz BS, Diehl SR, Gunsolley JC, Sparks BS, Brooks CN, Koertge TE, Califano JV, Burmeister JA, Schenkein HA (2000): Evidence of a substantial genetic basis for risk of adult periodontitis. J Periodontol $\underline{71}(11), 1699-1707$

Micheelis W, Reich E: Dritte Deutsche Mundgesundheitsstudie (DMS III)

Deutscher Ärzte-Verlag, Köln 1999

Micheelis W, Schiffner U (2006): Vierte Deutsche Mundgesundheitsstudie (DMS IV). Institut der deutschen Zahnärzte (Hrsg.); (IDZ Materialreihe Band 31).

Deutscher Zahnärzte Verlag DÄV, Köln 2006

Miserez AR, Braun JR (1995): Anwendung genetischer Prinzipien zur Ursachenabklärung der

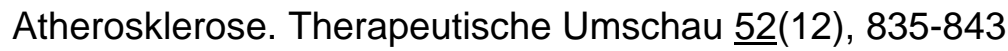

Müller HP: Parodontologie. Thieme Verlag, Stuttgart 2001

Murray PA, Grassi M, Winkler JR (1989): The microbiology of HIV-associated periodontal lesions. J Clin Periodontology $\underline{16}, 636-642$

Mustapha IZ, Debrey S, Oladubu M, Ugarte R. (2007): Markers of systemic bacterial exposure in periodontal disease and cardiovascular disease risk: a systematic review and meta-analysis. J Periodontol $\underline{78}$ (12), 2289-2302

Narula J, Pandey P, Arbustini E, Haider N, Narula N, Kolodgie FD, Dal Bello B, Semigran MJ, Bielsa-Masdeu A, Dec GW (1999): Apoptosis in heart failure: release of cytochrome C from mitochondria and activation of caspase-3 in human cardiomyopathy.

Proc Natl Acad Sci USA 96(14), 8144-8149

Neu HC: Infective endocarditis. In: Cheng TO (ed) Comprehensive cardiology international. Pergamon Press Inc., Oxford, 1986

Nkomo VT, Gardin JM, Skelton TN, Gottdiener JS, Scott CG, Enriquez-Sarano M (2006): Burden of valvular heart diseases: a population-based study. Lancet $\underline{368(9540), 1005-11}$ 
Nonnenmacher C, Stelzel M, Susin C, Sattler AM, Schaefer JR, Maisch B, Mutters R, Flores-deJacoby $L$ (2007): Periodontal microbiota in patients with coronary artery disease measured by real-time polymerase chain reaction: A case-control study. J Periodontol $\underline{78}(9), 1724-1730$

Nyad B, Fejerskov O (1987): Transmission electron microscopy of early microbial colo-nization of human enamel and root surfaces in vivo. Scand J Dent Res 95(4), 297-307

Nylander M, Lindahl TL, Bengtsson T, Grenegård M (2008): The periodontal pathogen Porphyromonas gingivalis sensitises human blood platelets to epinephrine.

Platelets $\underline{19}(5), 352-358$

Offenbacher S (1996): Periodontal disease: pathogenesis. Ann Periodontol 1(1), 821- 878

Offenbacher S, Katz V, Fertik G, Collins J, Boyd D, Maynor G, McKaig R, Beck J (1996): Periodontal infection as a possible risk factor for preterm low birth weight.

J Periodontol $\underline{67}$ (10 Suppl), 1103-1113

Offenbacher S, Beck JD, Lieff S, Slade G (1998): Role of periodontitis in systemic health: spontaneous preterm birth. J Dent Educ $\underline{62}(10), 852-858$

Offenbacher S, Beck JD, Moss K, Mendoza L, Paquette DW, Barrow DA, Couper DJ, Stewart DD, Falkner KL, Graham SP, Grossi S, Gunsolley JC, Madden T, Maupome G, Trevisan M, Van Dyke TE, Genco RJ (2009): Results from the Periodontitis and Vascular Events (PAVE) Study: a pilot multicentered, randomized, controlled trial to study effects of periodontal therapy in a secondary prevention model of cardiovascular disease. J Periodontol $\underline{80}$ (2), 190-201

Otten JE, Pelz K, Christmann G (1987): Anaerobic bacteremia following tooth extraction and removal of osteosynthesis plates. J Oral Maxillofac Surg 4ㄷ⑹, 477-480

Padilla C, Lobos O, Hubert E, González C, Matus S, Pereira M, Hasbun S, Descouvieres C (2006): Periodontal pathogens in atheromatous plaques isolated from patients with chronic periodontitis. J Periodontal Res $\underline{41}(4), 350-353$

Page RC (1991): The role of inflammatory mediators in the pathogenesis of periodontal disease. J Periodontol Res $\underline{26}$ (3 Pt 2), 230-242

Page RC, Schroeder HE (1976): Pathogenesis of inflammatory periodontal disease. A summary of current work. Lab Invest 34(3), 235-249

Page RC, Kornman K (1997): The pathogenesis of human periodontitis: An introduction. Periodontol $2000 \underline{14}$, 9-11

Page RC, Eke PI (2007): Case Definitions for Use in population-based surveillance of periodontitis. J Periodontol $\underline{78}$ (7 Suppl), 1387-99

Paraskevas S, Huizinga JD, Loos BG (2008): A systematic review and meta-analyses on Creactive protein in relation to periodontitis. J Clin Periodontol 35(4), 277-290 
Parolari A, Loardi C, Mussoni L, Cavallotti L, Camera M, Biglioli P, Tremoli E, Alamanni F (2009): Nonrheumatic calcific aortic stenosis: an overview from basic science to pharmacological prevention. Eur J Cardiothorac Surg 35(3), 493-504

Persson GR, Persson RE (2008): Cardiovascular disease and periodontitis: an update on the associations and risk. J Clin Periodontol $\underline{35}$, 362-379

Piconi S, Trabattoni D, Luraghi C et al (2009): Treatment of periodontal disease results in improvements in endothelial dysfunction and reduction of the carotid intima-media thickness. FASEB J $\underline{23}(4), 1196-1204$

Pischon N, Heng N, Bernimoulin J, Kleber B, Willich SN, Pischon T (2007): Obesity, inflammation, and periodontal disease. J Dent Res $\underline{86}, 400-409$

Pistorius A, Krahwinkel T, Willershausen B, Boekstegen C (2002): Relationship between Stress Factors and Periodontal Disease. European Journal of Medical Research 7/2002, S. 393-398

Plagmann HC: Lehrbuch der Parodontologie. Carl Hanser Verlag München Wien 1998

Pober JS, Min W, Bradley JR (2009): Mechanisms of endothelial dysfunction, injury, and death. Annu Rev Pathol $\underline{4}, 71-95$

Pollreisz A, Huang Y, Roth G, Cheng B, Kebschull M, Papapanou PN, et al. (2010): Enhanced monocyte migration and pro-inflammatory cytokine production by Porphyromonas gingivalis infection. J Periodontal Res $\underline{45}(2), 239-245$

Pousset F, Isnard R, Lechat P, Kalotka H, Carayon A, Maistre G, Escolano S, Thomas D, Komajda M (1997): Prognostic value of plasma endothelin-1 in patients with chronic heart failure. Eur Heart J 18(12), 254-258

Pussinen PJ, Jousilahti P, Alfthan G, Palosuo T, Asikainen S, Salomaa V (2003): Antibodies to periodontal pathogens are associated with coronary heart disease.

Arterioscler Thromb Vasc Biol $\underline{23}$, 1250-1254

Pussinen PJ, Alfthan G, Tuomilehto J, Asikainen S, Jousilahti P (2004): High serum antibody levels to Porphyromonas gingivalis predict myocardial infarction.

Eur J Cardiovasc Prev Rehabil 11, 408-411

Quirynen M, Mongardini C, de Soete M, Pauwels M, Coucke W, van Eldere J, van Steenberghe D (2000): The role of chlorhexidine in the one-stage full-mouth disinfection treatment of patients with advanced adult periodontitis. Long-term clinical and microbiological observations.

J Clin Periodontol 27(8), 578-589

Rahn R (1989): Bakteriämien bei zahnärztlich-chirurgischen Eingriffen. Hanser, München-Wien.

Rahn R, Shah PM, Schäfer V, Frenkel G, Halbherr K (1987): Bakteriämien bei chirurgischendodontischen Eingriffen. Zahnärztl Welt $\underline{\text { 96, }} 903$ 
Ramfjord SP, Morrison EC, Burgett FG, Nissle RR, Schick RA, Zann GJ, Knowles JW (1982): Oral hygiene and maintance of periodontal support. J Periodontol $\underline{53}(1), 26-30$

Rateitschak KH, Rateitschak EM, Wolf HF: Parodontologie, 2. Auflage; Georg-Thieme-Verlag, Stuttgart 1989

Rauch U, Osende JI, Fuster V, Badimon JJ, Fayad Z, Chesebro JH (2001): Thrombus formation on atherosclerotic plaques: pathogenesis and clinical consequences.

Ann Intern Med 134(3), 224-238

Renvert S, Ohlsson O, Persson S, Lang NP, Persson GR. (2004): Analysis of periodontal risk profile in adults with or without a history of myocardial infarction.

J Clin Periodontol $\underline{31}(1), 19-24$

Renz-Polster H, Krautzig S: Basislehrbuch Innere Medizin. Urban und Fischer-Verlag München 2008. 4. Auflage. ISBN 978-3-437-41053-6

Riviere GR, Weisz KS, Adams DF, Thomas DD (1991): Pathogen-related oral spirochetes from dental plaque are invasive. Infect Immun 59(10), 3377-3380

Roberts G (1999): Dentists are innocent! "Everyday" bacteremia is the real culprit: a review and assessment of the evidence that dental surgical procedures are a principal cause of bacterial endocarditis in children. Pediatr Cardiol 20(5), 317-325

Rodeheffer RJ, Jacobsen SJ, Gersh BJ, Kottke TE, McCann HA, Bailey KR, Ballard DJ (1993): The incidence and prevalence of congestive heart failure in Rochester, Minnesota. Mayo Clin Proc 68(12), 1143-1150

Romano F, Barbui A, Aimetti M (2007): Periodontal pathogens in periodontal pockets and in carotid atheromatous plaques. Minerva Stomatol $\underline{56}(4), 169-179$

Ross R (1999): Atherosclerosis-an inflammatory disease. N Engl J Med 340(2), 115-126

Roth GA, Moser B, Huang SJ, Brandt JS, Huang Y, Papapanou PN, et al. (2006): Infection with a periodontal pathogen induces procoagulant effects in human aortic endothelial cells.

J Thromb Haemost $\underline{4}(10), 2256-2261$

Sagalie FR, Carranza FA Jr, Newman MG, Cheng L, Lewin KJ (1982): Identification of Tissueinvading bacteria in human periodontal disease. J Periodont Res 17(5), 452-455

Sagalie FR, Marafany A, Camargo P (1988): Intragingival occurrence of Actinobacillus actinomycetemcomitand and Bacteriodes gingivalis in active destructive periodontal lesions. J Periodontol $\underline{59}(4), 259-265$

Sakurai K, Wang D, Suzuki J, Umeda M, Nagasawa T, Izumi Y, Ishikawa I, Isobe M (2007): High incidence of Actinobacillus actinomycetemcomitans infection in acute coronary syndrome. Int Heart J $\underline{48}(6)$, 663-675 
Salvi GE, Lawrence HP, Offenbacher S, Beck JD (1997): Influence of risk factors on the pathogenesis of periodontitis. Periodontol $2000 \underline{14}$, 173-201

Sanderink RBA, Bernhardt H, Knoke M, Meyer J, Weber C, Weiger R. Curriculum Orale Mikrobiologie und Immunologie. Quintessenz Verlags-GmbH, Berlin 2004

Sanderink RBA, Zitzmann NU, Saxer UP, Schlagenhauf U, Persson R, Erne P (2008): Parodontitis und Periimplantitis: in den menschlichen Körper disseminierende Biofilm-Infekte. Quintessenz 59, 273-285

Sanz M, D'Aiuto F, Deanfield J, Fernandez-Avilés F (2010): European workshop in periodontal health and cardiovascular disease - scientific evidence on the association between periodontal and cardiovascular diseases: a review of the literature.

Eur Heart J Suppl 12(Suppl B), B3-B12

Sartori S, Silvestri M (2002): Risk factors in periodontal disease. Minerva.

Stomatol 51(11-12), 495-499

Saxer UP, Mühlemann HR (1975): Motivation und Aufklärung.

Schweiz Monatsschr Zahnmed 85, 905-919

Schaefer AS, Richter GM, Groessner-Schreiber B et al (2009): Identification of a shared genetic susceptibility locus for coronary heart disease and periodontitis.

PLoS Genet $\underline{5}(2)$, e1000378

Schiött CR, Löe H (1970): The origin and variation in number of leucocytes in the human saliva. J Periodontol Res $\underline{5}(1)$, 36-41

Schlein RA, Kudlick EM, Reindorf CA, Gregory J, Royal GC (1991): Toothbrushing and transient bacteremia in patients undergoing orthodontic treatment.

Am J Orthod Dentofac Orthop 99(5), 466-472

Schocken DD, Arrieta MI, Leaverton PE, Ross EA (1992): Prevalence and mortality rate of congestive heart failure in the United States. J Am Coll Cardiol 20(2), 301-306

Schrier RW, Abraham WT (1999): Hormones and hemodynamics in heart failure.

N Engl J Med 341(8), 577-585

Schroeder HE: Pathobiologie oraler Strukturen: Zähne, Pulpa, Parodont; 3. Auflage; Karger-Verlag, Basel 1997

Schroeder HE: Orale Strukturbiologie, 5. Auflage, Georg-Thieme-Verlag, Stuttgart 2000

Schroeder HE, Attström R (1980): Pocket formation: An Hypothestis; in: The borderland between caries and periodontal disease, hrsg. Lehner T, Cimasoni G u.a.; Brune \& Stratton Press, London 1980 
Schulte D, Küppers V, Dartsch N, Broermann A, Li H, Zarbock A, Kamenyeva O, Kiefer F, Khandoga A, Massberg S, Vestweber D (2011): Stabilizing the VE-cadherin-catenin complex blocks leukocyte extravasation and vascular permeability. EMBO J $\underline{30}(20)$, 4157-70

Schunkert H, Hense H-W (1995): Molekulare Genetik kardiovaskulärer Erkrankungen. Deutsche medizinische Wochenschrift 120, 533-539

Sconyers JR, Crawford JJ, Moriarity JD (1973): Relationship of bacteremia to toothbrushing in patients with periodontitis. J Am Dent Assoc 87(3), 616-622

Seinost G, Wimmer G, Skerget M et al (2005): Periodontal treatment improves endothelial dysfunction in patients with severe periodontitis. Am Heart J 149(6), 1050-1054

Shan K, Kurrelmeyer K, Seta Y, Wang F, Dibbs Z, Deswal A, Lee-Jackson D, Mann DL (1997): The role of cytokines in disease progression in heart failure.

Current Opinion Cardiol 12(3), 218-223

Sheiham A (1991): Public health aspects of periodontal diseases in Europe.

J Clin Periodontol 18, 362-369

Silver JG, Martin AW, Bride BC (1977): Experimental transient bacteraemias in human subjects with varying degrees of plaque accumulation and gingival inflammation.

J Clin Periodontol $\underline{4}(2), 92-99$

Slavkin HC, Baum BJ (2000): Relationship of dental and oral pathology to systemic illness.

J Am Med Assoc 248(10), 1215-1217

Slots J (1979): Subgingival mikroflora and periodontal disease.

J Clin Periodontol $\underline{6}(5), 351-382$.

Slots J (1986): Bacterial specificity in adult periodontitis. A summary of recent work.

J Clin Periodontol 13(10), 912-917

Slots J, Genco RJ (1984): Black pigmented bacteroides species, capnocytophaga species, andactinobacillus actinomycetemcomitans in human periodontal disease: Virulence factors in colonization, survival, and tissue destruction. J Dent Res $\underline{63}(3), 412-421$

Slots J, Rams TE (1992): Microbiology of periodontal disease. In: Slots J \& Taubman M, eds.: Contemporary Oral Microbiology and Immunology. St. Louis: Mosby-Year Book, 1992

Smulow JB, Turesky SS, Hill RG (1983): The effect of supragingival plaque removal an anaerobic bacteria deep periodontal pockets. J of Am Dental Assoc 107(5), 737-742

Socransky SS, Haffajee AD, Cugini MA, Smith C, Kent RL (1998): Microbial complexes in subgingival plaque. J Clin Peridontol 25(2), 134-144

Socransky SS, Haffajee AD (2002): Dental biofilms: difficult therapeutic targets.

Periodontol $2000 \underline{28}, 12-55$ 
Spahr A, Klein E, Khuseyinova N, Boeckh C, Muche R, Kunze M, Rothenbacher D, Pezeshki G, Hoffmeister A, Koenig W. (2006): Periodontal infections and coronary heart disease: Role of periodontal bacteria and importance of total pathogen burden in the Coronary Event and Periodontal Disease (CORODONT) study. Arch Intern Med 166(5), 554-559

Stary HC, Chandler AB, Glagov S, Guyton JR, Insull WJ, Rosenfeld ME, Schaffer SA, Schwartz CJ, Wagner WD, Wissler RW (1994): A definition of initial, fatty streak, and intermediate lesions of atherosclerosis. A report from the Committee on Vascular Lesions of the Council on Arteriosclerosis, American Heart Association. Circulation 89(5), 2462-2478

Stary HC, Chandler AB, Dinsmore RE, Fuster V, Glagov S, Insull W Jr, Rosenfeld ME, Schwartz CJ, Wagner WD, Wissler RW(1995): Circulation 92(5), 1355-74

Statistisches Bundesamt (Destatis): Todesursachen in Deutschland 2010. Fachserie 12, Reihe 4 - Todesursachenstatistik 2010, Wiesbaden 2011

Stein JM, Kuch B, Conrads G, Fickl S, Chrobot J, Schulz S, Ocklenburg C, Smeets R (2009): Clinical periodontal and microbiologic parameters in patients with acute myocardial infarction. J Periodontol $\underline{80}(10), 1581-9$

Syrjanen J, Peltola J, Valtonen V et al (1989): Dental infections in association with cerebral infarction in young and middle-aged men. J Intern Med 225(3), 179-184

Tabia PV, Bassada NF, Marbury GE (1981): Effectivness of supragingival plaque cotrol on the development of subgingival plaque and gingival inflammation in patients with moderate pocket depth. J Periodontol $\underline{52}(2)$, 88-93

Takahashi K, Lappin D, Kinane DF (1996): In situ localization of cell synthesis and proliferation in periodontitis gingiva and tonsillar tissue. Oral Dis $\underline{2}(3), 210-6$

Takahashi Y, Davey M, Yumoto H, Gibson FC 3rd, Genco CA (2006): Fimbria-dependent activation of pro-inflammatory molecules in Porphyromonas gingivalis infected human aortic endothelial cells. Cell Microbiol $\underline{8}(5), 738-757$

Tang K, Lin M, Wu Y, Yan F (2011): Alterations of serum lipid and inflammatory cytokine profiles in patients with coronary heart disease and chronic periodontitis: a pilot study.

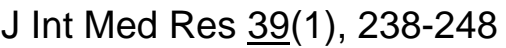

Tanner A, Maiden MFJ, Macuch PJ, Murray LL, Kent Jr RL (1998): Microbiota of health, gingivitis, and initial periodontitis. J Clin Periodontol 25(2), 85-98

Taubman MA, Kawai T (2001): Involvement of T-lymphocytes in periodontal disease and in direct and indirect induction of bone resorption. Crit Rev Oral Biol Med 12(2), 125-135

Theilade $E$ (1986): The non-specific theory in microbial etiology of inflammatory periodontal diseases. J Clin Periodontol 13(10), 905-91

Theilade E (1990): Factors controlling the microflora of the healthy mouth. In: Hill MJ, Marsh PD: Human Microbial Ecology. Boca Raton: CRC Press, pp. 1-56 
Tonetti MS (2009): Periodontitis and risk for atherosclerosis: an update on intervention trials. J Clin Periodontol $\underline{36}$ (Suppl 10), 15-19

Tonetti MS, Freiburghaus K, Lang NP, Bickel M (1993): Detection of inter-leukin-8 and matrix metalloproteinase transcripts in healthy and diseased gingival biopsies by RNA/PCR. J Periodontol Res 28 $($ Pt 2), 511-513

Tonetti MS, Gerber L, Lang NP (1994): Vascular adhesion molecules and initial development of inflammation in clinical healthy human keratinized mucosaaround teeth and osseointegrated implants. J Periodont Res $\underline{29}(6)$, 386-392

Tonetti MS, D'Aiuto F, Nibali L, Donald A, Storry C, Parkar M, Suvan J, Hingorani AD, Vallance P, Deanfield J. (2007): Treatment of periodontitis and endothelial function. N Engl J Med 356(9), 911-920

Travis J, Potempa J, Maeda H (1995): Are bacterial proteases pathogenic factors? Trends Mircobiol $\underline{3}(10)$, 405-407

Vahanian A, Baumgartner H, Bax J, Butchart E, Dion R, Filippatos G, Flachskampf F, Hall R, lung B, Kasprzak J, Nataf P, Tornos P, Torracca L, Wenink A (2007): Guidelines on the management of valvular heart disease. European Heart Journal 28(2), 230-268

Van der Velden U, Abbas F, Armand S, Graaff $\mathrm{J}$ de, Timmerman MF, van der Weijden GA, van Winkelhoff AJ, Winkel EG (1993): The effect of sibling relationship on the periodontal condition. J Clin Periodontol 20, 683-690

Van Dyke TE, Sheilesh D (2005): Risk factors for periodontitis.

$\mathrm{J}$ Int Acad Periodontol $\underline{7}(1)$, 3-7

Van Palenstein Helderman WH (1981): Microbial etiology of periodontal disease.

J Clin Periodontol $\underline{8}(4), 261-280$

Van Winkelhoff AJ, van Steensbergen TJM, de Graaff J (1988): The role of black pigmented Bacteroides in human oral infections. J Clin Periodontol 15(3), 145-155

Van Winkelhoff AJ, Slots J (1999): Actinobacillus actinomycetemcomitans and Porphyromonas gingivalis in nonoral infections.

Periodontol 2000, 20(1), 122-135

Virmani R, Burke AP, Farb A, Kolodgie FD (2006): Pathology of the vulnerable plaque. J Am Coll Cardiol $\underline{47}$ (8 Suppl), 13-18

Ward JR, Wilson HL, Francis SE, Crossman DC, Sabroe I (2009): Translational mini-review series on immunology of vascular disease: inflammation, infections and Toll-like receptors in cardiovascular disease. Clin Exp Immunol 156(3), 386-394

Warren JR, Marshall B. (1983): Unidentified curved bacilli on gastric epithelium in active chronic gastritis. Lancet 1 (8336), 1273-1275 
WHO (World Health Organization) 2006: BMI classification.

URL: http://www.who.int/bmi/index.jsp?introPage=intro 3.html

WHO (World Health Organization) 2011: The top 10 causes of death.

URL: http://www.who.int/mediacentre/factsheets/fs310/en/index2.html

Willershausen B, Kasaj A, Willershausen I, Zahorka D, Briseño B, Blettner M, Genth-Zotz S, Münzel T (2009): Association between chronic dental infection and acute myocardial infarction. J Endod 35(5), 626-30

Wimmer G, Pihlstrom BL (2008): A critical assessment of adverse pregnancy outcome and periodontal disease. J Clin Periodontol $\underline{35}$ (8 Suppl), 380-397

Wood WB, Smith MR, Berry JW, Perry WD (1951): Studies on the cellular immunology of acute bacteremia. J Exp Med 94(6), 521-34

Ximénez-Fyvie LA, Haffajee AD, Sokransky SS (2000): Microbial composition of supra- and subgingival plaque in subjects with adult periodontitis.

J Clin Periodontol 27(10), 722-732

Yakob M, Meurman JH, Jogestrand T, Nowak J, Söder PÖ, Söder B (2012): C-reactive protein in relation to early atherosclerosis and periodontitis. Clin Oral Investig 16(1), 259-65

Yazaki Y, Yamazaki T (1997): Reversing congestive heart failure with endothelin receptor antagonists. Circulation $\underline{95}, 1752-1754$

Yeung SC (2000): HIV infection and periodontal disease.

Ann R Australaes Doll Dent Surg 15, 331-334

Yun PLW, Decarlo AA, Chapple CC, Hunter N (2005): Functional implication of the hydrolysis of platelet endothelial cell adhesion molecule 1 (CD31) by gingipains of Porphyromonas gingivalis for the pathology of periodontal disease. Infect Immun $\underline{73}$ (3), 1386-1398

Zambon JJ, Grossi SG, Machtei EE (1996): Cigarette smoking increases the risk of subgingival infection with periodontalpathogens. J Periodontol $\underline{67}$ (10 Suppl), 1050-1054

Ziebolz D, Priegnitz A, Hasenfuß G, Helms HJ, Hornecker E and Mausberg R (2012): Oral health status of patients with acute coronary syndrome-a case control study.

BMC Oral Health $\underline{12}, 17$ 


\section{$\underline{\text { Lebenslauf }}$}

Mein Name ist Stefan Krebs. Ich wohne im Konvent 18 in 06484 Quedlinburg und bin deutscher Nationalität. Geboren wurde ich am 03.01.1985 in Quedlinburg. Meine schulische Ausbildung umfasst den Besuch der Grundschule Mummenthal von 1990 bis 1994 in Quedlinburg. Von 1994 bis 2004 besuchte ich das GutsMuths Gymnasium Quedlinburg. Im Jahr 2004 erlangte ich die Allgemeine Hochschulreife.

2005 habe ich das Studium der Zahnmedizin an der Georg-August-Unversität begonnen. Dort absolvierte ich im Juni 2010 das Staatsexamen.

Am 01.11.2012 begann ich meine Assistenzzeit in der Zahnarztpraxis Andrea Sauerzweig in Schönebeck. Zum 02.05.2012 wechselte ich die Ausbildungsstätte in die Praxis Dr.Volker Sauerzweig in Magdeburg. Dort war ich bis zum August 2013 tätig. Seit dem 01.09.2013 arbeite ich als angestellter Zahnarzt in der Zahnarztpraxis Dr.Sandra Kossel in Magdeburg. Nebenberuflich absolvierte ich im November 2013 das Curriculum Implantologie der Deutschen Gesellschaft für Implantologie. 